National Science Foundation Graduate Fellowship DGE-0234615 and Grant ATM-0324324

OBSERVATIONAL ANALYSIS OF THE PREDICTABILITY OF MESOSCALE CONVECTIVE SYSTEMS

by Israel L. Jirak

William R. Cotton, P.I.
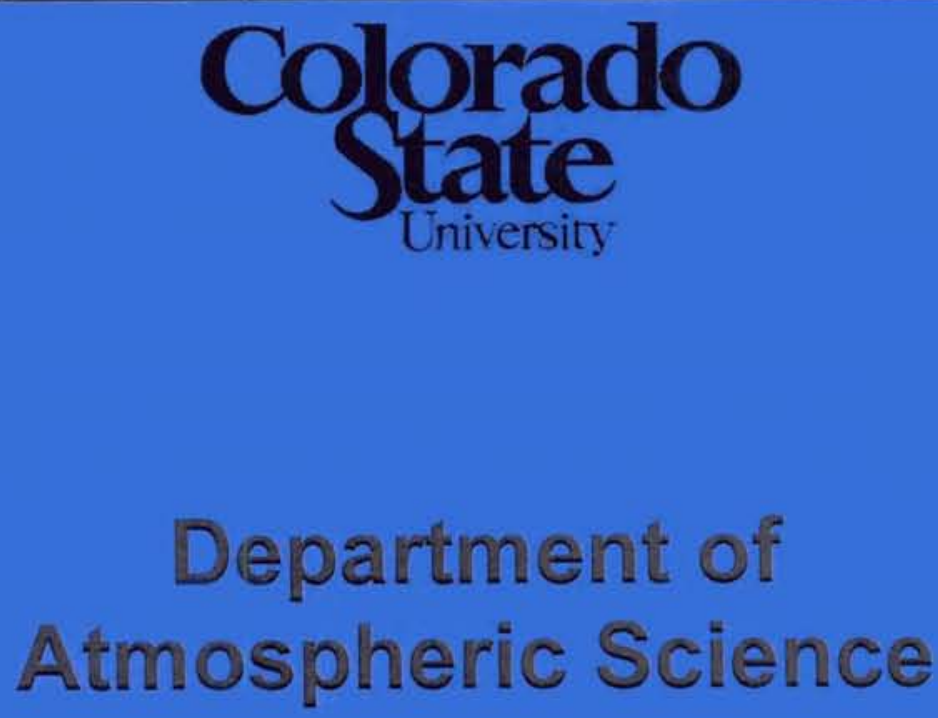

Paper No. 778 


\title{
OBSERVATIONAL ANALYSIS OF THE PREDICTABILITY OF MESOSCALE CONVECTIVE SYSTEMS
}

\author{
by \\ Israel L. Jirak \\ Department of Atmospheric Science \\ Colorado State University \\ Fort Collins, Colorado 80523
}

\begin{abstract}
Research Supported by
National Science Foundation

under a Graduate Fellowship DGE-0234615 and Grant ATM-0324324
\end{abstract}

October 27,2006

Atmospheric Science Paper No. 778 


\section{ABSTRACT \\ OBSERVATIONAL ANALYSIS OF THE PREDICTABILITY OF MESOSCALE CONVECTIVE SYSTEMS}

Mesoscale convective systems (MCSs) have a large influence on the weather over the central United States during the warm season by generating essential rainfall and severe weather. To gain insight into the predictability of these systems, the precursor environment of several hundred MCSs were thoroughly studied across the U.S. during the warm seasons of 1996-98. Surface analyses were used to identify triggering mechanisms for each system, and North American Regional Reanalyses (NARR) were used to examine dozens of parameters prior to MCS development. Statistical and composite analyses of these parameters were performed to extract valuable information about the environments in which MCSs form. Similarly, environments that are unable to support organized convective systems were also carefully investigated for comparison with MCS precursor environments.

The analysis of these distinct environmental conditions led to the discovery of significant differences between environments that support MCS development and those that do not support convective organization. MCSs were most commonly initiated by frontal boundaries; however, such features that enhance convective initiation are often not sufficient for MCS development, as the environment needs to lend additional support for the development and organization of long-lived convective systems. Low-level warm air advection, low-level vertical wind shear, and convective instability were found to be 
the most important parameters in determining whether concentrated convection would undergo upscale growth into a MCS.

Based on these results, an index was developed for use in forecasting MCSs. The MCS index is comprised of conditional terms to ensure that the index is only defined in regions where convective initiation and development are possible. The MCS index assigns a likelihood of MCS development based on three terms: $700 \mathrm{mb}$ temperature advection, 0-3 $\mathrm{km}$ vertical wind shear, and the lifted index (LI). Each of these parameters promotes convective development and organization through the enhancement of vertical lifting. An analysis of the MCS index showed that it exhibits similar diurnal, episodic, and seasonal characteristics to MCSs. In addition, an objective evaluation of the MCS index revealed that it possesses significant skill in forecasting MCSs, especially given that convective initiation has occurred, offering the possibility of usefulness in operational forecasting.

Israel L. Jirak

Department of Atmospheric Science Colorado State University

Fort Collins, Colorado 80523

Fall 2005 


\section{ACKNOWLEDGEMENTS}

The Department of Atmospheric Science at Colorado State University has offered me an excellent educational environment for the pursuit of knowledge over the past five years. I would like to express my sincere appreciation to my, Dr. William Cotton, for his guidance and support along the way. I would also like to thank Dr. Steven A. Rutledge, Dr. Richard H. Johnson, and Dr. Jorge A. Ramírez, for their time and useful comments regarding this research.

Infrared satellite data and radar composite data were obtained from the Global Hydrology Resource Center at the Global Hydrology and Climate Center in Huntsville, Alabama. The National Centers for Environmental Prediction (NCEP) North American Regional Reanalysis (NARR) and surface charts were acquired from the National Climatic Data Center (NCDC). Information about the Bow Echo and Mesoscale Convective Vortex (MCV) Experiment (BAMEX) was obtained from the BAMEX field catalog supported by the University Corporation for Atmospheric Research (UCAR) Joint Office of Science Support (JOSS). This research was supported by National Science Foundation (NSF) Graduate Fellowship DGE-0234615 and NSF Grant ATM-0324324.

Finally, I would like to thank my family for their encouragement and support. My wife, Hannah, has been beside me the entire way and provided me with the greatest gift of all, our firstborn son, Landon Brock. 


\section{TABLE OF CONTENTS}

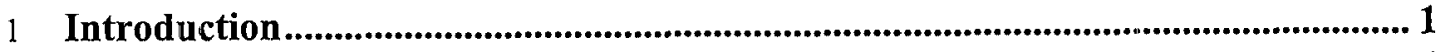

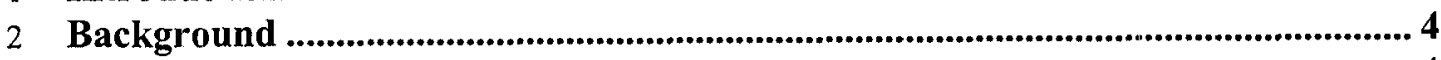

$2.1 \quad$ Forecasting thunderstorms and MCSs ................................................... 4

2.2 MCS classification .......................................................................... 7

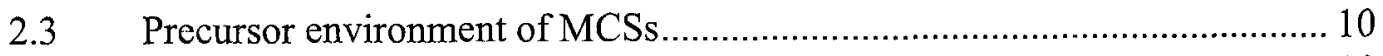

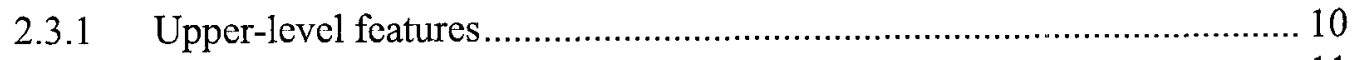

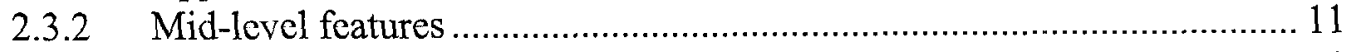

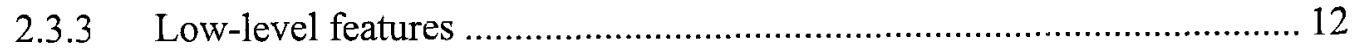

2.3.4 Stability parameters ...................................................................... 16

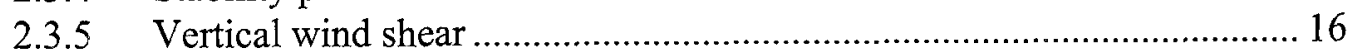

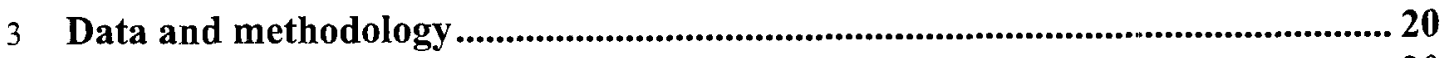

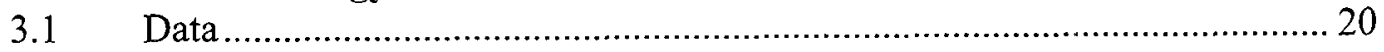

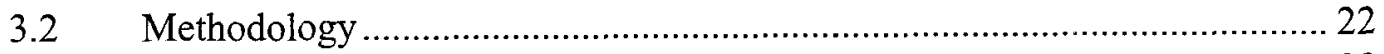

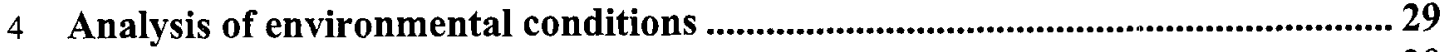

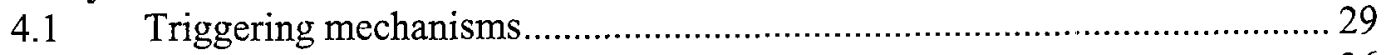

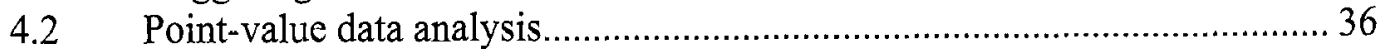

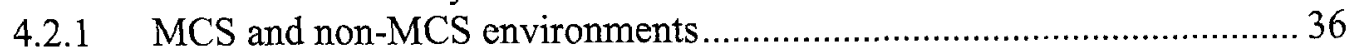

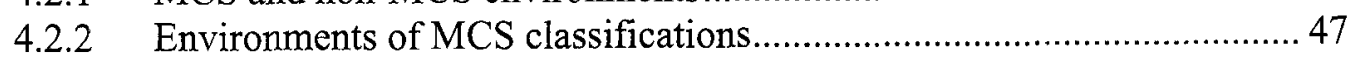

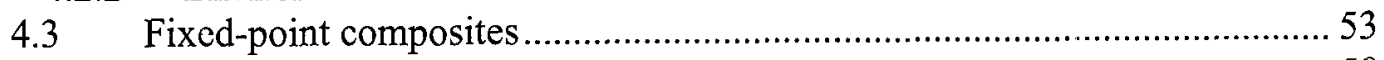

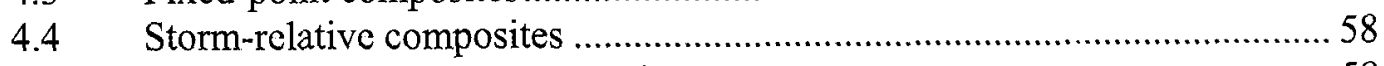

4.4.1 MCS and non-MCS composites...................................................... 58

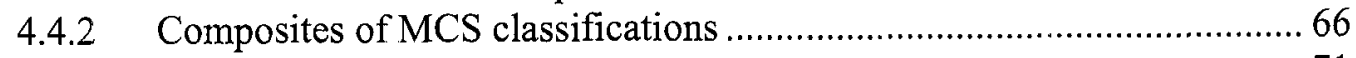

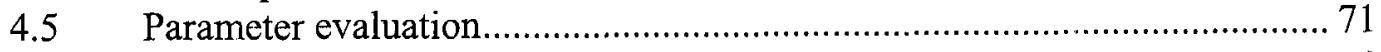

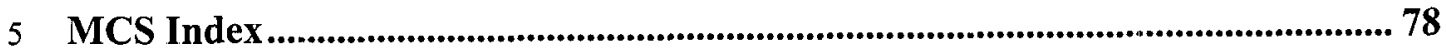

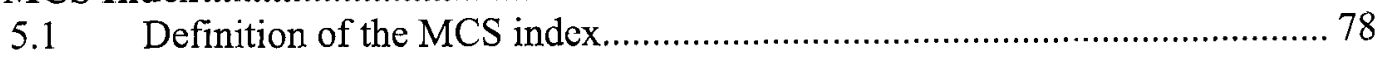

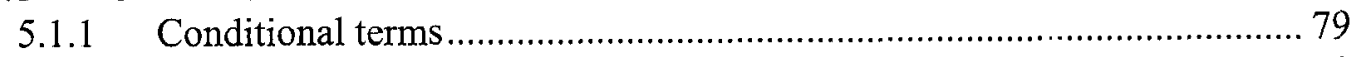

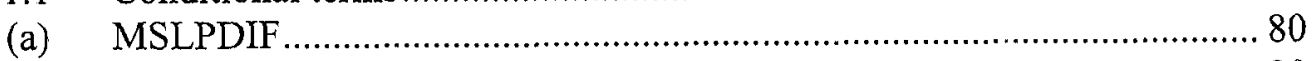

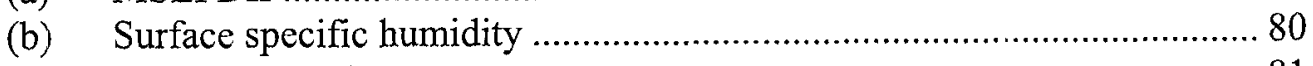

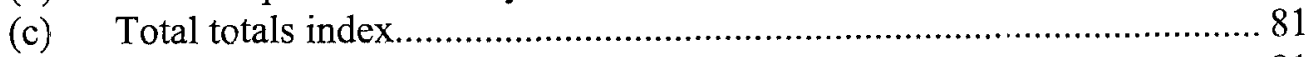

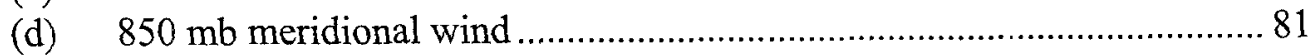

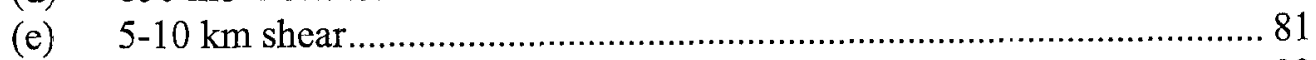

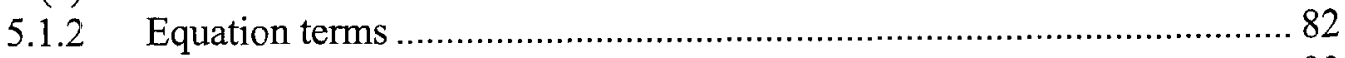

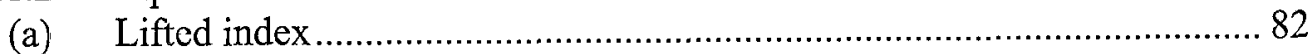

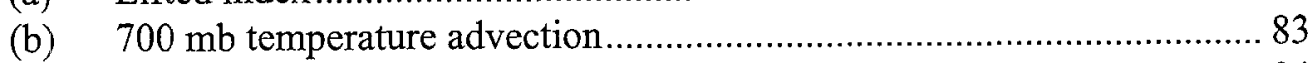

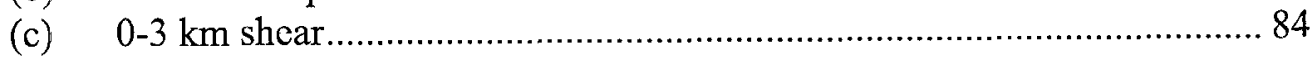




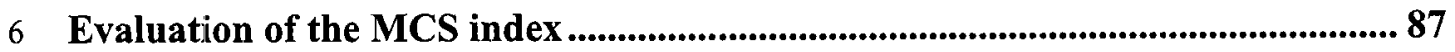

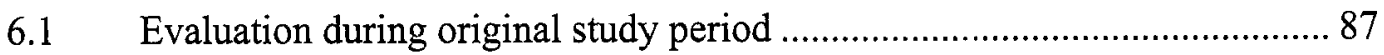

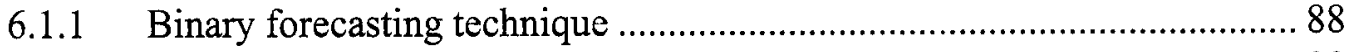

6.1.2 Diurnal and seasonal cycles ........................................................ 90

6.1.3 Warm season precipitation episodes ...................................................... 95

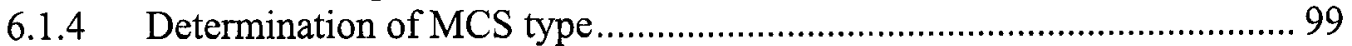

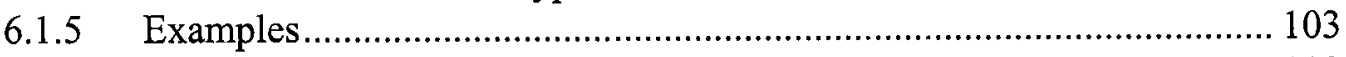

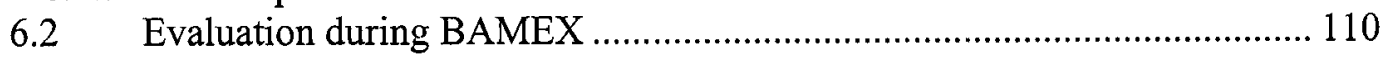

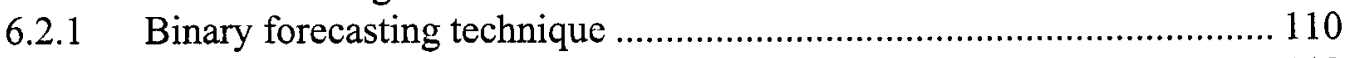

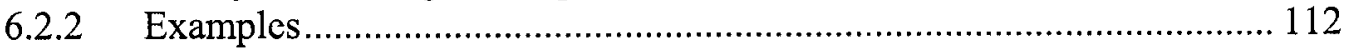

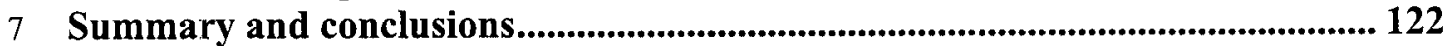

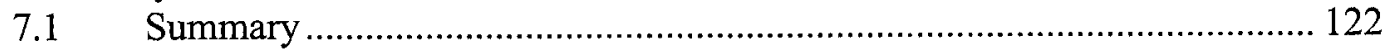

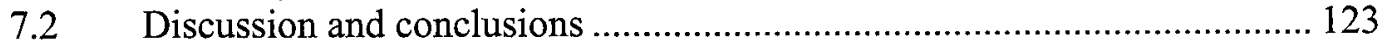

7.3 Suggestions for future research..................................................... 125 


\section{Chapter 1}

\section{Introduction}

Mesoscale convective systems (MCSs) frequently develop and traverse the central United States during the warm season. The prediction of these common, large thunderstorm complexes is important for two contrasting reasons. On the positive side, they generate essential rainfall for this agricultural region (Fritsch et al. 1986; Jirak et al. 2003, Ashley et al. 2003) while, on the negative side, they devastate property and possessions by producing severe weather (e.g., hail and damaging wind) over a large area (Maddox 1980; Houze et al. 1990; Jirak et al. 2003). Regardless of whether the impact of MCSs is primarily beneficial or harmful, advance knowledge of their development is desirable.

Unfortunately, forecasting MCSs is not only very challenging, but it is also an area with an overall lack of knowledge and specific prediction methods (Ziegler 2000). MCSs are comprised of individual thunderstorm elements that interact and subsequently merge into an organized convective system (Cotton and Anthes 1989). Thus, forecasting MCSs requires knowledge of areas favorable for convective initiation, organization, and sustenance over a range of spatial and time scales. Even though pinpointing the location of convective initiation is unlikely for many thunderstorms given the current density of the observational network (Stensrud and Fritsch 1994), much can still be learned about 
environments that are conducive for convective organization and sustenance of MCSs. In fact, MCSs tend to form frequently only in certain regions of the world that have preferred meteorological settings (e.g., leeward side of the Rocky Mountains in the U.S., leeward side of the Andes Mountains in South America, leeward side of the Himalayan Mountains in China, and tropical northern Africa) (Laing and Fritsch 2000), lending support to the possibility of improving forecasts of MCSs.

The objective of this study is to exploit this notion of MCS predictability by identifying important MCS precursors through a detailed observational analysis of the environment prior to the development of hundreds of MCSs over the U.S. This study builds on previous studies regarding the precursor environment of MCCs (Maddox 1983; Augustine and Howard 1988; Cotton et al. 1989; and Laing and Fritsch 2000) and other MCSs (Augustine and Caracena 1994; Anderson and Arritt 1998) by using data of higher temporal and spatial resolution to analyze many more and varied types of MCSs and by looking deeper into the issue of MCS predictability. To comprehensively address the issue of M.CS predictability, the MCS precursor environments are compared with environments that do not support convection and environments that support unorganized convection. From the analysis of these different conditions, parameters that best distinguish environments favorable for MCS development are identified as possible aids in forecasting MCSs. The ultimate goal is to develop a MCS index comprised of these predictive parameters that will objectively indicate the likelihood of MCS development in the next few hours at a given location.

The remainder of this paper will explain the process of analyzing the predictability of MCSs and convey the results of the analysis. In Chapter 2, the issue of forecasting 
convection is discussed, including the difficulty of forecasting the convective mode. A review of previous observational studies on the precursor environment of MCSs and other important features of MCS environments found in modeling studies is also presented. The third chapter provides a description of the MCS sample examined and the data and methodology used to analyze that sample. Chapter 4 presents statistical and graphical results of the precursor environment of MCSs, as well as comparisons to environments that do not support organized convection. The MCS index is introduced and explained in Chapter 5. Chapter 6 provides an evaluation of the MCS index during the original study period and during an independent convective season. Several examples of the index are provided to demonstrate its usefulness in forecasting MCSs. Finally, Chapter 7 provides a summary, conclusions, and suggestions for future research on the analysis of MCS predictability. 


\section{Chapter 2}

\section{Background}

\subsection{Forecasting thunderstorms and MCSs}

Thunderstorms develop when moist air rises from low levels and becomes warmer than its environment (i.e., positively buoyant). At this level of free convection (LFC), air rises without restraint until it becomes colder than the surrounding environment (i.e., negatively buoyant) at the equilibrium level (EL). A measure of the amount of positively buoyant energy between the LFC and the EL is called the convective available potential energy (CAPE). Generally, thunderstorms develop in areas of large CAPE; however, areas of large CAPE do not guarantee thunderstorm development. Frequently, there is a layer of warm air in the lower troposphere that prevents air from reaching the LFC and, consequently, inhibits thunderstorm development. Convective inhibition (CIN) is a measure of the amount of energy needed to lift the air to the LFC. Thus, one must have knowledge of both CAPE and CIN to determine the likelihood of thunderstorm development. The largest uncertainty of forecasting thunderstorms in certain parts of the world involves deciding if, when, and where CIN will be overcome. Daytime heating, large-scale forcing, and low-level convergence can all surmount CIN and lift air to the LFC resulting in thunderstorm development. Since convergence along mesoscale boundaries often provides enough lift to break the convective cap, the ability to locate 
these features are vital in order to correctly forecast the timing and location of convective initiation. Unfortunately, the current density of the observational network is not sufficient to resolve many of the mesoscale features important to convective initiation (Stensrud and Fritsch 1994).

The difficulty in forecasting thunderstorms does not end with the issue of convective initiation. Once thunderstorms develop, they can take on many different characteristics and appearances depending on the environment that they form in. Some common modes of convection include ordinary thunderstorms, multicell thunderstorms, supercell thunderstorms, and MCSs (including convective lines and clusters of all shapes and sizes). Vertical wind shear is one parameter that plays an important role in determining the mode of convection. Weisman and Klemp $(1982 ; 1984)$ found that for similar values of CAPE, ordinary thunderstorms are likely for small values of low-level shear, multicell thunderstorms are likely for intermediate values of low-level shear, and supercell thunderstorms are likely for large values of low-level shear. In accordance with this finding, thunderstorms that develop in an area with large values of shear have a high likelihood of producing severe weather (Johns and Doswell 1992; McNulty 1995). Although vertical wind shear can be used to discern the type of convective cells that will form, it does not sufficiently determine whether these thunderstorms will undergo upscale growth into MCSs. In fact, Doswell and Flueck (1989) and Jincai et al. (1992) reported that even though experimental forecasters were able to provide accurate forecasts of deep convection, they showed only marginal skill in determining the degree to which thunderstorms would experience mesoscale organization. The difficulty in discerning between the environments that support isolated thunderstorms and those that support 
MCSs is a consequence of MCSs often being a culmination of the merger of these individual convective elements (Jirak et al. 2003).

The reality is that there is a deficiency of formal studies and specific methods regarding the forecasting of MCSs (Ziegler 2000). Given the commonness and significance of these weather phenomena, the issue of forecasting them requires more attention. The only guidance provided to forecasters comes from previous studies on the precursor environment of MCSs (see Section 2.3). These studies only identify recurrent features prior to MCS development. They were not specifically conducted with the forecasting of MCSs in mind, so they do not present specific, objective methods to aid in the forecasting of MCSs. Operational forecasters at the Storm Prediction Center (SPC) and National Weather Service forecast offices (NWSFO) often discuss the possibility of thunderstorms merging into a MCS without using specific reasoning, other than an occasional reference to the low-level jet (LLJ). One particular concern is the possibility of a MCS advancing into a local NWS county warning area (CWA) overnight. An area may have favorable conditions for supporting a MCS even if it developed several hundred miles away, making for a difficult forecast. Operational numerical models can also provide some guidance to the forecasting of MCSs, especially by looking at the overnight precipitation fields. Even though the resolution of these models has increased significantly over time, they still are not able to resolve the initial convection of MCSs, which affects the ability of the model to accurately represent MCS development. Thus, additional specific tools could be useful to a forecaster in making decisions about the influence of MCSs on severe weather, precipitation, cloud cover, temperature, and winds. 
Even though the issue of MCS forecasting has not been studied extensively in the past, there are still promising indicators of learning more about MCS predictability. Mesoscale convective complexes (MCCs) are specific types of MCSs that form frequently only in certain regions of the world (Laing and Fritsch 1997, 2000), hinting at a possible predictive signal within these unique environments. Additionally, previous studies on the precursor environment of MCSs have identified recurrent features that are important to MCS development. These features will be discussed in detail in Section 2.3. Finally, inferences of even longer-term predictability can been seen in warm season precipitation episodes (Cotton et al. 1983; Carbone et al. 2002), which are coherent sequences of MCSs that persist on the order of a more than one day.

\subsection{MCS classification}

MCSs are generally defined by Houze (1993) as "a cloud system that occurs in connection with an ensemble of thunderstorms and produces a contiguous precipitation area $\sim 100 \mathrm{~km}$ or more in horizontal scale in at least one direction." One approach in studying MCSs involves classifying this broad range of convective weather phenomena into specific categories in order to analyze differences among the various systems. Different methods and approaches have been used over time to classify MCSs. Maddox (1980) first used infrared (IR) satellite imagery to classify large, organized, quasi-circular convective systems that frequently move across the central U.S. during the evening and nighttime hours. He called these massive systems mesoscale convective complexes (MCCs). Cotton et al. (1989) provide a dynamical definition of MCCs as "nearly geostrophically-balanced (systems) with a horizontal scale comparable to or larger than the Rossby radius of deformation, $\lambda_{R}$." Anderson and Arritt (1998) identified another 
large class of MCSs: persistent elongated convective systems (PECSs). As the name indicates, these systems are a quasi-linear version of MCCs. Jirak et al. (2003) used these two IR satellite-defined categories in conjunction with two new classifications of smaller MCSs to get a comprehensive classification scheme of MCSs. Smaller quasi-circular systems are called meso- $\beta$ circular convective systems (MBCCSs) while smaller quasilinear systems are called meso- $\beta$ elongated convective systems (MßECSs). The definitions of all satellite classifications are provided in Table 2.1. In their study of a few hundred MCSs over the central U.S., Jirak et al. (2003) found PECSs to be the largest, most common, most severe, and rainiest type of MCS.

Table 2.1: MCS definitions based upon analysis of IR satellite data.

\begin{tabular}{|c|c|c|c|}
\hline MCS category & Size & Duration & Shape \\
\hline $\mathrm{MCC}$ & \multirow{2}{*}{$\begin{array}{l}\text { Cold cloud region } \\
\leq-52^{\circ} \mathrm{C} \text { with area } \\
\geq 50000 \mathrm{~km}^{2}\end{array}$} & \multirow{2}{*}{$\begin{array}{l}\text { Size definition met } \\
\qquad \text { for } \geq 6 \text { hours }\end{array}$} & $\begin{array}{c}\text { Eccentricity } \geq 0.7 \text { at time of } \\
\text { maximum extent }\end{array}$ \\
\hline PECS & & & $\begin{array}{c}0.2 \leq \text { Eccentricity }<0.7 \text { at time } \\
\text { of maximum extent }\end{array}$ \\
\hline M $\beta C C S$ & \multirow{2}{*}{$\begin{array}{c}\text { Cold cloud region } \\
\leq-52^{\circ} \mathrm{C} \text { with area } \\
\geq 30000 \mathrm{~km}^{2} \& \text { maximum } \\
\text { size must be } \geq 50000 \mathrm{~km}^{2}\end{array}$} & \multirow{2}{*}{$\begin{array}{l}\text { Size definition met } \\
\text { for } \geq 3 \text { hours }\end{array}$} & $\begin{array}{c}\text { Eccentricity } \geq 0.7 \text { at time of } \\
\text { maximum extent }\end{array}$ \\
\hline MßECS & & & $\begin{array}{c}0.2 \leq \text { Eccentricity }<0.7 \text { at time } \\
\text { of maximum extent }\end{array}$ \\
\hline
\end{tabular}

Another more subjective method of classifying MCS entails classifying systems by their radar characteristics. One common approach is to examine the arrangement of the convective and stratiform regions of a mature MCS. The most common organization of MCSs is the leading-line/trailing-stratiform arrangement (Houze et al. 1990) with other 
systems having less common arrangements of leading stratiform and parallel stratiform regions (Parker and Johnson 2000). Another common method of radar classification is to identify MCSs by their developmental characteristics. Bluestein and Jain (1985) first identified common patterns of severe squall line formation. Jirak et al. (2003) expanded on this study to include the development of all types of MCSs. They introduced a threelevel classification of MCS development: presence of stratiform precipitation, arrangement of convective cells, and interaction of convective clusters (see Fig. 2.1). They found that MCSs that developed from convection arranged in a linear fashion were larger, longer-lived, more severe, and produced more precipitation than systems that developed from scattered convection (i.e., areal systems).

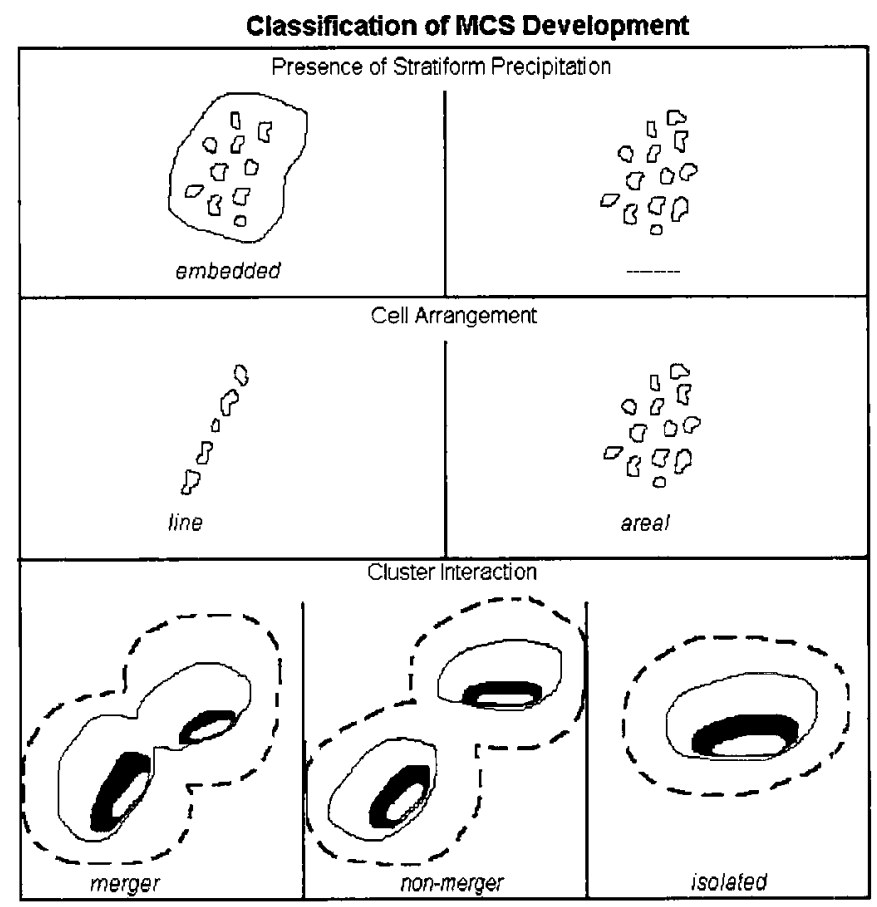

Figure 2.1: Idealized depiction of the threc-level classification scheme used to categorize MCS development as seen by radar reflectivity. The solid lines and contours represent relative reflectivity levels while the dashed lines represent the outline of the cold cloud shield. 


\subsection{Precursor environment of MCSs}

For just over a quarter-century, research on MCSs has significantly increased our awareness and understanding of these massive convective storms. We now have an idea about the basic structure, circulation, and organization of MCSs. Even with this understanding, forecasting MCSs is still a difficult task. Several studies (e.g., Maddox 1983; Augustine and Howard 1988; Cotton et al. 1989; Augustine and Caracena 1994; Anderson and Arritt 1998; Laing and Fritsch 2000) have examined the large-scale environment prior to MCS development in order to identify conditions favorable for MCSs. Their focus has primarily been on MCCs with some inclusion of other types of MCSs. These studies form the current basis of MCS forecasting, and their results are summarized in the subsections below.

\subsubsection{Upper-level features}

The upper levels are dominated by a synoptic-scale wave prior to MCS development (Anderson and Arritt 1998). MCSs tend to develop just upstream of a ridge in relatively weak southwesterly divergent flow at $200 \mathrm{mb}$ on the anticyclonic side of broad westerly jet stream (see Fig. 2.2) (Maddox 1983; Cotton et al. 1989; Anderson and Arritt 1998; Laing and Fritsch 2000). Maddox (1983) found MCCs to develop at the right exit region of the jet streak while Cotton et al. (1989) and Anderson and Arritt (1998) found MCSs to form at the right entrance region of the jet streak, which is a much more favorable region for thunderstorm development due to the upward motion present in this quadrant of the jet streak (Uccellini and Johnson 1979). At $200 \mathrm{mb}$, MCCs typically form in an area of minimum temperatures (Maddox 1983; Cotton et al. 1989). Additionally, $300 \mathrm{mb}$ 
Q-vector convergence is commonly found in regions of MCS development (Anderson and Arritt 1998), providing a measure of synoptic-scale ascent.

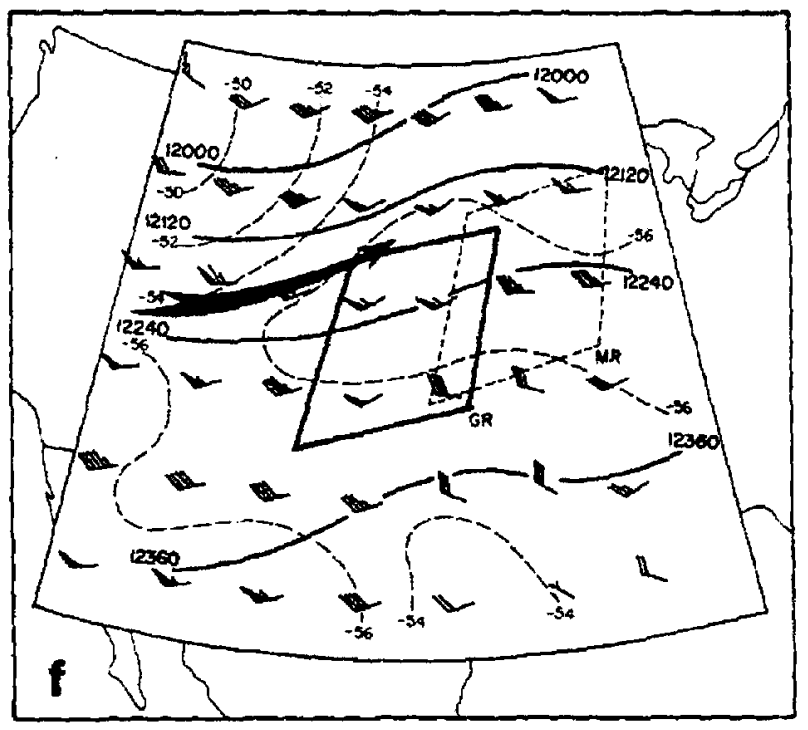

Figure 2.2: Analysis of the $\mathbf{2 0 0} \mathrm{mb}$ level prior to MCC development. The thick solid lines are height contours $(\mathrm{m})$, the dashed lines are isotherms $\left({ }^{\circ} \mathrm{C}\right)$, and the light solid lines are mixing ratios $\left(\mathrm{g} \mathrm{kg}^{-1}\right)$. Full wind barbs represent $5 \mathrm{~m} \mathrm{~s}^{-1}$, and a flag represents $25 \mathrm{~m} \mathrm{~s}^{-1}$. The dark arrow indicates the axis of maximum winds. The genesis region is indicated by the solid quadrilateral (from Maddox 1983).

\subsubsection{Mid-level features}

MCCs typically form downstream of a weak short-wave trough at $500 \mathrm{mb}$ (see Fig. 2.3) (Maddox 1983; Laing and Fritsch 2000) associated with wcak positive vorticity advection (PVA) (Maddox 1983). This is an area of a strong south-to-north temperature gradient with an accompanying increase in winds to the north, but overall relatively weak west-southwesterly flow $\left(\sim 7-18 \mathrm{~ms}^{-1}\right)$ (Maddox 1983). Temperature advection is approximately neutral in this area (Maddox 1983; Laing and Fritsch 2000) with moist conditions in place (Maddox 1983). Furthermore, Augustine and Howard (1988) found strong Q-vector convergence vertically in phase at $400 \mathrm{mb}$ and $600 \mathrm{mb}$ for an active 
month of MCC development, suggesting that favorable forcing was common enough at mid-tropospheric levels to be depicted in a monthly composite.

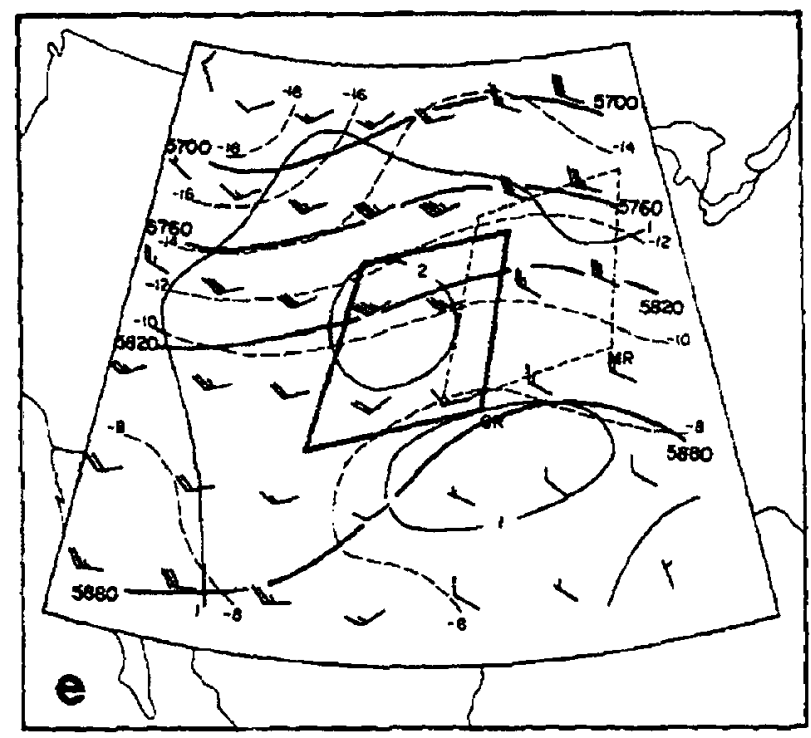

Figure 2.3: As in Fig. 2.2, but for the $500 \mathrm{mb}$ level prior to MCC development (from Maddox 1983).

\subsubsection{Low-level features}

The wind and height fields at $700 \mathrm{mb}$ suggest a weak short-wave trough approaching the area of MCC formation (see Fig. 2.4) (Maddox 1983). Figure 2.5 reveals that the most notable feature found at $700 \mathrm{mb}$ is the strong warm air advection coincident with the location of MCS development. As several studies have noted (e.g., Maddox and Doswell 1982; Maddox 1983; Cotton et al. 1989; Laing and Fritsch 2000), warm air advection is often important in providing the environmental upward motion needed for the development and sustenance of MCSs. 


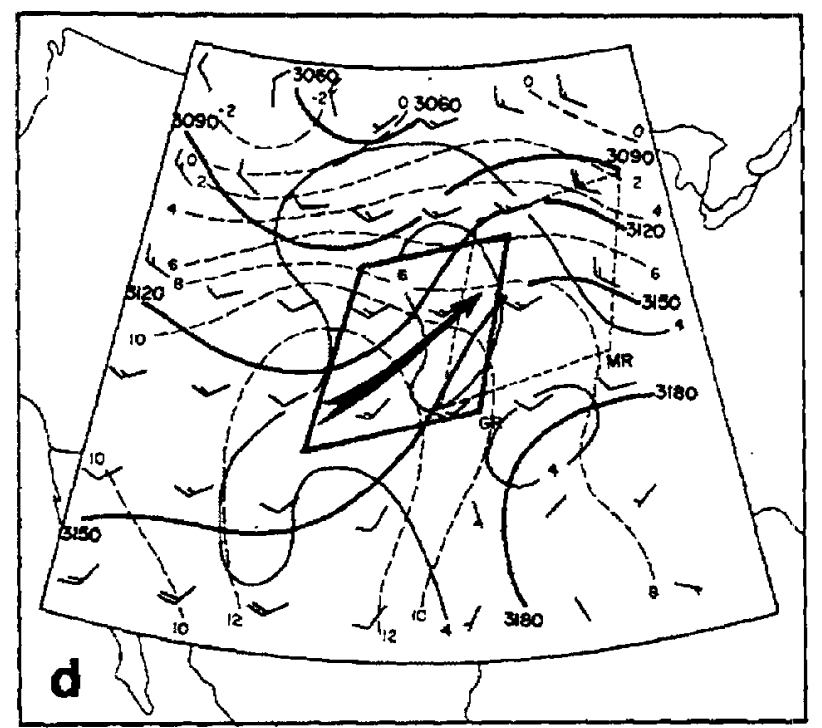

Figure 2.4: As in Fig. 2.2, but for the $700 \mathrm{mb}$ level prior to MCC development (from Maddox 1983).

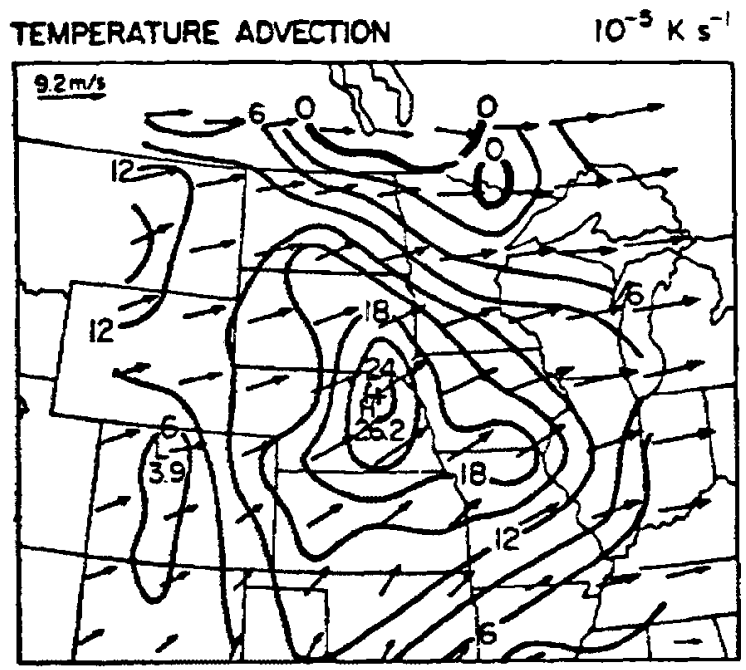

Figure 2.5: Analysis of $700 \mathrm{mb}$ temperature advection in $\mathrm{K} \mathrm{s}^{-1}$ (from Cotton et al. 1989).

A strong southerly low-level jet (LLJ) exists at $850 \mathrm{mb}$ advecting warm, moist air into the region of MCS development (see Fig. 2.6) (Maddox 1983; Cotton et al. 1989; Anderson and Arritt 1998; Laing and Fritsch 2000). Even though the LLJ is a recurrent feature of the precursor environment of MCSs, Parker and Johnson (2000) noted that $39 \%$ of the MCS cases they studied were not associated with a LLJ. The region is also 
commonly characterized by a broad trough just to the west (Maddox 1983) and a tongue of moist air extending up from the south (Maddox 1983; Cotton et al. 1989). Augustine and Caracena (1994) also found that large, long-lived MCSs often form in a frontogenetic region at $850 \mathrm{mb}$.

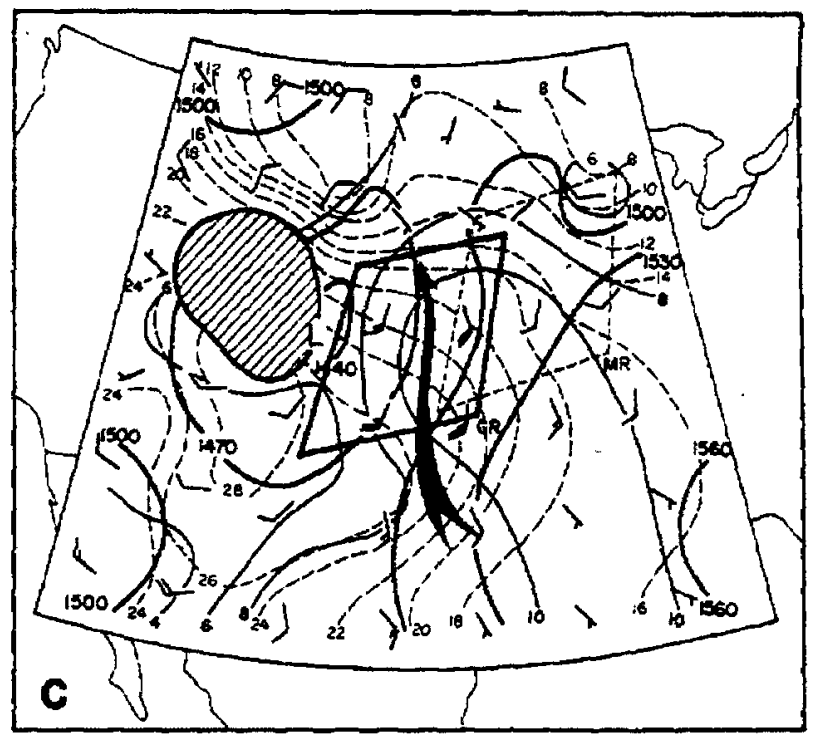

Figure 2.6: As in Fig. 2.2, but for the $850 \mathrm{mb}$ level prior to MCC development (from Maddox 1983). The hatched region indicates surface elevations above $850 \mathrm{mb}$.

At the surface, convergence is commonly found along an east-west oriented front stretching through the region of MCS development (see Fig. 2.7) (Maddox 1983; Cotton et al. 1989; Anderson and Arritt 1998; Laing and Fritsch 2000). In fact, the intersection of this front and the LLJ may be a preferred region for MCS genesis (Augustine and Caracena 1994). MCSs tend to develop to the north of a late afternoon surface geostrophic wind maximum, which acts a proxy for the location of the nocturnal LLJ (Augustine and Caracena 1994). Augustine and Caracena (1994) illustrate in Fig. 2.8 that this area downwind of the afternoon surface geostrophic wind maximum may be a preferred maturation region for large, long-lived, nocturnal MCSs given that the area is 
also frontogenetic at $850 \mathrm{mb}$. Finally, a band of moist air typically extends into the region of MCC development from the Gulf of Mexico (Maddox 1983).

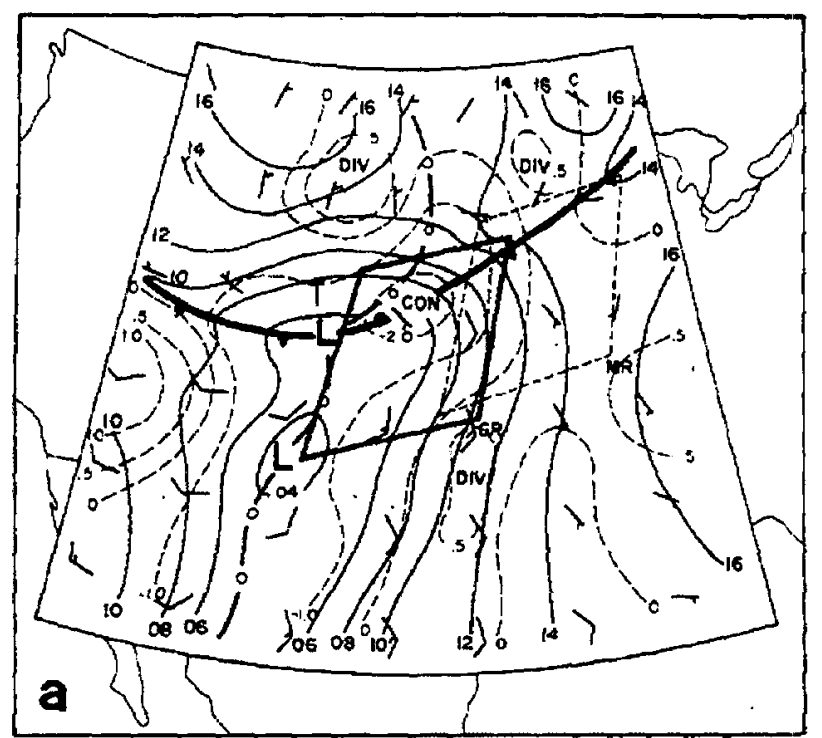

Figure 2.7: Analysis of surface features prior to MCC development. The solid lines represent mean sea-level pressure, and the dashed lines represent divergence $\left(10^{-5} \mathrm{~s}^{-1}\right)$ (from Maddox 1983).

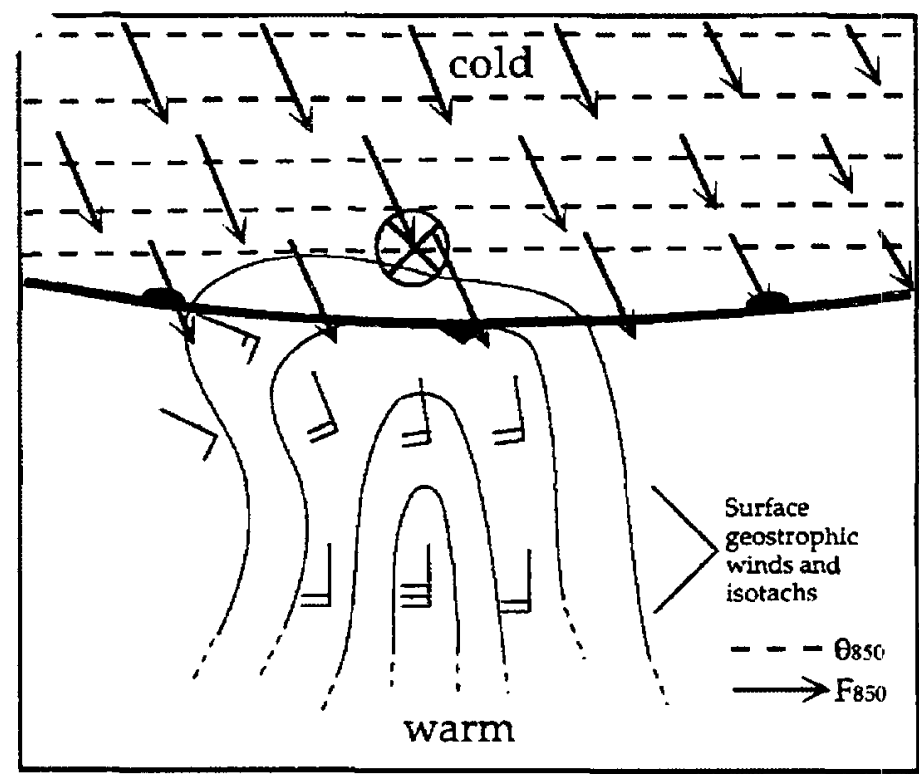

Figure 2.8: Schematic of the probable location of a large MCS at maturity. The thin solid lines represent the late afternoon surface geostrophic isotachs, the dashed lines represent the $850 \mathrm{mb}$ isentropes at $0000 \mathrm{UTC}$, and the arrows represent the $850 \mathrm{mb}$ frontogenesis vectors at 0000 UTC (from Augustine and Caracena 1994). 


\subsubsection{Stability parameters}

MCSs typically form in a region of unstable air. Maddox (1983) found a maximum in the Total Totals Index (TT) within the genesis region of MCCs. Laing and Fritsch (2000) also found high values of CAPE and the K index prior to MCC development. Other severe weather parameters, such as the lifted index and SWEAT index, typically indicate that MCSs develop in an area with a moderate potential for thunderstorms (Jirak et al. 2003). MCSs are also favored in regions where a lid-strength term is minimized, so convection is not inhibited (Anderson and Arritt 1998).

\subsubsection{Vertical wind shear}

As discussed previously, low-level vertical wind shear has an important influence on the type and severity of the thunderstorm that develops. Rotunno et al. (1988), Weisman (1992), and Weisman and Rotunno (2004) also theorize through modeling studies that low-level vertical wind shear is critical to sustaining long-lived squall lines through the interaction with the convectively-generated cold pool. Figure 2.9 shows schematically the process by which the ambient wind shear interacts with the storm cold pool to create conditions favorable for long-lived MCSs. Initially, the thunderstorm tilts downshear before the storm generates a significant cold pool (see Fig. 2.9a). When the horizontal vorticity associated with the cold pool balances the horizontal vorticity of the ambient shear, deep lifting is facilitated at the leading edge of the cold pool, creating strong, vertical convective cells (see Fig. 2.9b). As the cold pool strengthens over time, its associated circulation will overwhelm the ambient shear causing the system to tilt upshear, eventually leading to the dissipation of the MCS (see Fig. 2.9c). Laing and Fritsch (2000) found that MCCs around the globe typically form near a maximum in low- 
level shear (see Fig. 2.10), lending support to the idea that low-level shear is important for the development of long-lived MCSs.
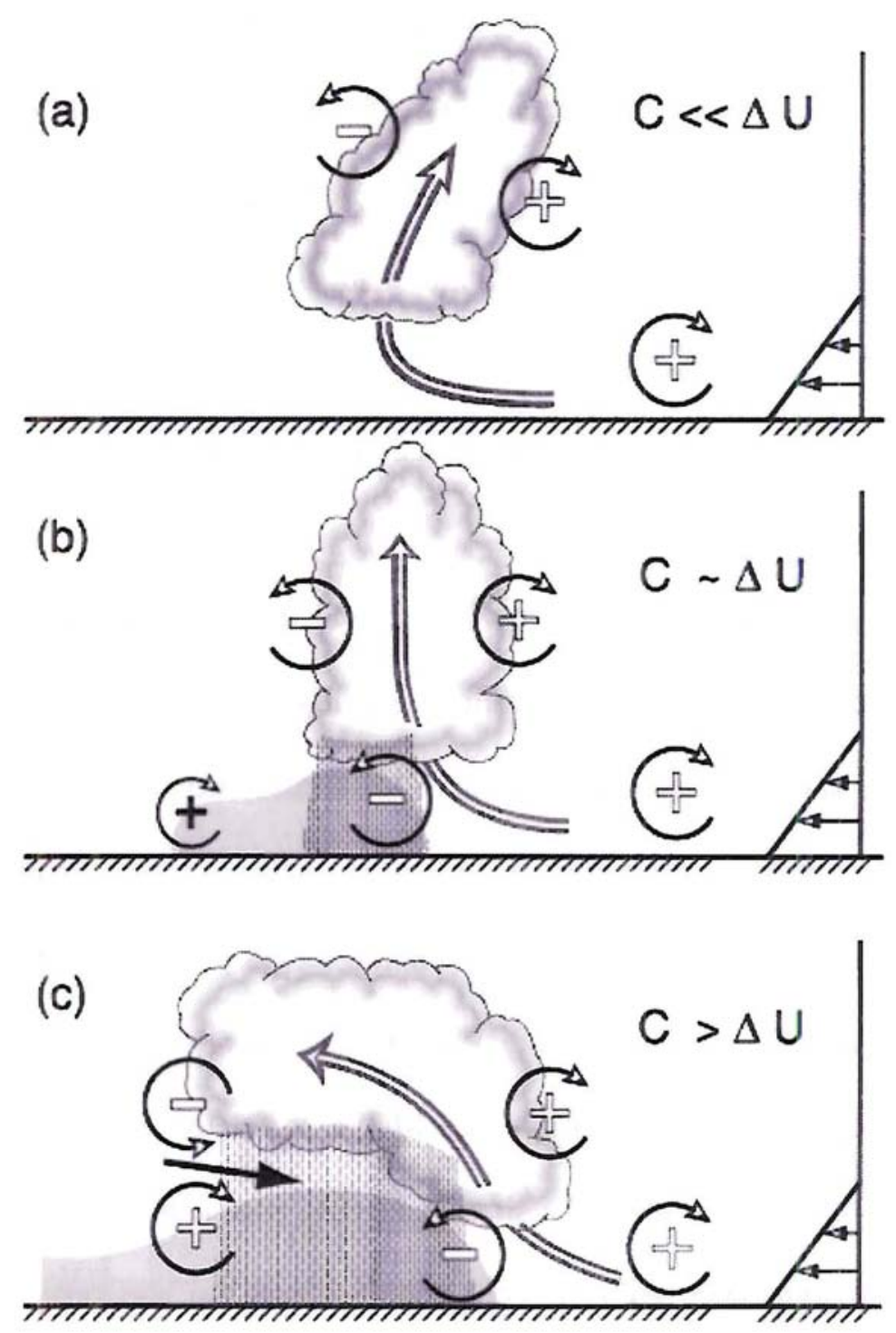

Figure 2.9: Schematic representation of the three stages in the evolution of a convective system. (a) The initial updraft leans downshear due to the ambient shear before the system develops a cold pool. (b) The system is upright as the storm-induced cold pool balances the effect of the ambient shear. (c) The system tilts upshear as the cold pool begins to overwhelm the ambient shear. The ambient shear $(\Delta \mathrm{U})$ is represented on the right while the cold pool $(\mathrm{C})$ is shaded below the storm. The sources of horizontal vorticity are indicated by the curved arrows (from Weisman and Rotunno 2004). 

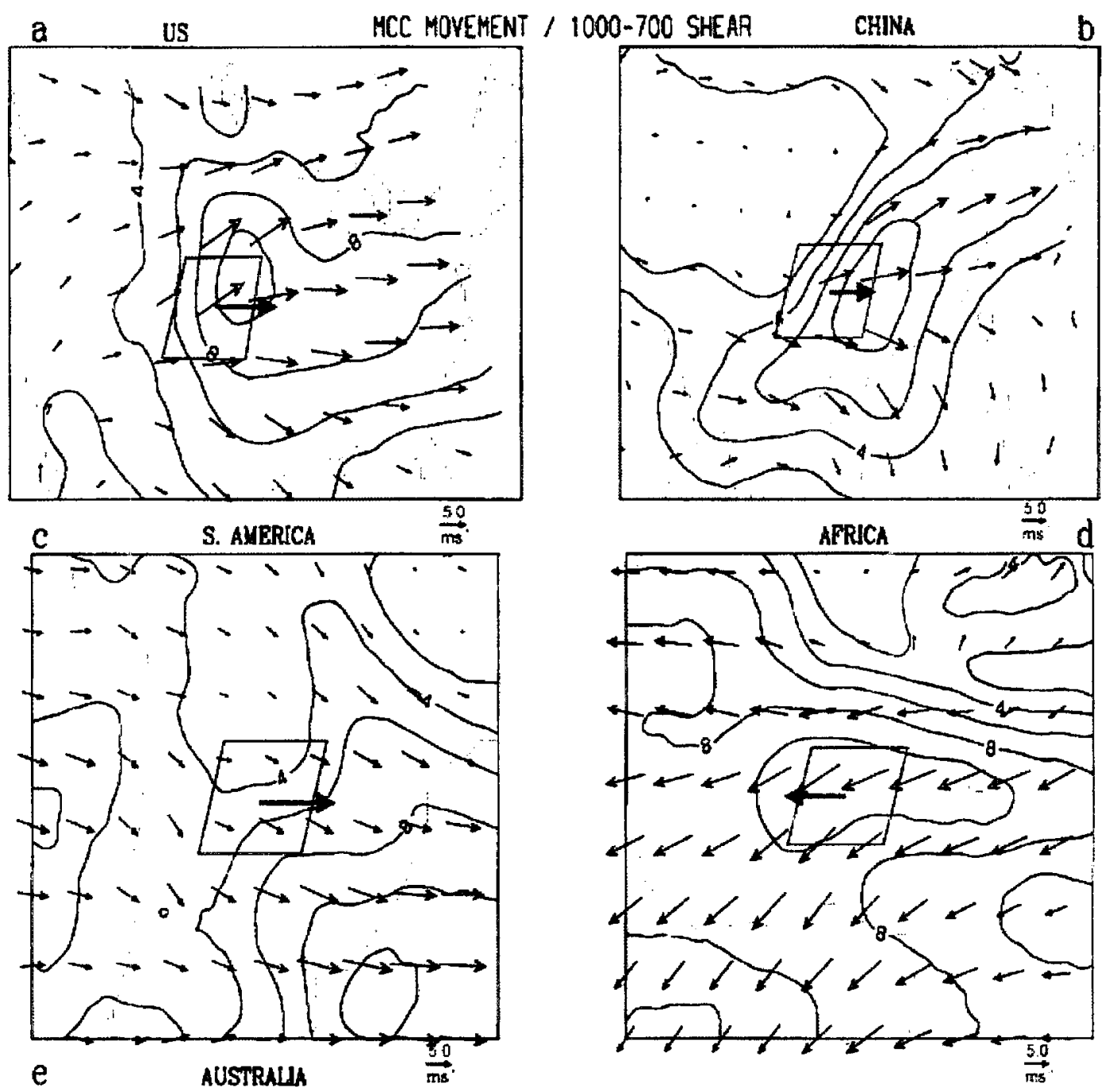

Figure 2.10: 1000-700 mb vertical wind shear for MCC populations around the globe. The solid contours represent the magnitude of the shear $\left(\mathrm{m} \mathrm{s}^{-1}\right)$. The shear vectors are the smaller arrows while the large, bold arrows represent MCC motion. The quadrilaterals represent the MCC genesis regions (from Laing and Fritsch 2000).

Much of the focus regarding the effect of vertical wind shear on MCS development has been placed on the low levels. In fact, the ambient shear was set to zero above the low levels in these early simulations. Weisman and Rotunno (2004) extended previous modeling studies to examine surface-based shear that extends above $5 \mathrm{~km}$ and discovered that deeper-layer shear results in more isolated convection and less overall system rainfall. Weisman (1993) and Doswell and Evans (2003) also note that strong deep layer 
shear (i.e. 0-6 km) may be more supportive of supercell thunderstorms than long-lived, severe wind-producing MCSs (i.e., bow echoes and derechoes).

Coniglio et al. (2004) examined the effect of adding upper-level shear (i.e., $5-10 \mathrm{~km}$ ), whilc maintaining moderate values of low-level shear, in simulations of organized convective systems. In varying only the upper-level shear, Fig. 2.11 reveals that moderate values (i.e., $\sim 5-15 \mathrm{~m} \mathrm{~s}^{-1}$ ) of $5-10 \mathrm{~km}$ shear are the most conducive for producing large vertical displacements that lead to larger, more prolific rain-producing systems (Coniglio et al. 2004). Increasing the upper-level shear beyond $8 \mathrm{~m} \mathrm{~s}^{-1}$ limits parcel overturning, which results in smaller vertical displacements and less favorable conditions for long-lived convective systems.

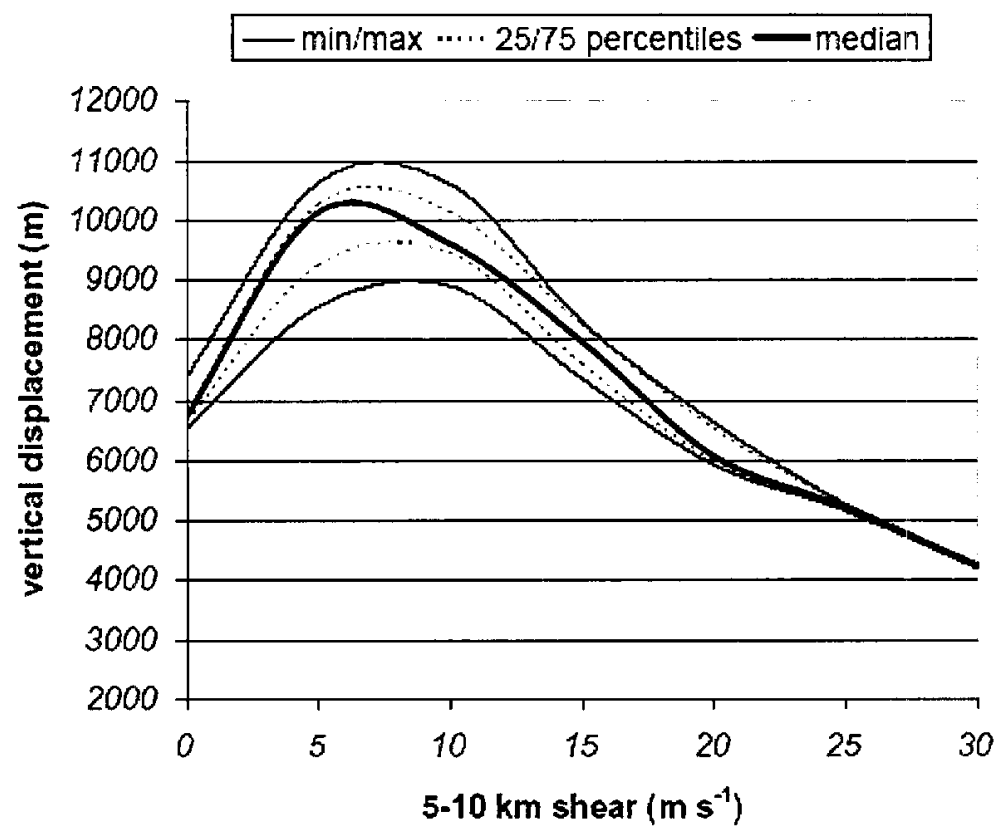

Figure 2.11: The maximum vertical displacement $(\mathrm{m})$ of low-level (i.e., $0-2 \mathrm{~km}$ ) parcels for a variety of $5-10 \mathrm{~km}$ vertical wind shears from the simulation of convective systems. The minimum, maximum, $25^{\text {th }}$ and $75^{\text {th }}$ percentiles, and median values from a set of 21 trajectories are shown (from Coniglio et al. 2004). 


\section{Chapter 3}

\section{Data and methodology}

From this point on, the focus of this thesis shifts from previous studies to the current study. This chapter provides an overview of the type of data that were used in this study and how they were analyzed. Several types of data were obtained to thoroughly examine the precursor environment of MCSs. Additionally, numerous methods were employed to extract information through the analysis of these data. The data and methodologies utilized are described below.

\subsection{Data}

The MCS sample used for this study was selected by Jirak et al. (2003) in their classification study on MCS development. The sample includes more than 300 systems that formed over the central United States during the warm seasons (April-August) of 1996-1998. This sample was chosen because of the detailed satellite and radar lifecycle information on record for the MCSs. Systems of all shapes and sizes were included in the sample and were classified by their cloud shield characteristics and developmental characteristics. This comprehensive information allows for a thorough investigation of the preexisting environment for all types of MCSs.

One type of data used in the analysis of this sample of MCSs was surface analyses produced by the Hydrometeorological Prediction Center (HPC) of the National Centers 
for Environmental Prediction (NCEP). These surface analyses are subjectively analyzed by HPC forecasters every three hours (i.e., $00 \mathrm{UTC}, 03 \mathrm{UTC}, 06 \mathrm{UTC}, \ldots .$.$) and are$ available in image format from the National Climatic Data Center (NCDC). The forecasters analyze surface pressure, fronts, troughs, outflow boundaries, and drylines (see Fig. 3.1); thus, the analyses provide a convenient, consistent method for identifying surface features commonly associated with the development of MCSs.

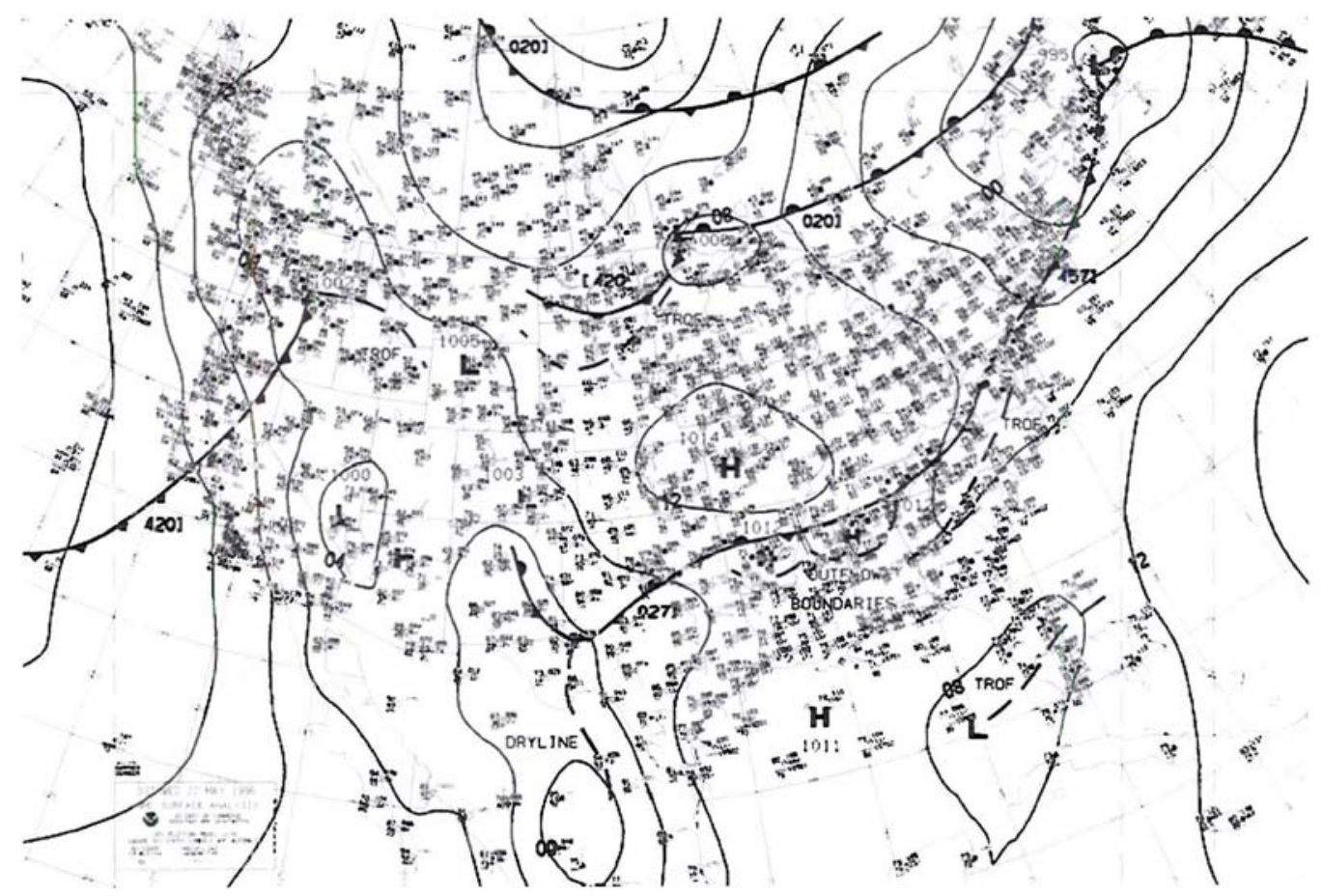

Figure 3.1: NCEP [formerly National Meteorological Center (NMC)] surface analysis for 03 UTC on 22 May 1996. This example shows the analysis of fronts, troughs, outflow boundaries, and a dryline.

Data from the NCEP North American Regional Reanalysis (NARR) were also used in this study. This new dataset contains reanalyses generated by a slightly modified version of the 2003 operational Eta model and 3D-Var Data Assimilation System (EDAS) (Mesinger et al. 2004). These analyses are of relatively high resolution at $32 \mathrm{~km}$ in the horizontal, 45 layers in the vertical, and $3 \mathrm{~h}$ intervals. The NARR improves upon the NCEP Global Reanalysis in resolution and accuracy due to modeling and data 
assimilation improvements, as well as the incorporation of more data (e.g., precipitation, profiler winds, and surface winds and moisture) (Mesinger et al. 2004). The NARR provides a long-term, consistent, high-resolution dataset to examine the environment prior to the development of MCSs over the U.S.

Analyses and forecasts generated by the Eta model and EDAS were obtained from the National Center for Atmospheric Research (NCAR) during the period of the Bow Echo and MCV Experiment (BAMEX). These products were available to forecasters in realtime during this field project that occurred from 20 May through 6 July 2003 . Thus, the data were used during this independent convective season to verify the results found in this study. Additionally, IR satellite data were acquired from the Global Hydrology Resource Center (GHRC) at the Global Hydrology and Climate Center in Huntsville, Alabama. The satellite data were used to objectively identify MCSs during BAMEX.

\subsection{Methodology}

The NCEP surface analyses were used to identify any detectable triggering mechanism that generated the initial convection for each MCS. Radar data were used to locate the original convective cells that underwent upscale growth into a mature MCS. The surface analyses were then examined with the location and orientation of the convection in mind. If the convection were initiated near a feature that likely influenced its development, then that feature was recorded to be associated with the initial convection of the MCS. The results of this subjective analysis are presented in Section

$$
4.1 \text {. }
$$

The gridded reanalyses and analyses were used to thoroughly inspect the precursor environment of 383 MCSs sampled in the Jirak et al. (2003) study and 50 MCSs during 
BAMEX. Numerous basic (e.g., height, wind, moisture, and temperature) and derived (e.g., divergence, vorticity, and advection) fields were examined from these datasets six hours prior to initiation, three hours prior to initiation, and at the time of MCS initiation to determine their importance in MCS development. In addition, the environment was also examined for the condition of "widespread convection." This condition is defined as a group of highly concentrated thunderstorms that does not undergo upscale growth and organization into a MCS. A couple examples of widespread convection are shown in Figs. 3.2 and 3.3 to provide an idea of how this condition evolves on radar imagery. During the warm seasons of $1996-98$, there were 300 instances of widespread convection identified. Please note that this condition can occur at the same time that a MCS exists somewhere else over the central U.S. Finally, data were also obtained for days without MCSs. This condition is defined as a period of at least $6 \mathrm{~h}$ after the last MCS dissipation and at least $12 \mathrm{~h}$ prior to any new MCS initiation across the entire domain. The data for days without MCSs were taken from either 00 UTC or 12 UTC for a total of 209 occurrences during the warm seasons of 1996-98. Three different methods were used to analyze all of this data while looking for predictive signals: point-value data analysis, fixed-point compositing, and storm-relative compositing.

The point-value data method involves simply taking a single value of a given field for each condition. Prior to MCS development, the data were extracted from the location of the centroid of the MCS at initiation based on $-52^{\circ} \mathrm{C}$ cold cloud shield threshold. For widespread convection, data were taken from the approximate center of the group of thunderstorms at the time of the maximum number of convective cells. On days without MCSs, pulling a single, representative value from the domain was not as straightforward. 
Even though MCSs do not develop on these days, the most likely location of MCS development still needs to be identified in order to get meaningful, comparable data. The data were taken from two locations on days without MCSs: the location of the domainmaximum SWEAT index and the location of the maximum CAPE over land. The SWEAT index was chosen because it is typically large prior to MCS development (Jirak et al. 2003), and it is comprised of multiple parameters (e.g., moisture, stability, and winds), so it is likely to produce better results in a variety of meteorological settings. CAPE was chosen due to the fact that thunderstorms often develop in areas of large CAPE. Once all of the point-value data were collected, typical parameter ranges and values were compared for the different conditions, allowing for a statistical analysis of the data discussed in Section 4.2.
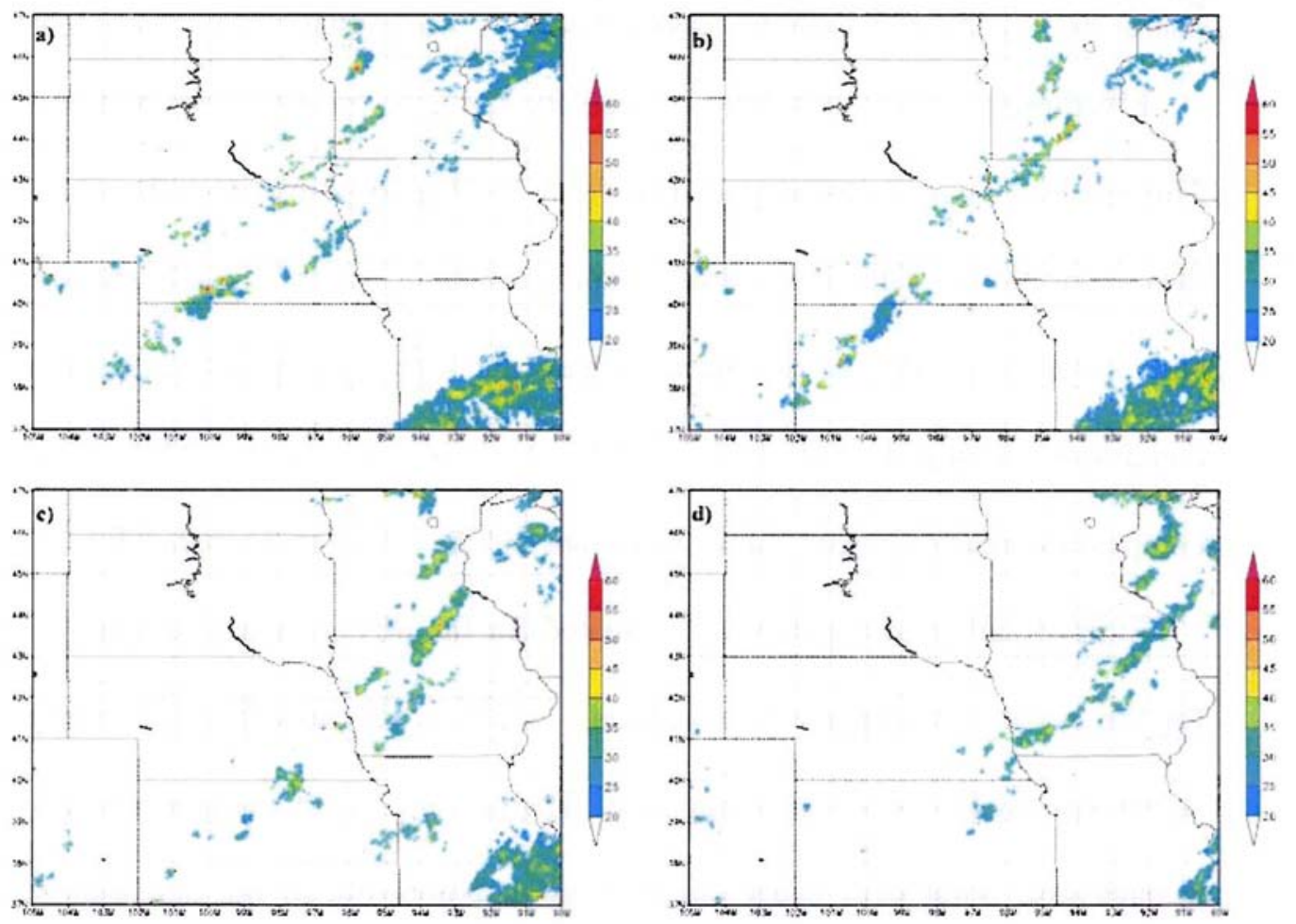

Figure 3.2: Example of widespread convection that developed along a cold front, as seen by radar reflectivity. The images are from a) 2100 , b) 2300 UTC on 17 June 1997 , c) 0100 , and d) 0400 UTC on 18 June 1997. 

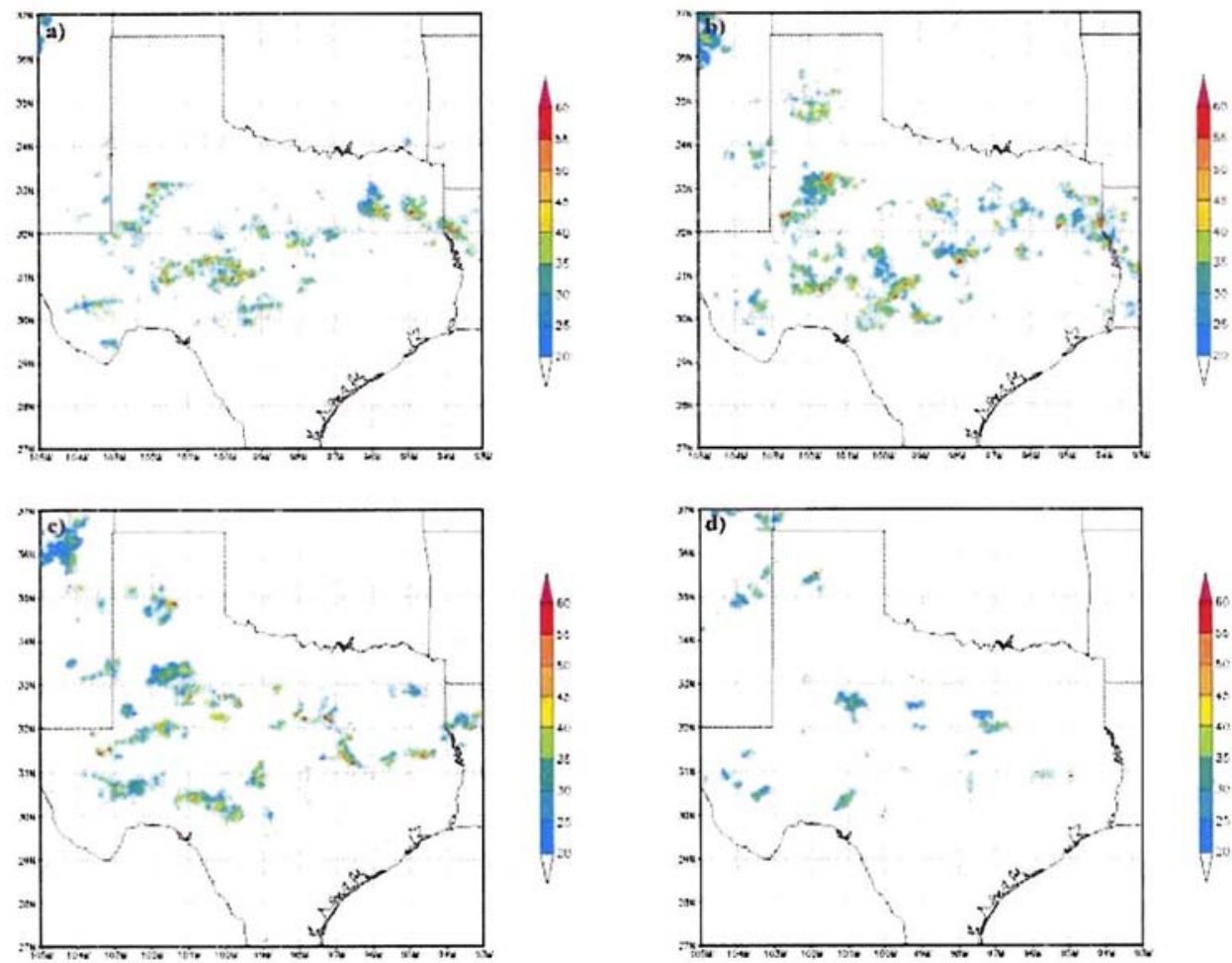

gure 3.3: Example of widespread convection across Texas, as seen by radar reflectivity. The images are from a) 2000, b) 2200 UTC on 16 July 1998, c) 0000 UTC, and d) 0300 UTC on 17 July 1998.

Fixed-point composites were created for the U.S. on days with and without MCSs. This method involves averaging data from fixed grid points over the U.S. for both of these conditions. The fixed-point composite method smoothes out small-scale features and provides an idea of the basic large-scale flow pattern for each of the different conditions (Augustine and Howard 1991; Anderson and Arritt 1998). The fixed-point composites created for this study are shown and discussed in Section 4.3.

Storm-relative composites were created for the precursor environment of MCSs and for the cases of widespread convection. A $20^{\circ} \times 15^{\circ}$ movable grid centered on each storm was used to create the composite. The deviation from the grid mean was averaged at each grid point over every storm to get a composite of the deviation values. The average of the grid means was then added to the composited deviation values to get 
meaningful meteorological quantities. This method of compositing the deviation values helps reduce the uncertainty that arises from parameters with seasonally-varying means (Anderson and Arritt 1998). Finally, the data were filtered with a one-pass Barnes filter (Barnes 1964; Doswell 1977) using a response function similar to that of Anderson and Arritt (1998) to remove the small-scale noise that results from compositing. Stormrelative composites allow for the retention of some of the mesoscale features important to MCS development (Maddox 1983; Cotton et al. 1989). Section 4.4 reveals the results found from creating the storm-relative composites.

The results from each of the methods described above were examined and subjectively evaluated to determine if any good predictors of MCS development could be identified. Additionally, some objective methods were implemented to test the skill of the various parameters specifically in forecasting for MCSs. One method involved using a binary forecast, where a forecast is given (i.e., yes or no) based on a threshold value and whether or not a MCS is observed. Based on this contingency table (see Fig. 3.2), numerous terms (e.g., probability of detection (POD), false alarm rate (FAR), bias (B), threat score (TS), and Heidke skill score (HSS) (see Eq. 3.1) (Wilks 1995)) can be calculated to objectively evaluate the ability of different environmental parameters to forecast MCSs. Perfect forecasts receive POD and TS values of one while the worst forecasts receive values of zero. The HSS is also one for perfect forecasts, but it can become negative for forecasts worse than the reference forecast. Better forecasts have a lower FAR, so the best FAR is 0 , and the worst FAR is 1 . A bias greater than one indicates that the event was forecast more often than it occurred (i.e., an overforecast) 
while a bias less than one reveals that the event was observed more than it was forecast (i.e., an underforccast). The results of this analysis are conveyed in Section 4.5.

Table 3.1: 2 X 2 contingency table for binary forecasting.

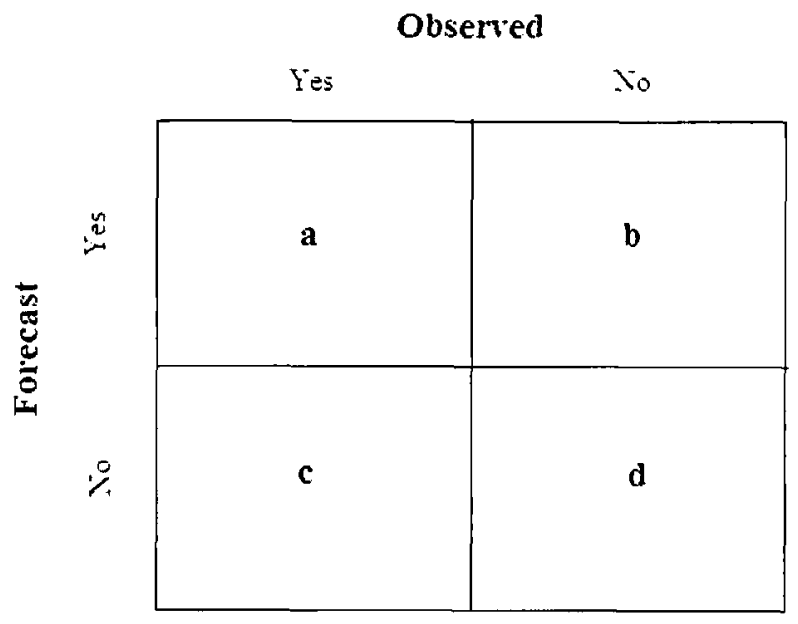

$P O D=\frac{a}{a+c} ; T S=\frac{a}{a+b+c} ; F A R=\frac{b}{a+b} ; B=\frac{a+b}{a+c} ; H S S=\frac{2(a d-b c)}{(a+c)(c+d)+(a+b)(b+d)}$

\section{Equation 3.1}

A procedure called "classification and regression trees" (CART) was also used in the analysis of determining variables that are helpful in forecasting MCSs. CART is a nonparametric approach to classification, so no assumptions need to be made about the relationship between the predictors and the predictand. For each event, there is a set of predictor values and a predictand category, which are chosen by the user. For cxample, the predictors could be CAPE and $0-3 \mathrm{~km}$ shear with possible predictand categories of "MCC" or "PECS." Given the predictor data and predictand category for all events in a sample, CART creates a decision tree that attempts to fit as many of the events as possible to the proper category. This tree is essentially a series of questions (e.g., CAPE 
$>1000 \mathrm{~J} \mathrm{~kg}^{-1}$ ?) that can be answered yes or no that leads to a fitted response category. One problem with this method is that it often overfits the dataset, which could lead to poor prediction on an independent dataset. To reduce this problem, the tree can be "pruned," which results in a simpler tree by reducing the number of terminal nodes (i.c., fewer levels of questions). The "best" tree size can be determined by using cross validation. First, a resubstitution error is calculated for trees of all sizes based on the proportion of events that are misclassified. The resubstitution error generally underestimates the true error variance. Then, a subset of $10 \%$ of the events is removed, and a tree is created with the remaining $90 \%$ of events. A cross-validation error is calculated using the proportion of the subset of events that are misclassified for the range of tree sizes compared to the original tree. The best tree is chosen as the simplest tree (i.e., fewest terminal nodes) with a cross-validation error within one standard error of the resubstitution error. This method was used in forecasting the type of MCS that developed, and the results are discussed in Section 6.1.4. 


\section{Chapter 4}

\section{Analysis of environmental conditions}

Using the data and methodology described previously, the environmental conditions were thoroughly examined for the location of MCS development, areas of unorganized widespread convection, and days without MCSs. This analysis was performed in an attempt to learn more about the MCS precursor environment and how it differs from other environments that do not support organized convection. The next several sections will divulge results on triggering mechanisms, point-value data, fixed-point composites, storm-relative composites, and the evaluation of parameters in forecasting MCSs.

\subsection{Triggering mechanisms}

NCEP surface analyses were used to locate any detectable triggering mechanism that generated the initial convection of each MCS. This was performed to get an idea of the boundaries that commonly result in MCS initiation and to see if certain types of MCSs have a propensity to be initiated by particular boundaries. Additionally, the triggering mechanisms that generated convection that did not develop into a MCS (i.e., widespread convection) were also identified. The distribution of the triggering mechanisms for MCSs and widespread convection can be found in Table 4.1. MCS convection was most commonly initiated by stationary fronts ( $27 \%$ of sample), cold fronts $(21 \%)$, and troughs $(18 \%)$. Other mechanisms that led less frequently to MCS formation include orographic 
influences $(12 \%)$, warm fronts $(7 \%)$, drylines $(4 \%)$, and outflow boundaries $(2 \%)$. Around $10 \%$ of the MCSs were initiated by multiple features while $17 \%$ did not have an identifiable trigger. For the condition of widespread convection, troughs $(27 \%)$, stationary fronts $(15 \%)$, cold fronts $(13 \%)$, and orographic influences $(13 \%)$ were the most common triggering mechanisms. Other less common mechanisms that led to unorganized widespread convection include warm fronts $(2 \%)$, drylines $(1 \%)$, and outflow boundaries (1\%). In fact, one-third of the cases of widespread convection did not have an identifiable triggering mechanism. In addition, widespread convection was more commonly initiated by surface pressure troughs than MCSs. These results suggest that the stronger, well-defined low-level convergence associated with cold fronts and stationary fronts are important in generating highly concentrated thunderstorms that can interact with one another and develop into a MCS.

Fronts have often been documented to influence MCS evolution (Maddox 1983; McAnelly and Cotton 1986; Smull and Augustine 1993; Trier and Parsons 1993), so it is not surprising that stationary fronts and cold fronts were the most common features to produce MCS convection. However, convection that is generated along a frontal boundary is not guaranteed to develop into a MCS, as shown by more than one-fourth of the widespread convection cases being initiated along a frontal boundary. This suggests that strong low-level convergence (i.e., along a frontal boundary) and instability, which allow for convective development, are often not sufficient conditions to support longlived MCSs. There must be other features present in the ambient environment that aid in MCS development, hence the motivation for this thesis. 
Table 4.1: Distribution of triggering mechanisms for MCSs and widespread convection conditions.

\begin{tabular}{|c|c|c|}
\hline Triggering mechanism & $\mathrm{MCS}$ & $\begin{array}{l}\text { Widespread } \\
\text { Convection }\end{array}$ \\
\hline Stationary front & 104 & 45 \\
\hline Cold front & 81 & 40 \\
\hline Warm front & 26 & 6 \\
\hline Trough & 69 & 80 \\
\hline Orographic influence & 48 & 39 \\
\hline Dryline & 16 & 4 \\
\hline Outflow boundary & 9 & 4 \\
\hline Multiple features (included in totals above): & 39 & 19 \\
\hline Orographic influence \& trough & 17 & 14 \\
\hline Orographic influence \& stationary front & 11 & 3 \\
\hline Orographic influence \& cold front & 2 & 1 \\
\hline Orographic influcnce \& dryline & 1 & 0 \\
\hline Trough \& stationary front & 2 & 1 \\
\hline Trough \& cold front & 2 & 0 \\
\hline Trough \& warm front & 1 & 0 \\
\hline Stationary front $\&$ cold front & 1 & 0 \\
\hline Stationary front \& dryline & 1 & 0 \\
\hline Stationary front \& outflow boundary & 1 & 0 \\
\hline Other (e.g., triple point and MCV) & 8 & 2 \\
\hline Unidentified & 65 & 99 \\
\hline Total & 387 & 300 \\
\hline
\end{tabular}

Drylines are also common zones of thunderstorm formation (Rhea 1966); however, they apparently are not very favorable locations for MCS development since less than 5\% of the MCSs in this sample developed along a dryline. In agreement with this result, Parker and Johnson (2000) also found that the dryline was associated with only $8 \%$ of the 
MCSs they studied. One could speculate that the reason for the infrequent development of MCSs along a dryline is due to the unfavorable environmental conditions in the vicinity of the dryline. A subjective examination reveals that only $1 \%$ of the widespread convection cases were initiated by drylines, which indicates that thunderstorms do not often develop in high concentrations along a dryline. Thus, the true explanation for the lack of MCS development along a dryline may be that the convection initiated by a dryline may be too isolated and sparse to allow for interaction and upscale growth into MCSs.

Examination of the various classes of MCSs reveals that there is a greater likelihood for some types of MCSs to develop along specific boundaries. The distribution of triggering mechanisms is shown in Table 4.2 for the satellite classifications from Jirak et al. (2003). Of the MCSs that developed along a cold front, $77 \%$ were elongated systems (i.e., PECS and M $\mathrm{BECS}$ ) while these systems comprised $60 \%$ of the total sample of MCSs. The strong, linear forcing of a cold front, therefore, is more likely to lead to an elongated MCS. More than half of the systems initiated by a dryline were the smaller meso- $\beta$ MCSs (i.e., M $\beta C C S$ and M $\beta E C S$ ) even though these systems accounted for just $38 \%$ of all MCSs in the sample. This provides additional evidence that drylines are not the most favored locations for the development of large MCSs. 
Table 4.2: Distribution of triggering mechanisms for the IR satellite classifications of MCSs.

\begin{tabular}{lccccc}
\hline & & & & & \\
Triggering mechanism & MCC & PECS & MßCCS & MßECS & Total \\
\hline Stationary front & 32 & 43 & 12 & 17 & $\mathbf{1 0 4}$ \\
Cold front & 11 & 44 & 8 & 18 & $\mathbf{8 1}$ \\
Warm front & 7 & 7 & 5 & 7 & $\mathbf{2 6}$ \\
Trough & 11 & 30 & 13 & 15 & $\mathbf{6 9}$ \\
Orographic influence & 15 & 17 & 7 & 9 & $\mathbf{4 8}$ \\
Dryline & 3 & 4 & 5 & 4 & $\mathbf{1 6}$ \\
Outflow boundary & 1 & 4 & 2 & 2 & $\mathbf{9}$ \\
Multiple features (included) & 10 & 20 & 2 & 7 & $\mathbf{3 9}$ \\
Other & 2 & 2 & 3 & 1 & $\mathbf{8}$ \\
Unidentified & 18 & 18 & 12 & 17 & $\mathbf{6 5}$ \\
\hline & & & & & \\
Total & $\mathbf{9 0}$ & $\mathbf{1 4 9}$ & $\mathbf{6 5}$ & $\mathbf{8 3}$ & $\mathbf{3 8 7}$ \\
\hline
\end{tabular}

Table 4.3 shows the triggering mechanisms for MCSs classified by whether stratiform precipitation was present at the time of initiation. Only a couple of differences stand out regarding the triggering mechanisms for embedded and non-embedded MCSs. Only $9 \%$ of the troughs and $9 \%$ of the cold fronts in this study resulted in triggering the convection of embedded systems even though embedded systems make up 17\% of the total MCSs. Thus, embedded systems are less likely than expected to be initiated by these features. In addition, more embedded systems had unidentifiable triggering mechanisms $(28 \%)$ than would be expected, which suggests that low-level triggering mechanisms may not be as important for the development of these systems as compared to non-embedded systems. 
Table 4.3: Distribution of triggering mechanisms for the first radar development classification level: presence of stratiform precipitation.

Triggering mechanism Embedded Not Embed. Unclass. Total

\begin{tabular}{lcccc}
\hline Stationary front & 21 & $\mathbf{7 9}$ & 4 & $\mathbf{1 0 4}$ \\
Cold front & 7 & 72 & 2 & $\mathbf{8 1}$ \\
Warm front & 6 & 20 & 0 & $\mathbf{2 6}$ \\
Trough & 6 & 60 & 3 & $\mathbf{6 9}$ \\
Orographic influence & 6 & 41 & 1 & $\mathbf{4 8}$ \\
Dryline & 3 & 13 & 0 & $\mathbf{1 6}$ \\
Outflow boundary & 3 & 6 & 0 & $\mathbf{9}$ \\
Multiple features (incl.) & 7 & 31 & 1 & $\mathbf{3 9}$ \\
Other & 2 & 6 & 0 & $\mathbf{8}$ \\
Unidentified & 18 & 46 & 1 & $\mathbf{6 5}$ \\
\hline & & & & $\mathbf{3 8 7}$ \\
Total & $\mathbf{6 5}$ & $\mathbf{3 1 2}$ & $\mathbf{1 0}$ & \\
\hline
\end{tabular}

MCSs with different convective cell arrangement at initiation also reveal preferences for specific initiating boundaries. The distribution of triggering mechanisms for these systems is shown in Table 4.4. Nearly half of all systems with linearly-arranged convection (i.e., line systems) developed along a cold front. In fact, even though only $16 \%$ of all MCSs were line systems, $37 \%$ of the systems initiated by a cold front were of this arrangement. Cold fronts are much more likely to produce line systems than any other boundary, which is significant because these MCSs are larger, longer-lived, more severe, and produce more precipitation than areal systems (Jirak et al. 2003). In addition, areal systems were more likely to have an unidentifiable surface trigger. Thus, 
given that a MCS is expected to develop along a specific boundary, some inferences can be made about the characteristics of the system.

Table 4.4: Distribution of triggering mechanisms for the second radar development classification level: arrangement of convective cells.

\begin{tabular}{lccccc} 
Triggering mechanism & Line & Areal & Combination & Unclass. & Total \\
\hline Stationary front & 10 & 48 & 42 & 4 & $\mathbf{1 0 4}$ \\
Cold front & 30 & 25 & 24 & 2 & $\mathbf{8 1}$ \\
Warm front & 4 & 11 & 11 & 0 & $\mathbf{2 6}$ \\
Trough & 10 & 33 & 23 & 3 & $\mathbf{6 9}$ \\
Orographic influence & 2 & 27 & 18 & 1 & $\mathbf{4 8}$ \\
Dryline & 2 & 13 & 1 & 0 & $\mathbf{1 6}$ \\
Outflow boundary & 3 & 5 & 1 & 0 & $\mathbf{9}$ \\
Multiple features (incl.) & 4 & 15 & 19 & 1 & $\mathbf{3 9}$ \\
Other & 0 & 5 & 3 & 0 & $\mathbf{8}$ \\
Unidentified & 6 & $\mathbf{4 8}$ & 10 & 1 & $\mathbf{6 5}$ \\
\hline & & & & & $\mathbf{1 0}$ \\
\hline
\end{tabular}

The distribution of triggering mechanisms for MCSs classified by the interaction of convective clusters is displayed in Table 4.5. The dryline once again stands out from the other features when distinguishing among MCS classifications. Nearly half of the systems produced along a dryline were non-merger or isolated systems while these systems only comprised about one-fourth of the overall MCS sample. Therefore, a dryline is more likely to produce a non-merger or isolated system than would be expected based on the overall distribution of the systems. This result further validates the uncommon occurrence of multiple convective clusters developing and merging along a 
dryline. In addition, merger systems are much more likely to be initiated by multiple triggers than the other types of systems.

Table 4.5: Distribution of triggering mechanisms for the third radar development classification level: interaction of convective clusters.

\begin{tabular}{lccccc} 
Triggering mechanism & Merger & Non-merger & Isolated & Unclass. & Total \\
\hline Stationary front & 74 & 7 & 19 & 4 & $\mathbf{1 0 4}$ \\
Cold front & 60 & 3 & 16 & 2 & $\mathbf{8 1}$ \\
Warm front & 18 & 4 & 4 & 0 & $\mathbf{2 6}$ \\
Trough & 53 & 8 & 5 & 3 & $\mathbf{6 9}$ \\
Orographic influence & 41 & 4 & 2 & 1 & $\mathbf{4 8}$ \\
Dryline & 9 & 3 & 4 & 0 & $\mathbf{1 6}$ \\
Outflow boundary & 7 & 1 & 1 & 0 & $\mathbf{9}$ \\
Multiple features & 34 & 3 & 1 & 1 & $\mathbf{3 9}$ \\
Other & 4 & 1 & 3 & 0 & $\mathbf{8}$ \\
Unidentified & 43 & 4 & 17 & 1 & $\mathbf{6 5}$ \\
\hline
\end{tabular}

\subsection{Point-value data analysis}

\subsubsection{MCS and non-MCS environments}

In order to get a general idea of the typical values for numerous parameters prior to MCS development, data were extracted from the centroid of the MCS six hours before initiation. For comparison purposes, data were also taken from the center of a concentrated group of thunderstorms that did not organize into a MCS and from a location of possible thunderstorm development on days without MCSs. The nature of these data allows for a statistical analysis of the differences among these assorted 
conditions. The tables throughout this section list the average and standard deviation of numerous parameters for these different conditions. A t-test was performed to determine if the mean of the parameters in the MCS precursor environment differ from the other conditions at the $99 \%$ confidence level. In addition, the first quartile, median, and third quartile values are listed for each parameter. This is especially informative for those parameters that can take either positive or negative values. The results are presented throughout this section starting with the upper levels.

Table 4.6 displays the point-value data of upper-level parameters for the different atmospheric conditions studied. The upper-level winds are stronger prior to MCS development than for the widespread convection conditions. However, the winds are weaker for the MCS precursor environment as compared to days when MCSs did not form. This suggests that intermediate-strength upper-level winds may be the most conducive for supporting MCS development, consistent with Coniglio et al. (2004). At $200 \mathrm{mb}$, MCSs typically form in an environment with cooler temperatures, which likely indicates that large-scale lifting is occurring (Maddox 1983). The upper-level forcing prior to MCS development, however, is not significantly different from the other environmental conditions. In fact, only about half of the MCS precursor environments exhibit upper-level divergence and q-vector convergence. Thus, it would be difficult to identify a MCS environment based on upper-level forcing alone. Potential vorticity (PV) in the upper levels (i.e., $330 \mathrm{~K}$ ) is statistically less on average prior to MCS formation than for the other conditions. A more detailed discussion about PV will follow in the section on mid-level features. 
Table 4.6: Point-value data of upper-level parameters for different environmental conditions. For each parameter the mean, standard deviation $(\sigma), 1^{\text {st }}$ quartile value (1Q), median, and $3^{\text {rd }}$ quartile value (3Q) are listed. Bold numbers indicate that the mean is different from the MCS precursor environment at the $99 \%$ confidence level.

\begin{tabular}{|c|c|c|c|c|c|}
\hline \multicolumn{2}{|l|}{ Parameter } & \multirow{2}{*}{ MCS-6h } & \multirow{3}{*}{$\begin{array}{c}\text { Widespread } \\
\text { Convection } \\
19.6\end{array}$} & \multirow{3}{*}{$\begin{array}{c}\text { No MCS } \\
\text { Max SWEAT } \\
31.8\end{array}$} & \multirow{3}{*}{$\begin{array}{c}\text { No MCS } \\
\text { Max CAPE } \\
25.9\end{array}$} \\
\hline & & & & & \\
\hline \multirow{5}{*}{$\left(\mathrm{m} \mathrm{s}^{-1}\right)$} & mean & 24.2 & & & \\
\hline & $\sigma$ & 12.7 & 12.9 & 13.9 & 17.0 \\
\hline & $1 \mathrm{Q}$ & 15.1 & 9.7 & 22.0 & 10.9 \\
\hline & med. & 22.8 & 16.0 & 29.4 & 23.6 \\
\hline & $3 Q$ & 31.5 & 26.9 & 40.3 & 38.1 \\
\hline \multirow{5}{*}{$\begin{array}{l}200 \mathrm{mb} \text { temperature } \\
(\mathrm{K})\end{array}$} & mean & 217.6 & 220.1 & 219.3 & 219.0 \\
\hline & $\sigma$ & 3.5 & 3.6 & 3.4 & 3.3 \\
\hline & $1 Q$ & 214.9 & 218.4 & 216.8 & 217.3 \\
\hline & med. & 218.2 & 220.3 & 219.5 & 219.7 \\
\hline & $3 \mathrm{Q}$ & 220.2 & 221.9 & 221.9 & 221.1 \\
\hline \multirow{5}{*}{$\begin{array}{l}200 \mathrm{mb} \text { specific humidity } \\
\left(\mathrm{g} \mathrm{kg}^{-1}\right)\end{array}$} & mean & $4.1 \mathrm{E}-02$ & $4.6 \mathrm{E}-02$ & $3.7 \mathrm{E}-02$ & $4.2 \mathrm{E}-02$ \\
\hline & $\sigma$ & $1.6 \mathrm{E}-02$ & $1.9 \mathrm{E}-02$ & $1.4 \mathrm{E}-02$ & $1.7 \mathrm{E}-02$ \\
\hline & $1 Q$ & $2.9 \mathrm{E}-02$ & $3.3 \mathrm{E}-02$ & $2.8 \mathrm{E}-02$ & $2.8 \mathrm{E}-02$ \\
\hline & med. & $3.8 \mathrm{E}-02$ & $4.4 \mathrm{E}-02$ & $3.5 \mathrm{E}-02$ & $4.0 \mathrm{E}-02$ \\
\hline & $3 Q$ & $5.2 \mathrm{E}-02$ & $5.8 \mathrm{E}-02$ & $4.5 \mathrm{E}-02$ & $5.5 \mathrm{E}-02$ \\
\hline \multirow{5}{*}{$\begin{array}{l}200 \mathrm{mb} \text { divergence } \\
\left(\mathrm{s}^{-1}\right)\end{array}$} & mean & $5.5 \mathrm{E}-06$ & $4.0 \mathrm{E}-06$ & $4.4 \mathrm{E}-06$ & $1.1 \mathrm{E}-06$ \\
\hline & $\sigma$ & $3.0 \mathrm{E}-05$ & $2.0 \mathrm{E}-05$ & $1.9 \mathrm{E}-05$ & $1.9 \mathrm{E}-05$ \\
\hline & $1 \mathrm{Q}$ & $-7.7 \mathrm{E}-06$ & $-7.8 \mathrm{E}-06$ & $-6.4 \mathrm{E}-06$ & $-1.0 \mathrm{E}-05$ \\
\hline & med. & $1.7 E-06$ & $3.3 E-06$ & $1.9 \mathrm{E}-06$ & $-2.0 \mathrm{E}-06$ \\
\hline & $3 Q$ & $1.4 \mathrm{E}-05$ & $1.3 E-05$ & 1. $4 \mathrm{E}-05$ & $9.8 \mathrm{E}-06$ \\
\hline \multirow{5}{*}{$\begin{array}{l}300 \mathrm{mb} \text { wind speed } \\
\left(\mathrm{m} \mathrm{s}^{-1}\right)\end{array}$} & mean & 19.9 & 16.4 & 26.9 & 20.4 \\
\hline & $\sigma$ & 10.4 & 11.8 & 12.6 & 13.8 \\
\hline & $1 Q$ & 12.0 & 7.3 & 18.1 & 8.7 \\
\hline & med. & 18.9 & 13.7 & 25.9 & 16.8 \\
\hline & $3 Q$ & 26.5 & 22.3 & 35.7 & 29.6 \\
\hline \multirow{5}{*}{$\begin{array}{l}300 \mathrm{mb} \text { temperature } \\
(\mathrm{K})\end{array}$} & mean & 236.7 & 236.8 & 236.0 & 237.1 \\
\hline & $\sigma$ & 4.7 & 5.7 & 4.8 & 5.3 \\
\hline & $1 \mathrm{Q}$ & 233.4 & 231.9 & 233.8 & 234.2 \\
\hline & med. & 236.8 & 238.8 & 236.8 & 238.6 \\
\hline & $3 \mathrm{Q}$ & 240.6 & 241.3 & 239.0 & 241.3 \\
\hline \multirow{5}{*}{$\begin{array}{l}300 \mathrm{mb}^{-\mathrm{b}} \text { specific humidity } \\
\left(\mathrm{g} \mathrm{kg}^{-1}\right)\end{array}$} & mean & $2.6 \mathrm{E}-01$ & $2.7 \mathrm{E}-01$ & $1.8 \mathrm{E}-01$ & $2.3 \mathrm{E}-01$ \\
\hline & $\sigma$ & $1.6 \mathrm{E}-01$ & $1.8 \mathrm{E}-01$ & $1.3 \mathrm{E}-01$ & $1.7 \mathrm{E}-01$ \\
\hline & $1 \mathrm{Q}$ & $1.4 \mathrm{E}-01$ & $1.1 \mathrm{E}-01$ & $9.1 \mathrm{E}-02$ & $9.0 \mathrm{E}-02$ \\
\hline & med. & $2.2 \mathrm{E}-01$ & $2.1 \mathrm{E}-01$ & $1.5 \mathrm{E}-01$ & $1.8 \mathrm{E}-01$ \\
\hline & $3 Q$ & $3.7 \mathrm{E}-01$ & $4.2 \mathrm{E}-01$ & $2.6 \mathrm{E}-01$ & $3.6 \mathrm{E}-01$ \\
\hline \multirow{5}{*}{$\begin{array}{l}300 \mathrm{mb} \text { divergence } \\
\left(\mathrm{s}^{-1}\right)\end{array}$} & mean & $3.4 \mathrm{E}-06$ & $2.7 \mathrm{E}-06$ & $2.7 \mathrm{E}-06$ & $-6.4 \mathrm{E}-07$ \\
\hline & $\sigma$ & $1.9 \mathrm{E}-05$ & $1.6 \mathrm{E}-05$ & $1.9 \mathrm{E}-05$ & $1.8 \mathrm{E}-05$ \\
\hline & $1 Q$ & $-7.0 \mathrm{E}-06$ & $-5.6 \mathrm{E}-06$ & $-7.2 \mathrm{E}-06$ & $-9.7 \mathrm{E}-06$ \\
\hline & med. & $1.6 \mathrm{E}-06$ & $2.4 \mathrm{E}-06$ & $2.3 \mathrm{E}-06$ & $-3.3 E-07$ \\
\hline & $3 Q$ & $1.0 \mathrm{E}-05$ & $1.1 \mathrm{E}-05$ & $1.2 \mathrm{E}-05$ & 8.0E-06 \\
\hline \multirow{5}{*}{$\begin{array}{l}300 \text { q-vector divergence } \\
\left(\mathrm{K} \mathrm{m}^{-2} \mathrm{~s}^{-1}\right)\end{array}$} & $\overrightarrow{\text { mean }}$ & $7.2 \mathrm{E}-16$ & $-5.1 E-16$ & $-1.0 \mathrm{E}-15$ & $-1.8 \mathrm{E}-15$ \\
\hline & $\sigma$ & $1.1 \mathrm{E}-14$ & $7.5 \mathrm{E}-15$ & $8.8 \mathrm{E}-15$ & $1.3 \mathrm{E}-14$ \\
\hline & $1 Q$ & $-1.8 \mathrm{E}-15$ & $-1.7 \mathrm{E}-15$ & $-3.2 \mathrm{E}-15$ & $-2.8 \mathrm{E}-15$ \\
\hline & med. & $-4.7 \mathrm{E}-17$ & $2.0 \mathrm{E}-16$ & $-6.1 \mathrm{E}-16$ & $-3.7 \mathrm{E}-16$ \\
\hline & $3 Q$ & $2.2 \mathrm{E}-15$ & $2.0 \mathrm{E}-15$ & $1.9 \mathrm{E}-15$ & $1.2 \mathrm{E}-15$ \\
\hline \multirow{5}{*}{$\begin{array}{l}330 \mathrm{~K} \text { potential vorticity } \\
\text { (PVU) }\end{array}$} & mean & 0.70 & 1.56 & 1.16 & 1.27 \\
\hline & $\sigma$ & 0.78 & 1.91 & 1.47 & 1.83 \\
\hline & $1 \mathrm{Q}$ & 0.34 & 0.47 & 0.35 & 0.36 \\
\hline & med. & 0.49 & 0.69 & 0.56 & 0.51 \\
\hline & $3 Q$ & 0.72 & 1.55 & 1.25 & 0.89 \\
\hline
\end{tabular}


The mid-tropospheric point-value data are shown in Table 4.7. Wind speeds at 500 $\mathrm{mb}$ are typically less for convection that does not organize into a MCS as opposed to convection that does organize into a MCS. The mid levels are also slightly moister prior to MCS development than on days without MCSs. From the $\omega$-equation of quasigeostrophic theory, one would expect upward vertical motion in a region of positive differential vorticity advection. However, positive vorticity advection at $500 \mathrm{mb}$ does not appear to be an important feature to the development of MCSs. In fact, the mean and median values of $500 \mathrm{mb}$ vorticity advection are actually negative for the precursor environment of MCSs, which would not favor rising motion. The values of mid-level PV (i.e., $320 \mathrm{~K}$ ) are not necessarily what one would expect for the different conditions. A positive PV anomaly usually develops in the middle troposphere due to the heating profile within the stratiform region of MCSs (Hertenstein and Schubert 1991; Olsson and Cotton 1997). It is theorized that the MCS-generated positive PV anomaly can help lift low-level air to sustain the system (Raymond and Jiang 1990). Several cases have been noted in which a mid-level PV anomaly has led to ensuing convection and MCS devclopment (e.g., Johnson et al. 1989; Fritsch et al. 1994). The results from this study reveal that unorganized widespread convection typically develops in a region of higher mid-level PV than MCSs. This finding certainly does not dispel the idea that mid-level positive PV anomalies can enhance convective development and sustenance. The result merely suggests that a positive PV anomaly is not a sufficient condition for the development of a MCS. Other environmental features must also be present in order support the upscale growth of convection into a MCS. It appears that for this study it was 
more common for a PV anomaly to generate convection in an unfavorable region of MCS development than a favorable region.

Table 4.7: Same as Table 4.6, except for mid-level parameters. An asterisk (*) indicates that the given parameter is part of the index; thus, the values are insignificantly large.

\begin{tabular}{llcccc}
\hline Parameter & & Widespread & No MCS & $\begin{array}{c}\text { No MCS } \\
\text { Max CAPE }\end{array}$ \\
\hline $500 \mathrm{mb}^{-1}$ wind speed & mean & $\mathbf{1 4 . 5}$ & $\mathbf{1 0 . 3}$ & $16.4^{*}$ & 12.5 \\
$\left(\mathrm{~m} \mathrm{~s}^{-1}\right)$ & $\sigma$ & 6.4 & 6.8 & 7.1 & 8.2 \\
& $1 \mathrm{Q}$ & 9.7 & 4.9 & 11.3 & 5.9 \\
& med. & 13.9 & 8.8 & 15.3 & 10.5 \\
& $3 \mathrm{Q}$ & 18.9 & 13.7 & 20.0 & 17.9 \\
\hline $500 \mathrm{mb}^{2}$ temperature & mean & $\mathbf{2 6 2 . 9}$ & 262.3 & $\mathbf{2 6 1 . 5}$ & 263.0 \\
$(\mathrm{~K})$ & $\sigma$ & 3.4 & 5.7 & 4.7 & 4.9 \\
& $1 \mathrm{Q}$ & 260.8 & 259.2 & 259.5 & 260.3 \\
& med. & 263.5 & 264.5 & 262.4 & 264.9 \\
& $3 \mathrm{Q}$ & 265.7 & 266.3 & 264.6 & 266.6 \\
\hline $500 \mathrm{mb}^{-1}$ specific humidity & mean & $\mathbf{1 . 9}$ & 1.9 & $\mathbf{1 . 5}$ & $\mathbf{1 . 5}$ \\
$(\mathrm{g} \mathrm{kg})$ & $\sigma$ & 0.8 & 0.9 & 0.9 & 1.0 \\
& $1 \mathrm{Q}$ & 1.3 & 1.1 & 0.8 & 0.7 \\
& med. & 1.9 & 1.9 & 1.4 & 1.3 \\
& $3 \mathrm{Q}$ & 2.5 & 2.6 & 2.1 & 2.4 \\
\hline $500 \mathrm{mb}^{-1}$ vorticity advection & mean & $-3.1 \mathrm{E}-10$ & $4.7 \mathrm{E}-10$ & $4.2 \mathrm{E}-10$ & $6.4 \mathrm{E}-10$ \\
$\left(\mathrm{~s}^{-2}\right)$ & $\sigma$ & $4.9 \mathrm{E}-09$ & $3.7 \mathrm{E}-09$ & $5.4 \mathrm{E}-09$ & $3.5 \mathrm{E}-09$ \\
& $1 \mathrm{Q}$ & $-1.9 \mathrm{E}-09$ & $-6.3 \mathrm{E}-10$ & $-1.9 \mathrm{E}-09$ & $-3.9 \mathrm{E}-10$ \\
& med. & $-9.4 \mathrm{E}-11$ & $1.8 \mathrm{E}-10$ & $4.5 \mathrm{E}-10$ & $2.8 \mathrm{E}-10$ \\
& $3 \mathrm{Q}$ & $1.6 \mathrm{E}-09$ & $1.2 \mathrm{E}-09$ & $2.3 \mathrm{E}-09$ & $1.7 \mathrm{E}-09$ \\
\hline $320 \mathrm{~K}$ potential vorticity & mean & $\mathbf{0 . 4 2}$ & $\mathbf{0 . 8 1}$ & 0.60 & $\mathbf{0 . 7 8}$ \\
$(\mathrm{PVU})$ & $\sigma$ & 0.41 & 1.01 & 0.86 & 1.22 \\
& $1 \mathrm{Q}$ & 0.22 & 0.39 & 0.23 & 0.25 \\
& med. & 0.35 & 0.55 & 0.38 & 0.41 \\
& $3 \mathrm{Q}$ & 0.48 & 0.73 & 0.59 & 0.56 \\
\hline
\end{tabular}

Although the mid and upper levels revealed some differences among the various atmospheric conditions, the lower levels show more significant differences. At $700 \mathrm{mb}$ (see Table 4.8), the winds are stronger prior to MCS development than for unorganized widespread convection. In addition, the average temperature is a little warmer, possibly indicating a stronger cap to convection. Temperature advection at $700 \mathrm{mb}$ is also much stronger for the MCS precursor environment than for the widespread convection condition with nearly an order of magnitude difference in the median. More than threefourths of the MCSs had warm air advection at six hours prior to initiation, signifying the 
importance and recurrent nature of this parameter to MCS development. Similar to differential vorticity advection, warm air advection also indicates rising motion according to the $\omega$-equation of quasi-geostrophic theory. Thus, this existing, ambient upward vertical motion aids in the development and sustenance of MCSs (Maddox and Doswell 1982; Maddox 1983; Cotton et al. 1989; Laing and Fritsch 2000). Even with the strong forcing in the temperature advection field, q-vector convergence, which directly indicates rising motion without the possibility of competing terms (i.e., differential vorticity advection and temperature advection), does not show a statistically significant difference among the conditions. More than half of the MCSs in the study, though, did develop in a region of q-vector convergence.

Table 4.8: Same as Table 4.6, except for $700 \mathrm{mb}$ parameters.

\begin{tabular}{|c|c|c|c|c|c|}
\hline Parameter & & MCS-6h & $\begin{array}{l}\text { Widespread } \\
\text { Convection }\end{array}$ & $\begin{array}{c}\text { No MCS } \\
\text { Max SWEAT }\end{array}$ & $\begin{array}{c}\text { No MCS } \\
\text { Max CAPE }\end{array}$ \\
\hline \multirow{5}{*}{$\begin{array}{l}700 \mathrm{mb} \text { wind speed } \\
\left(\mathrm{m} \mathrm{s}^{-1}\right)\end{array}$} & mean & 9.4 & 7.2 & 9.7 & 9.2 \\
\hline & $\sigma$ & 4.9 & 4.7 & 5.6 & 5.5 \\
\hline & $1 \mathrm{Q}$ & 5.5 & 3.6 & 5.6 & 5.6 \\
\hline & med. & 8.6 & 6.0 & 8.2 & 8.0 \\
\hline & $3 Q$ & 12.7 & 9.7 & 12.4 & 12.4 \\
\hline \multirow{5}{*}{$\begin{array}{l}700 \mathrm{mb} \text { temperature } \\
(\mathrm{K})\end{array}$} & mean & 281.7 & 279.3 & 280.9 & 280.5 \\
\hline & $\sigma$ & 3.5 & 5.8 & 4.6 & 4.5 \\
\hline & $1 \mathrm{Q}$ & 279.8 & 275.9 & 278.5 & 278.8 \\
\hline & med. & 282.3 & 280.9 & 281.9 & 281.5 \\
\hline & $3 Q$ & 284.0 & 282.5 & 284.1 & 283.6 \\
\hline \multirow{5}{*}{$\begin{array}{l}700 \mathrm{mb} \text { specific humidity } \\
\left(\mathrm{g} \mathrm{kg}^{-1}\right)\end{array}$} & mean & 5.8 & 5.9 & 5.4 & 4.8 \\
\hline & $\sigma$ & 1.9 & 1.9 & 2.0 & 2.2 \\
\hline & $1 \mathrm{Q}$ & 4.4 & 4.3 & 4.1 & 3.0 \\
\hline & med. & 5.9 & 6.1 & 5.2 & 4.9 \\
\hline & $3 Q$ & 7.4 & 7.4 & 7.0 & 6.5 \\
\hline \multirow{5}{*}{$\begin{array}{l}700 \mathrm{mb} \text { temp. advection } \\
\left(\mathrm{K} \mathrm{s}^{-1}\right)\end{array}$} & mean & $4.5 \mathrm{E}-05$ & $6.8 \mathrm{E}-06$ & $4.3 \mathrm{E}-05$ & $7.0 \mathrm{E}-06$ \\
\hline & $\sigma$ & $7.3 \mathrm{E}-05$ & $5.5 \mathrm{E}-05$ & $9.3 \mathrm{E}-05$ & $6.6 \mathrm{E}-05$ \\
\hline & $1 Q$ & $4.0 \mathrm{E}-06$ & $-9.4 \mathrm{E}-06$ & $1.3 \mathrm{E}-06$ & $-1.9 \mathrm{E}-05$ \\
\hline & med. & $3.3 \mathrm{E}-05$ & $3.9 \mathrm{E}-06$ & $3.1 \mathrm{E}-05$ & $3.1 \mathrm{E}-06$ \\
\hline & $3 Q$ & $7.0 \mathrm{E}-05$ & $2.2 \mathrm{E}-05$ & 7.1E-05 & $3.1 E-05$ \\
\hline \multirow{5}{*}{$\begin{array}{l}700 \mathrm{mb}^{-} \text {-vector divergence } \\
\left(\mathrm{K} \mathrm{m}^{-2} \mathrm{~s}^{-1}\right)\end{array}$} & mean & $-2.3 E-16$ & $1.3 \mathrm{E}-16$ & $-1.7 \mathrm{E}-15$ & $-4.4 \mathrm{E}-16$ \\
\hline & $\sigma$ & $5.6 \mathrm{E}-15$ & $5.0 \mathrm{E}-15$ & $1.0 \mathrm{E}-14$ & $4.6 \mathrm{E}-15$ \\
\hline & $1 \mathrm{Q}$ & $-2.4 \mathrm{E}-15$ & $-1.5 \mathrm{E}-15$ & $-4.5 E-15$ & $-1.7 \mathrm{E}-15$ \\
\hline & med. & $-1.8 \mathrm{E}-16$ & $-3.0 \mathrm{E}-17$ & $-7.5 \mathrm{E}-16$ & $-1.1 \mathrm{E}-16$ \\
\hline & $3 Q$ & $1.7 \mathrm{E}-15$ & $1.5 \mathrm{E}-15$ & $2.4 \mathrm{E}-1.5$ & $1.3 \mathrm{E}-15$ \\
\hline
\end{tabular}


Table 4.9 displays the point-value data for parameters at $850 \mathrm{mb}$. Again, the wind speeds are stronger for the MCS precursor environment than for the condition of widespread convection, especially the meridional component of the wind (i.e., v-wind component). In fact, southerly-component flow was present prior to the development of more than three-fourths of the MCSs in this study. The winds at $850 \mathrm{mb}$ are often used as a proxy for the LLJ, which has often been noted as a recurrent feature of the MCS precursor environment (Maddox 1983; Cotton et al. 1989; Anderson and Arritt 1998; Laing and Fritsch 2000). Somewhat surprisingly, however, other forcing features were not as prominent at $850 \mathrm{mb}$. Convergence, warm air advection, and frontogenesis all existed for more than half of the MCS precursor environments, but there generally were not statistically-significant differences among the various conditions. The MCS precursor environment only showed stronger convergence and warm air advection than the non-MCS days (based on the location of maximum CAPE). 
Table 4.9: Same as Table 4.6, except for $850 \mathrm{mb}$ parameters. An asterisk (*) indicates that the given parameter is part of the index; thus, the values are insignificantly large.

\begin{tabular}{|c|c|c|c|c|c|}
\hline \multicolumn{2}{|l|}{ Parameter } & MCS-6h & \multirow{2}{*}{$\begin{array}{c}\text { Widespread } \\
\text { Convection } \\
\mathbf{5 . 7}\end{array}$} & \multirow{2}{*}{$\begin{array}{c}\text { No MCS } \\
\text { Max SWEAT } \\
\mathbf{8 . 9}^{*}\end{array}$} & \multirow{2}{*}{$\begin{array}{c}\text { No MCS } \\
\text { Max CAPE } \\
7.0\end{array}$} \\
\hline \multirow{5}{*}{$\begin{array}{l}850 \mathrm{mb} \text { wind speed } \\
\left(\mathrm{m} \mathrm{s}^{-1}\right)\end{array}$} & mean & 7.4 & & & \\
\hline & $\sigma$ & 4.3 & 4.0 & 4.8 & 4.5 \\
\hline & $1 \mathrm{Q}$ & 4.4 & 2.9 & 5.2 & 3.6 \\
\hline & med. & 6.4 & 4.8 & 7.6 & 6.2 \\
\hline & $3 Q$ & 9.7 & 7.3 & 11.5 & 9.2 \\
\hline \multirow{5}{*}{$\begin{array}{l}850 \mathrm{mb} \text { temperature } \\
(\mathrm{K})\end{array}$} & mean & 292.4 & 291.4 & 291.6 & 290.6 \\
\hline & $\sigma$ & 4.9 & 6.8 & 5.1 & 4.3 \\
\hline & $1 \mathrm{Q}$ & 289.6 & 287.9 & 288.0 & 287.7 \\
\hline & med. & 292.8 & 291.2 & 291.1 & 291.5 \\
\hline & $3 Q$ & 295.7 & 295.2 & 295.2 & 293.5 \\
\hline \multirow{5}{*}{$\begin{array}{l}850 \mathrm{mb}^{-1} \text { specific humidity } \\
\left(\mathrm{g} \mathrm{kg}^{-1}\right)\end{array}$} & mean & 10.3 & 9.7 & $10.6^{*}$ & 10.1 \\
\hline & $\sigma$ & 2.7 & 2.9 & 2.9 & 3.2 \\
\hline & $1 Q$ & 8.8 & 7.7 & 8.8 & 8.0 \\
\hline & med. & 10.7 & 10.3 & 10.6 & 10.3 \\
\hline & $3 Q$ & 12.2 & 11.9 & 12.5 & 12.6 \\
\hline \multirow{5}{*}{$\begin{array}{l}850 \mathrm{mb} \text { moisture divergence } \\
\left(\mathrm{s}^{-1}\right)\end{array}$} & mean & $-7.0 \mathrm{E}-08$ & $-6.4 \mathrm{E}-08$ & $-6.0 \mathrm{E}-08$ & $6.7 \mathrm{E}-08$ \\
\hline & $\sigma$ & 2.7E-07 & $1.6 \mathrm{E}-07$ & $3.6 \mathrm{E}-07$ & $2.2 \mathrm{E}-07$ \\
\hline & $1 \mathrm{Q}$ & $-2.0 \mathrm{E}-07$ & $-1.3 \mathrm{E}-07$ & $-2.5 \mathrm{E}-07$ & $-4.2 \mathrm{E}-08$ \\
\hline & med. & $-4.9 \mathrm{E}-08$ & $-4.5 \mathrm{E}-08$ & $-5.1 \mathrm{E}-08$ & $6.9 \mathrm{E}-08$ \\
\hline & $3 Q$ & $7.6 \mathrm{E}-08$ & $3.2 \mathrm{E}-08$ & $1.3 \mathrm{E}-07$ & $1.6 \mathrm{E}-07$ \\
\hline \multirow{5}{*}{$\begin{array}{l}850 \mathrm{mb} \text { v-wind speed } \\
\left(\mathrm{m} \mathrm{s}^{-1}\right)\end{array}$} & mean & 4.1 & 1.9 & $6.5^{*}$ & 2.7 \\
\hline & $\sigma$ & 4.7 & 4.4 & 4.3 & 4.6 \\
\hline & $1 \mathrm{Q}$ & 1.0 & -0.4 & 4.2 & -0.6 \\
\hline & med. & 3.7 & 2.0 & 5.7 & 2.2 \\
\hline & $3 Q$ & 6.9 & 4.3 & 8.9 & 5.9 \\
\hline \multirow{5}{*}{$\begin{array}{l}850 \mathrm{mb} \theta_{\mathrm{e}} \\
(\mathrm{K})\end{array}$} & mean & 337.5 & 334.4 & 337.4 & 334.7 \\
\hline & $\sigma$ & 11.7 & 13.9 & 12.6 & 12.5 \\
\hline & 1Q & 330.7 & 324.8 & 329.0 & 326.6 \\
\hline & med. & 339.1 & 338.4 & 336.9 & 335.1 \\
\hline & $3 Q$ & 346.7 & 344.8 & 346.8 & 344.4 \\
\hline \multirow{5}{*}{$\begin{array}{l}850 \mathrm{mb} \text { temp. advection } \\
\left(\mathrm{K} \mathrm{s}^{-1}\right)\end{array}$} & mean & $3.1 \mathrm{E}-05$ & $1.1 \mathrm{E}-05$ & $3.1 \mathrm{E}-05$ & $5.8 \mathrm{E}-06$ \\
\hline & $\sigma$ & $8.9 \mathrm{E}-05$ & $6.7 \mathrm{E}-05$ & $1.3 \mathrm{E}-04$ & $4.8 \mathrm{E}-05$ \\
\hline & $1 Q$ & $-7.0 \mathrm{E}-06$ & $-1.2 \mathrm{E}-05$ & $-2.1 \mathrm{E}-05$ & $-1.7 \mathrm{E}-05$ \\
\hline & med. & $2.4 \mathrm{E}-05$ & $3.4 \mathrm{E}-06$ & $3.8 \mathrm{E}-05$ & 4.0E-06 \\
\hline & $3 Q$ & $6.4 \mathrm{E}-05$ & $2.7 \mathrm{E}-05$ & $8.7 \mathrm{E}-05$ & $2.5 \mathrm{E}-05$ \\
\hline \multirow{5}{*}{$\begin{array}{l}850 \mathrm{mb} \text { frontogenesis } \\
\left(\mathrm{s}^{-1}\right)\end{array}$} & mean & $1.9 \mathrm{E}-15$ & $3.1 \mathrm{E}-15$ & $1.8 \mathrm{E}-14$ & $3.2 \mathrm{E}-15$ \\
\hline & $\sigma$ & $2.7 \mathrm{E}-14$ & $2.7 \mathrm{E}-14$ & $1.7 \mathrm{E}-13$ & $2.1 \mathrm{E}-14$ \\
\hline & $1 Q$ & $-1.2 \mathrm{E}-15$ & $-1.0 \mathrm{E}-15$ & $-4.1 \mathrm{E}-15$ & $-6.4 \mathrm{E}-16$ \\
\hline & med. & $3.3 \mathrm{E}-16$ & $1.2 \mathrm{E}-16$ & $4.4 \mathrm{E}-16$ & $1.1 \mathrm{E}-16$ \\
\hline & $3 Q$ & $5.0 \mathrm{E}-15$ & $1.9 \mathrm{E}-15$ & $8.4 \mathrm{E}-15$ & $2.1 \mathrm{E}-15$ \\
\hline
\end{tabular}

The winds are stronger for the MCS precursor environment than the condition of unorganized widespread convection through the entire depth of the troposphere down to the surface (see Table 4.10). The MCS precursor environment is also very moist at the 
surface with an average surface specific humidity of $13.5 \mathrm{~g} \mathrm{~kg}^{-1}\left(\sim 18^{\circ} \mathrm{C}\right.$ surface dewpoint temperature). Surface convergence is commonly found prior to MCS development, but the values are not significantly different from the other conditions. One parameter that does show a statistically-significant difference among the conditions is the mean sealevel pressure difference between Jacksonville, Florida, and El Paso, Texas (MSLPDIF). The reason why these locations were chosen will become more obvious when the parameter is discussed later. For now, the important thing to note is that this parameter is calculated at fixed locations unlike all of the other parameters discussed in this section. A positive value of MSLPDIF represents high pressure on the southeast coast of the U.S. and low pressure in the lee of the Rocky Mountains. Essentially, this pressure configuration leads to strong southerly to southeasterly winds advecting warm, moist air form the Gulf of Mexico into the Central Plains. Clearly, the table shows that large values of MSLPDIF favor the development of MCSs over the central U.S.

The stability parameters (CAPE, LI, SWEAT) in Table 4.11 indicate that MCSs typically develop in more unstable environments than the other conditions. Even when compared to the data taken from the location of the maximum CAPE on days without MCSs, the average precursor environment of MCSs still shows a larger TT index. An interesting result is that the CIN for the MCS precursor environment is much larger on average than for the condition of widespread convection. At first, this result seems to go against intuition, but it may suggest that a modest cap may be important for explosive, simultaneous convection resulting in the interaction of thunderstorms rather than weaker CIN, which could lead to more random thunderstorm generation. 
Table 4.10: Same as Table 4.6, except for surface parameters.

\begin{tabular}{llcccc}
\hline Parameter & & MCS-6h & $\begin{array}{c}\text { Widespread } \\
\text { Convection }\end{array}$ & $\begin{array}{c}\text { No MCS } \\
\text { Max SWEAT }\end{array}$ & $\begin{array}{c}\text { No MCS } \\
\text { Max CAPE }\end{array}$ \\
\hline Surface wind speed & mean & $\mathbf{4 . 4}$ & $\mathbf{3 . 8}$ & 4.7 & 3.8 \\
$\left(\mathrm{~m} \mathrm{~s}^{-1}\right)$ & $\sigma$ & 2.1 & 1.9 & 2.3 & 1.8 \\
& $1 \mathrm{Q}$ & 2.8 & 2.4 & 3.1 & 2.5 \\
& med. & 4.3 & 3.4 & 4.2 & 3.6 \\
& $3 \mathrm{Q}$ & 5.6 & 4.8 & 6.0 & 4.6 \\
\hline Surface temperature & mean & $\mathbf{2 9 9 . 4}$ & 300.1 & $\mathbf{2 9 4 . 6}$ & 298.4 \\
$(\mathrm{~K})$ & $\sigma$ & 6.2 & 7.6 & 7.7 & 6.3 \\
& $1 \mathrm{Q}$ & 296.0 & 295.3 & 289.4 & 295.4 \\
& med. & 300.0 & 301.3 & 294.7 & 299.7 \\
& $3 \mathrm{Q}$ & 303.5 & 305.8 & 299.6 & 302.5 \\
\hline Surface specific humidity & mean & $\mathbf{1 3 . 5}$ & $\mathbf{1 2 . 0}$ & $\mathbf{1 1 . 3}$ & $\mathbf{1 6 . 3}$ \\
$\left(\mathrm{g} \mathrm{kg}{ }^{-1}\right)$ & $\sigma$ & 3.7 & 4.1 & 4.0 & 5.0 \\
& $1 \mathrm{Q}$ & 10.8 & 9.0 & 8.3 & 13.7 \\
& med. & 13.5 & 12.0 & 11.2 & 17.1 \\
& $3 \mathrm{Q}$ & 16.2 & 15.3 & 14.4 & 20.4 \\
\hline Surface moisture divergence & mean & $-7.6 \mathrm{E}-08$ & $-6.8 \mathrm{E}-08$ & $-1.7 \mathrm{E}-07$ & $-1.4 \mathrm{E}-07$ \\
$\left(\mathrm{~s}^{-1}\right)$ & $\sigma$ & $2.9 \mathrm{E}-07$ & $2.1 \mathrm{E}-07$ & $3.5 \mathrm{E}-07$ & $3.6 \mathrm{E}-07$ \\
& $1 \mathrm{Q}$ & $-2.2 \mathrm{E}-07$ & $-1.6 \mathrm{E}-07$ & $-3.4 \mathrm{E}-07$ & $-3.0 \mathrm{E}-07$ \\
& med. & $-5.7 \mathrm{E}-08$ & $-5.4 \mathrm{E}-08$ & $-1.5 \mathrm{E}-07$ & $-1.4 \mathrm{E}-07$ \\
& $3 \mathrm{Q}$ & $1.0 \mathrm{E}-07$ & $3.2 \mathrm{E}-08$ & $1.2 \mathrm{E}-08$ & $3.6 \mathrm{E}-08$ \\
\hline MSLPDIF & mean & $\mathbf{9 . 1}$ & $\mathbf{7 . 9}$ & $\mathbf{5 . 0}$ & $\mathbf{5 . 0}$ \\
$(\mathrm{mb})$ & $\sigma$ & 3.9 & 4.2 & 5.3 & 5.3 \\
& $1 \mathrm{Q}$ & 6.5 & 5.3 & 1.7 & 1.7 \\
& med. & 9.0 & 8.4 & 4.9 & 4.9 \\
& $3 \mathrm{Q}$ & 11.5 & 10.7 & 8.4 & 8.4 \\
\hline
\end{tabular}

In general, the MCS precursor environment has larger shear than the other atmospheric conditions studied (see Table 4.12). Please note that three of the five terms in the SWEAT index are based on wind speed and shear, so the shear values taken at the location of the maximum SWEAT index on days without MCSs are expected to be large and not meaningful for comparison purposes. The difference in shear is especially significant through the lower half of the troposphere between the MCS precursor environment and the cases of widespread convection. It appears that speed and directional shear are important in supporting convection through the upscale-growth process, resulting in MCSs. 
Table 4.11: Same as Table 4.6, except for stability and moisture parameters. An asterisk (*) indicates that the given parameter is part of the index; thus, the values are insignificantly large.

\begin{tabular}{|c|c|c|c|c|c|}
\hline \multicolumn{2}{|l|}{ Parameter } & MCS-6h & $\begin{array}{l}\text { Widespread } \\
\text { Convection }\end{array}$ & $\begin{array}{c}\text { No MCS } \\
\text { Max SWEAT }\end{array}$ & $\begin{array}{c}\text { No MCS } \\
\text { Max CAPE }\end{array}$ \\
\hline CAPE & mean & 1560 & 1083 & 1165 & $2552^{*}$ \\
\hline \multirow{4}{*}{$\left(\mathrm{J} \mathrm{kg}^{-1}\right)$} & $\sigma$ & 1088 & 784 & 989 & 1444 \\
\hline & $1 \mathrm{Q}$ & 695 & 464 & 320 & 1070 \\
\hline & med. & 1563 & 989 & 1023 & 2723 \\
\hline & $3 \mathrm{Q}$ & 2358 & 1594 & 1803 & 3789 \\
\hline CIN & mean & -53.2 & -20.5 & -59.9 & -42.4 \\
\hline \multirow[t]{4}{*}{$\left(\mathrm{J} \mathrm{kg}^{-1}\right)$} & $\sigma$ & 67.4 & 45.9 & 74.4 & 66.3 \\
\hline & $1 \mathrm{Q}$ & -74.0 & -16.6 & -82.7 & -43.0 \\
\hline & med. & -28.8 & -3.4 & -29.3 & -14.3 \\
\hline & $3 Q$ & -7.0 & -1.0 & -10.2 & -7.0 \\
\hline TT & mean & 51.0 & 50.1 & $53.6^{*}$ & 48.8 \\
\hline \multirow[t]{4}{*}{$(\mathrm{K})$} & $\sigma$ & 5.2 & 4.9 & 5.5 & 5.1 \\
\hline & $1 \mathrm{Q}$ & 47.8 & 46.2 & 51.9 & 45.5 \\
\hline & med. & 51.7 & 50.0 & 55.1 & 48.3 \\
\hline & $3 Q$ & 54.7 & 53.8 & 57.1 & 52.5 \\
\hline LI & mean & -4.4 & -3.1 & -4.1 & -5.6 \\
\hline \multirow[t]{4}{*}{ (K) } & $\sigma$ & 3.3 & 2.4 & 3.1 & 2.7 \\
\hline & $1 Q$ & -6.6 & -4.6 & -6.2 & -7.6 \\
\hline & med. & -4.9 & -3.3 & -4.5 & -6.1 \\
\hline & $3 \mathrm{Q}$ & -2.9 & -1.8 & -2.3 & -3.9 \\
\hline \multirow{5}{*}{$\begin{array}{l}\text { Precipitable Water } \\
(\mathrm{mm})\end{array}$} & mean & 33.8 & 33.4 & 28.8 & 38.0 \\
\hline & $\sigma$ & 10.4 & 12.0 & 11.4 & 12.6 \\
\hline & $1 \mathrm{Q}$ & 26.0 & 23.5 & 20.1 & 29.6 \\
\hline & med. & 33.3 & 33.1 & 28.5 & 39.8 \\
\hline & $3 \mathrm{Q}$ & 41.0 & 44.1 & 37.1 & 48.4 \\
\hline \multirow[t]{5}{*}{ SWEAT index } & mean & 307 & 238 & 430 * & 243 \\
\hline & $\sigma$ & 110 & 87 & 75 & 105 \\
\hline & $1 \mathrm{Q}$ & 222 & 184 & 369 & 176 \\
\hline & med. & 304 & 220 & 421 & 222 \\
\hline & $3 Q$ & 379 & 278 & 476 & 300 \\
\hline
\end{tabular}


Table 4.12: Same as Table 4.6, except for shear parameters.

\begin{tabular}{llcccc}
\hline Parameter & MCS-6h & $\begin{array}{c}\text { Widespread } \\
\text { Convection }\end{array}$ & $\begin{array}{c}\text { No MCS } \\
\text { Max SWEAT }\end{array}$ & $\begin{array}{c}\text { No MCS } \\
\text { Max CAPE }\end{array}$ \\
\hline $0-1 \mathrm{~km}^{-1}$ shear & mean & $\mathbf{5 . 1}$ & $\mathbf{3 . 1}$ & $\mathbf{6 . 3}$ & 4.8 \\
$\left(\mathrm{~m} \mathrm{~s}^{-}\right)$ & $\sigma$ & 3.7 & 3.2 & 4.0 & 3.3 \\
& $1 \mathrm{Q}$ & 2.4 & 1.1 & 3.3 & 2.4 \\
& med. & 4.3 & 2.0 & 5.6 & 4.1 \\
& $3 \mathrm{Q}$ & 6.7 & 3.8 & 8.3 & 6.3 \\
\hline $0-3 \mathrm{~km}^{-1}$ shear & mean & $\mathbf{1 1 . 5}$ & $\mathbf{7 . 7}$ & 12.3 & $\mathbf{9 . 3}$ \\
$\left(\mathrm{m} \mathrm{s}^{-1}\right)$ & $\sigma$ & 5.0 & 4.9 & 5.1 & 4.7 \\
& $1 \mathrm{Q}$ & 7.9 & 4.0 & 8.5 & 5.4 \\
& med. & 11.0 & 6.5 & 12.0 & 9.0 \\
& 3Q & 14.8 & 10.4 & 15.5 & 12.5 \\
\hline $0-6 \mathrm{~km}^{-1}$ shear & mean & $\mathbf{1 6 . 5}$ & $\mathbf{1 1 . 3}$ & $\mathbf{1 9 . 8}$ & $\mathbf{1 3 . 4}$ \\
$\left(\mathrm{m} \mathrm{s}^{-}\right)$ & $\sigma$ & 7.3 & 8.0 & 7.9 & 8.3 \\
& $1 \mathrm{Q}$ & 11.1 & 5.6 & 14.3 & 7.0 \\
& med. & 16.3 & 9.4 & 18.9 & 12.0 \\
\hline $\mathbf{5 - 1 0 ~ k m}$ shear & $3 \mathrm{Q}$ & 21.5 & 15.4 & 24.2 & 18.9 \\
$\left(\mathrm{~m} \mathrm{~s}^{-1}\right)$ & mean & $\mathbf{1 0 . 8}$ & 10.7 & $\mathbf{1 4 . 9}$ & 13.0 \\
& $\sigma$ & 7.1 & 7.5 & 9.1 & 9.3 \\
& $1 \mathrm{Q}$ & 5.4 & 5.4 & 8.1 & 5.9 \\
& med. & 9.1 & 9.2 & 12.6 & 11.1 \\
\hline Storm-relative helicity & mean & $\mathbf{1 2 6 . 8}$ & $\mathbf{6 9 . 8}$ & 144.8 & $\mathbf{8 3 . 4}$ \\
$\left(\mathrm{m}^{2} \mathrm{~s}^{-2}\right)$ & $\sigma$ & 93.5 & 79.3 & 102.8 & 65.0 \\
& $1 \mathrm{Q}$ & 66.2 & 23.1 & 78.9 & 37.3 \\
& med. & 106.0 & 45.8 & 121.3 & $\mathbf{7 5 . 5}$ \\
& $3 \mathrm{Q}$ & 168.2 & 94.8 & 184.2 & 115.3 \\
\hline
\end{tabular}

\subsubsection{Environments of MCS classifications}

The data for the precursor MCS environments were also examined with respect to the different MCS classifications of Jirak et al. (2003). Table 4.13 shows the point-value data for the IR satellite classifications only for parameters with statistically-significant differences in the means at the $95 \%$ confidence level. None of the parameters really stand out as good indicators to distinguish which environments might produce a particular type of MCS. At $200 \mathrm{mb}$, the larger systems (i.e., MCCs and PECSs) devcloped in regions of cooler temperatures than the smaller systems. PECSs typically developed in areas of stronger low-level wind speeds and shear than MBCCSs. Finally, 
larger elongated systems were more likely to form in a region of stronger surface convergence than smaller elongated systems.

Table 4.13: Same as Table 4.6, except for IR satellite classifications of MCSs. Bold numbers indicate that the means are different at the $95 \%$ confidence level.

\begin{tabular}{|c|c|c|c|c|c|}
\hline \multicolumn{6}{|l|}{ Parameter } \\
\hline & & $\mathrm{MCC}$ & PECS & MßCCS & MßECS \\
\hline \multirow{5}{*}{$\begin{array}{l}200 \mathrm{mb} \text { temperature } \\
(\mathrm{K})\end{array}$} & mean & 216.9 & 217.0 & 218.7 & 218.6 \\
\hline & $\sigma$ & 3.5 & 3.5 & 2.9 & 3.5 \\
\hline & $1 Q$ & 214.3 & 214.2 & 216.7 & 215.6 \\
\hline & med. & 217.2 & 217.8 & 219.5 & 219.3 \\
\hline & $3 Q$ & 220.0 & 219.8 & 220.8 & 221.1 \\
\hline \multirow{5}{*}{$\begin{array}{l}330 \mathrm{~K} \text { potential vorticity } \\
\text { (PVU) }\end{array}$} & mean & 0.53 & 0.76 & 0.67 & 0.79 \\
\hline & $\sigma$ & 0.52 & 0.75 & 0.94 & 0.91 \\
\hline & $1 Q$ & 0.25 & 0.37 & 0.35 & 0.35 \\
\hline & med. & 0.39 & 0.52 & 0.50 & 0.55 \\
\hline & $3 Q$ & 0.57 & 0.76 & 0.64 & 0.76 \\
\hline \multirow{5}{*}{$\begin{array}{l}850 \mathrm{mb} \text { wind speed } \\
\left(\mathrm{m} \mathrm{s}^{-1}\right)\end{array}$} & mean & 6.8 & 8.4 & 6.1 & 7.1 \\
\hline & $\sigma$ & 3.5 & 5.2 & 3.0 & 3.9 \\
\hline & $1 \mathrm{Q}$ & 4.6 & 4.5 & 4.4 & 4.0 \\
\hline & med. & 6.4 & 7.2 & 5.7 & 6.7 \\
\hline & $3 Q$ & 8.9 & 12.2 & 8.0 & 9.6 \\
\hline \multirow{5}{*}{$\begin{array}{l}\text { Surface moisture divergence } \\
\left(\mathrm{s}^{-1}\right)\end{array}$} & mean & $-7.4 \mathrm{E}-08$ & $-1.1 \mathrm{E}-07$ & $-8.3 \mathrm{E}-08$ & $-5.7 \mathrm{E}-09$ \\
\hline & $\sigma$ & $3.1 \mathrm{E}-07$ & $2.9 \mathrm{E}-07$ & $3.0 \mathrm{E}-07$ & $2.6 \mathrm{E}-07$ \\
\hline & $1 Q$ & $-2.2 \mathrm{E}-07$ & $-2.5 \mathrm{E}-07$ & $-2.4 \mathrm{E}-07$ & $-1.2 \mathrm{E}-07$ \\
\hline & med. & $-6.9 E-08$ & $-9.2 E-08$ & $-5.0 \mathrm{E}-08$ & $-1.2 \mathrm{E}-09$ \\
\hline & $3 Q$ & $1.2 \mathrm{E}-07$ & $7.1 \mathrm{E}-08$ & $1.1 \mathrm{E}-07$ & 1.3E-07 \\
\hline \multirow{5}{*}{$\begin{array}{l}\mathrm{CIN} \\
\left(\mathrm{J} \mathrm{kg}^{-1}\right)\end{array}$} & mean & -66.8 & -50.6 & -56.4 & -40.4 \\
\hline & $\sigma$ & 70.8 & 67.7 & 75.8 & 52.7 \\
\hline & $1 Q$ & -96.4 & -66.1 & -73.7 & -54.3 \\
\hline & med. & -40.3 & -27.7 & -34.4 & -19.1 \\
\hline & $3 Q$ & -10.6 & -4.4 & -8.2 & -5.0 \\
\hline \multirow{5}{*}{$\begin{array}{l}0-1 \mathrm{~km} \text { shear } \\
\left(\mathrm{m} \mathrm{s}^{-1}\right)\end{array}$} & mean & 4.9 & 5.8 & 4.1 & 4.7 \\
\hline & $\sigma$ & 3.1 & 4.5 & 2.3 & 3.3 \\
\hline & $1 Q$ & 2.7 & 2.1 & 2.0 & 2.4 \\
\hline & med. & 4.4 & 4.7 & 3.9 & 3.9 \\
\hline & $3 Q$ & 6.5 & 8.6 & 5.9 & 6.6 \\
\hline
\end{tabular}

Classifying MCSs by whether the convection develops in a region of stratiform precipitation reveals several significant differences between the systems (see Table 4.14). Embedded systems typically have larger values of PV at mid and upper levels prior to development than systems that develop in a region free of stratiform precipitation. This suggests the presence and influence of extratropical cyclones and remnant MCS stratiform precipitation on embedded systems. In general, the low levels are warmer and 
moister for systems that do not form from embedded thunderstorms. Additionally, the MCS precursor environments without stratiform precipitation are typically much more unstable than embedded systems, leading to more severe weather (Jirak et al. 2003).

Very significant differences among the systems also arise by simply categorizing MCSs according to how the initial thunderstorms are arranged. The differences are important since MCSs that develop from linearly-arranged convection are typically larger, longer-lived, more severe, and rainier than systems that develop from scattered convection (i.e., areal systems). Table 4.15 shows that line systems have stronger wind speeds and wind shear through the depth of the troposphere than areal systems. Keep in mind that areal systems still develop in a moderate amount of shear to support long-lived convection. In fact, the average shear of areal systems is larger than the widespread convection condition discussed earlier at the $99 \%$ confidence level. Thus, given sufficient shear, the exact magnitude of shear may help determine the arrangement of convection, and hence, the severity, size, and longevity of the resultant MCS. Also, note that even though one might expect stronger low-level convergence (i.e., along a frontal boundary) for line systems, a statistically-significant difference was not found for lowlevel convergence among these types of systems. Table 4.16 also lists some other parameters of significance. The low levels are generally cooler prior to the development of line systems as opposed to areal systems, but the $700 \mathrm{mb}$ temperature advection is larger on average, providing more upward forcing. 
Table 4.14: Same as Table 4.13, except for the first radar development classification level: presence of stratiform precipitation.

\begin{tabular}{|c|c|c|c|}
\hline Parameter & & embedded & $\begin{array}{c}\text { not } \\
\text { embedded }\end{array}$ \\
\hline \multirow{5}{*}{$\begin{array}{l}330 \mathrm{~K} \text { potential vorticity } \\
\text { (PVU) }\end{array}$} & mean & 1.05 & 0.63 \\
\hline & $\sigma$ & 1.18 & 0.65 \\
\hline & $1 \mathrm{Q}$ & 0.36 & 0.33 \\
\hline & med. & 0.58 & 0.48 \\
\hline & $3 Q$ & 1.40 & 0.69 \\
\hline \multirow{5}{*}{$\begin{array}{l}320 \mathrm{~K} \text { potential vorticity } \\
\text { (PVU) }\end{array}$} & mean & 0.59 & 0.38 \\
\hline & $\sigma$ & 0.60 & 0.35 \\
\hline & $1 \mathrm{Q}$ & 0.25 & 0.22 \\
\hline & med. & 0.42 & 0.35 \\
\hline & $3 Q$ & 0.74 & 0.47 \\
\hline \multirow{5}{*}{$\begin{array}{l}500 \mathrm{mb}^{-1} \text { specific humidity } \\
\left(\mathrm{g} \mathrm{kg}^{-1}\right)\end{array}$} & mean & 2.2 & 1.9 \\
\hline & $\sigma$ & 1.0 & 0.8 \\
\hline & $1 \mathrm{Q}$ & 1.5 & 1.3 \\
\hline & med. & 2.1 & 1.9 \\
\hline & $3 \mathrm{Q}$ & 3.0 & 2.5 \\
\hline \multirow{5}{*}{$\begin{array}{l}700 \mathrm{mb} \text { temperature } \\
(\mathrm{K})\end{array}$} & mean & 280.1 & 282.0 \\
\hline & $\sigma$ & 3.9 & 3.3 \\
\hline & $1 \mathrm{Q}$ & 277.8 & 280.1 \\
\hline & med. & 281.2 & 282.4 \\
\hline & $3 Q$ & 282.8 & 284.3 \\
\hline \multirow{5}{*}{$\begin{array}{l}850 \mathrm{mb} \theta_{\mathrm{e}} \\
(\mathrm{K})\end{array}$} & mean & 332.5 & 338.5 \\
\hline & $\sigma$ & 14.0 & 11.0 \\
\hline & $1 \mathrm{Q}$ & 322.6 & 331.6 \\
\hline & med. & 336.8 & 339.9 \\
\hline & $3 Q$ & 341.9 & 347.3 \\
\hline \multirow{5}{*}{$\begin{array}{l}\text { Surface temperature } \\
\text { (K) }\end{array}$} & mean & 296.5 & 300.0 \\
\hline & $\sigma$ & 7.4 & 5.8 \\
\hline & $1 \mathrm{Q}$ & 291.3 & 296.7 \\
\hline & med. & 296.3 & 300.7 \\
\hline & $3 Q$ & 301.6 & 303.7 \\
\hline \multirow{5}{*}{$\begin{array}{l}\text { Surface specific humidity } \\
\left(\mathrm{g} \mathrm{kg}^{-1}\right)\end{array}$} & mean & 12.1 & 13.8 \\
\hline & $\sigma$ & 4.0 & 3.6 \\
\hline & $1 Q$ & 9.2 & 11.1 \\
\hline & med. & 12.7 & 13.7 \\
\hline & $3 \mathrm{Q}$ & 14.9 & 16.4 \\
\hline \multirow{5}{*}{$\begin{array}{l}\text { CAPE } \\
\left(\mathrm{J} \mathrm{kg}^{-1}\right)\end{array}$} & mean & 966 & 1679 \\
\hline & $\sigma$ & 1009 & 1066 \\
\hline & $1 \mathrm{Q}$ & 12 & 886 \\
\hline & med. & 688 & 1644 \\
\hline & $3 Q$ & 1629 & 2463 \\
\hline TT & mean & 48.3 & 51.6 \\
\hline \multirow{4}{*}{$(\mathrm{K})$} & $\sigma$ & 6.5 & 4.8 \\
\hline & 1Q & 45.6 & 48.5 \\
\hline & med. & 49.2 & 52.0 \\
\hline & $3 \mathrm{Q}$ & 52.9 & 55.1 \\
\hline & mean & -2.4 & -4.8 \\
\hline \multirow[t]{4}{*}{$(\mathrm{K})$} & $\sigma$ & 3.9 & 3.0 \\
\hline & 1Q & -4.7 & -6.7 \\
\hline & med. & -2.9 & -5.1 \\
\hline & $3 Q$ & -0.1 & -3.3 \\
\hline
\end{tabular}


Table 4.15: Same as Table 4.13, except wind and shear parameters for the second radar development classification level: arrangement of convective cells.

\begin{tabular}{|c|c|c|c|c|}
\hline \multicolumn{5}{|l|}{ Parameter } \\
\hline & & Areal & Line & Combination \\
\hline \multirow{5}{*}{$\begin{array}{l}200 \mathrm{mb} \text { wind speed } \\
\left(\mathrm{m} \mathrm{s}^{-1}\right)\end{array}$} & mean & 22.0 & 28.2 & 25.3 \\
\hline & $\sigma$ & 12.1 & 14.2 & 12.3 \\
\hline & $1 \mathrm{Q}$ & 13.3 & 16.4 & 17.2 \\
\hline & med. & 20.6 & 29.0 & 24.6 \\
\hline & $3 Q$ & 29.5 & 38.6 & 31.1 \\
\hline \multirow{5}{*}{$\begin{array}{l}300 \mathrm{mb} \text { wind speed } \\
\left(\mathrm{m} \mathrm{s}^{-i}\right)\end{array}$} & mean & 18.2 & 23.4 & 20.5 \\
\hline & $\sigma$ & 10.2 & 10.8 & 9.7 \\
\hline & 1Q & 10.9 & 16.3 & 12.8 \\
\hline & med. & 17.0 & 22.3 & 19.7 \\
\hline & $3 Q$ & 24.9 & 30.7 & 27.1 \\
\hline \multirow{5}{*}{$\begin{array}{l}500 \mathrm{mb} \text { wind speed } \\
\left(\mathrm{m} \mathrm{s}^{-1}\right)\end{array}$} & mean & 13.1 & 18.1 & 14.9 \\
\hline & $\sigma$ & 5.8 & 7.4 & 6.3 \\
\hline & $1 \mathrm{Q}$ & 9.0 & 12.9 & 9.9 \\
\hline & med. & 12.4 & 18.4 & 14.7 \\
\hline & $3 Q$ & 17.1 & 23.3 & 19.3 \\
\hline \multirow{5}{*}{$\begin{array}{l}700 \mathrm{mb} \text { wind speed } \\
\left(\mathrm{m} \mathrm{s}^{-1}\right)\end{array}$} & mean & 8.1 & 12.9 & 9.8 \\
\hline & $\sigma$ & 4.2 & 6.0 & 4.5 \\
\hline & $1 \mathrm{Q}$ & 5.0 & 7.8 & 6.3 \\
\hline & med. & 7.3 & 13.0 & 10.0 \\
\hline & $3 Q$ & 11.2 & 18.0 & 12.7 \\
\hline \multirow{5}{*}{$\begin{array}{l}850 \mathrm{mb} \text { wind speed } \\
\left(\mathrm{m} \mathrm{s}^{-1}\right)\end{array}$} & mean & 6.7 & 10.4 & 6.8 \\
\hline & $\sigma$ & 3.6 & 5.7 & 3.8 \\
\hline & $1 \mathrm{Q}$ & 4.1 & 5.8 & 4.4 \\
\hline & med. & 6.1 & 9.9 & 6.3 \\
\hline & $3 Q$ & 9.0 & 14.3 & 9.2 \\
\hline \multirow{5}{*}{$\begin{array}{l}850 \mathrm{mb} \text { v-wind speed } \\
\left(\mathrm{m} \mathrm{s}^{-1}\right)\end{array}$} & mean & 3.5 & 6.5 & 3.9 \\
\hline & $\sigma$ & 4.6 & 5.9 & 4.1 \\
\hline & 1Q & 0.6 & 3.0 & 1.0 \\
\hline & med. & 3.1 & 5.2 & 3.4 \\
\hline & $3 Q$ & 6.2 & 9.8 & 6.3 \\
\hline \multirow{5}{*}{$\begin{array}{l}\text { Surface wind speed } \\
\left(\mathrm{m} \mathrm{s}^{-1}\right)\end{array}$} & mean & 4.1 & 5.6 & 4.2 \\
\hline & $\sigma$ & 2.0 & 2.2 & 1.9 \\
\hline & 1Q & 2.6 & 4.1 & 2.7 \\
\hline & med. & 3.9 & 5.3 & 4.3 \\
\hline & $3 \mathrm{Q}$ & 5.2 & 7.1 & 5.4 \\
\hline \multirow{5}{*}{$\begin{array}{l}0-1 \mathrm{~km} \text { shear } \\
\left(\mathrm{m} \mathrm{s}^{-1}\right)\end{array}$} & mean & 4.4 & 7.2 & 5.2 \\
\hline & $\sigma$ & 3.0 & 5.0 & 3.6 \\
\hline & 1Q & 2.1 & 3.2 & 2.5 \\
\hline & med. & 3.8 & 6.3 & 4.4 \\
\hline & $3 Q$ & 6.2 & 9.9 & 6.8 \\
\hline \multirow{5}{*}{$\begin{array}{l}0-3 \mathrm{~km} \text { shear } \\
\left(\mathrm{m} \mathrm{s}^{-1}\right)\end{array}$} & mean & 10.7 & 13.3 & 12.0 \\
\hline & $\sigma$ & 4.7 & 5.6 & 5.0 \\
\hline & $1 \mathrm{Q}$ & 7.2 & 9.2 & 8.4 \\
\hline & med. & 10.5 & 12.9 & 11.2 \\
\hline & $3 Q$ & 13.9 & 16.9 & 15.1 \\
\hline \multirow{5}{*}{$\begin{array}{l}0-6 \mathrm{~km} \text { shear } \\
\left(\mathrm{m} \mathrm{s}^{-1}\right)\end{array}$} & mean & 15.6 & 18.6 & 16.9 \\
\hline & $\sigma$ & 7.2 & 7.9 & 7.1 \\
\hline & $1 \mathrm{Q}$ & 10.2 & 13.7 & 11.2 \\
\hline & med. & 14.3 & 17.3 & 17.3 \\
\hline & $3 Q$ & 20.5 & 24.1 & 20.9 \\
\hline
\end{tabular}



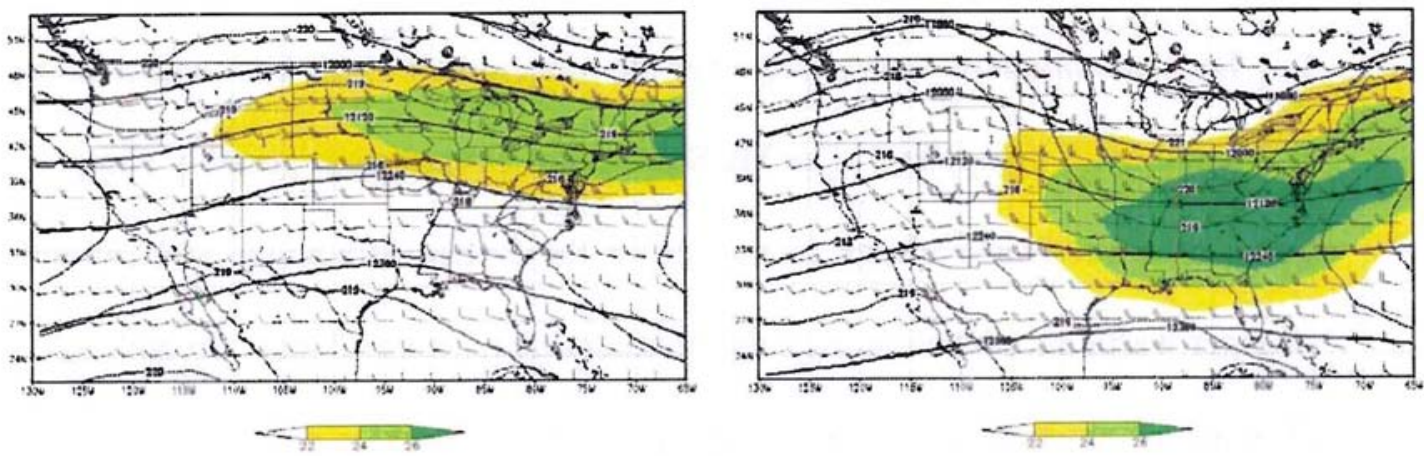

Figure 4.1: $200 \mathrm{mb}$ fixed-point composite of $6 \mathrm{~h}$ prior to MCS initiation (left panel) and times without MCSs (right panel). The solid lines represent height contours ( $\mathrm{m}$ ), the dashed lines represent isotherms $(\mathrm{K})$, and the shading represents wind speed $\left(\mathrm{m} \mathrm{s}^{-1}\right)$. Each full wind barb represents 10 $\mathrm{m} \mathrm{s}^{-1}$.

Figure 4.2 shows the composites for $500 \mathrm{mb}$. A similar height pattern extends down to this level for both composites. The ridge is stronger and farther west on days without MCSs than prior to MCS development. Temperature advection is relatively weak for both conditions at this level. The MCS precursor environment does show moister conditions farther north with a noticeable tongue of moist air extending northward along the Rocky Mountains.
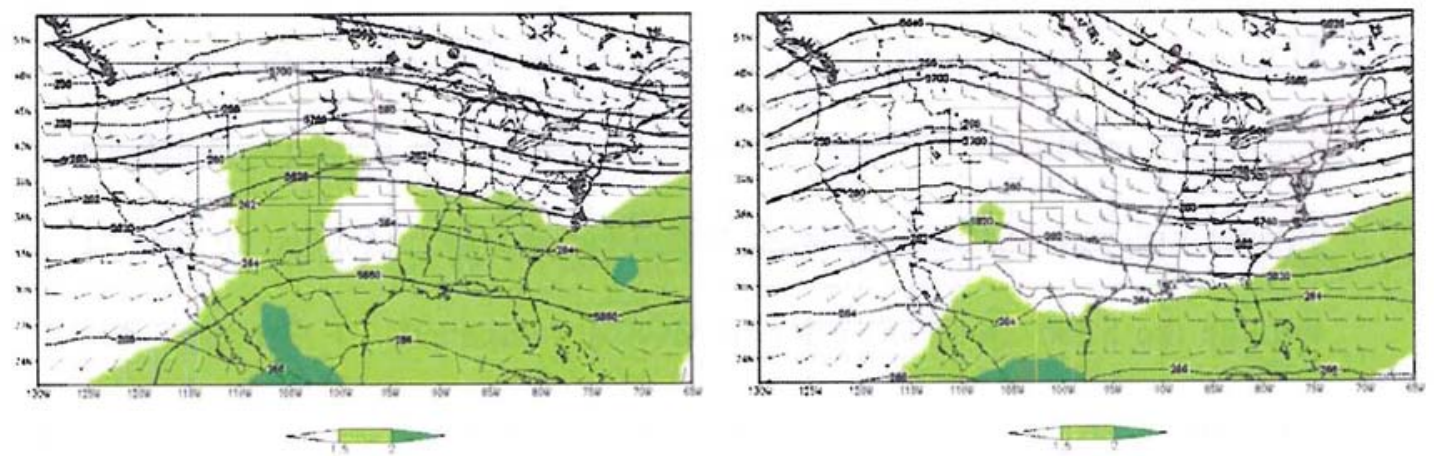

Figure 4.2: $500 \mathrm{mb}$ fixed-point composite of $6 \mathrm{~h}$ prior to MCS initiation (left panel) and times without MCSs (right panel). The solid lines represent height contours ( $m$ ), the dashed lines represent isotherms $(\mathrm{K})$, and the shading represents specific humidity $\left(\mathrm{g} \mathrm{kg}^{-1}\right)$. Each full wind barb represents $10 \mathrm{~m} \mathrm{~s}^{-1}$. 
The height, temperature, and moisture composite fields for $700 \mathrm{mb}$ are shown in Fig. 4.3. Both conditions reveal ridging over the western half of the U.S. with a stronger ridge in the non-MCS composite. The MCS precursor environment possibly shows a stronger signal of a shortwave trough in the lee of the Rocky Mountains and certainly shows stronger warm air advection over the Southern and Central Plains. In addition, a tongue of moist air extends northward along the lee of the Rockies prior to MCS development that is absent on days without MCSs.
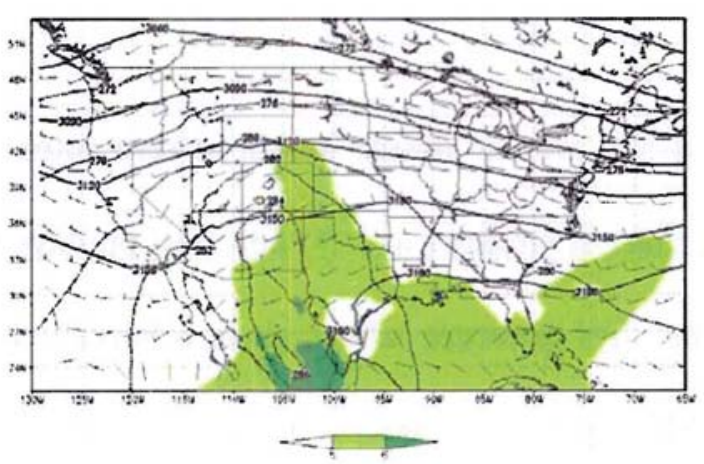
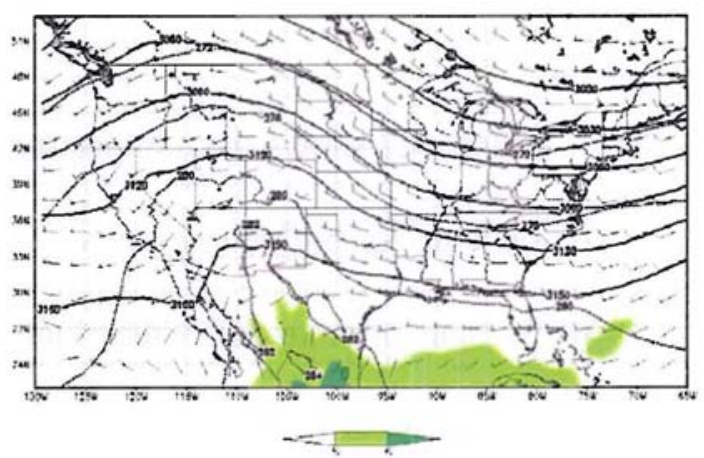

Figure 4.3: Same as Fig. 4.2, except for $700 \mathrm{mb}$.

At $850 \mathrm{mb}$, significant differences also exist in the height and wind fields between days with and without MCSs (see Fig. 4.4). The trough in the vicinity of the Rocky Mountains is much more organized prior to MCS development than on days without convective organization. This results in a broader area of strong, southerly winds that extends well into the Central Plains. In addition, a region of moist air stretches northward through the Southern Plains prior to MCS development. Both composites show weak warm air advection across the central U.S., but the MCS precursor environment reveals much more significant moisture advection into the Central Plains. 
Table 4.16: Same as Table 4.13, except temperature parameters for the second radar development classification level: arrangement of convective cells.

\begin{tabular}{llccc}
\hline Parameter & & & & \\
& & Areal & Line & Combination \\
\hline 700 mb temperature & mean & $\mathbf{2 8 1 . 9}$ & $\mathbf{2 8 0 . 6}$ & 281.9 \\
$(\mathrm{~K})$ & $\sigma$ & 3.4 & 3.5 & 3.4 \\
& $1 \mathrm{Q}$ & 280.2 & 277.6 & 279.8 \\
& med. & 282.3 & 281.3 & 282.8 \\
& $3 \mathrm{Q}$ & 284.2 & 283.2 & 284.2 \\
\hline $700 \mathrm{mb}$ temp. advection & mean & $\mathbf{3 . 8 E}-\mathbf{0 5}$ & $\mathbf{8 . 1 E}-\mathbf{0 5}$ & $\mathbf{3 . 9 E}-05$ \\
$\left(\mathrm{~K} \mathrm{~s}^{-1}\right)$ & $\sigma$ & $5.6 \mathrm{E}-05$ & $1.1 \mathrm{E}-04$ & $7.1 \mathrm{E}-05$ \\
& $1 \mathrm{Q}$ & $4.4 \mathrm{E}-06$ & $2.2 \mathrm{E}-05$ & $-3.0 \mathrm{E}-06$ \\
& med. & $2.7 \mathrm{E}-05$ & $4.5 \mathrm{E}-05$ & $3.4 \mathrm{E}-05$ \\
& $3 \mathrm{Q}$ & $6.2 \mathrm{E}-05$ & $1.1 \mathrm{E}-04$ & $6.9 \mathrm{E}-05$ \\
\hline $850 \mathrm{mb}$ temperature & mean & $\mathbf{2 9 2 . 8}$ & $\mathbf{2 9 0 . 5}$ & $\mathbf{2 9 2 . 8}$ \\
$(\mathrm{K})$ & $\sigma$ & 4.9 & 4.8 & 4.6 \\
& $1 \mathrm{Q}$ & 290.3 & 287.4 & 290.6 \\
& med. & 292.8 & 290.7 & 293.2 \\
& $3 \mathrm{Q}$ & 296.2 & 294.2 & 295.7 \\
\hline $850 \mathrm{mb} \theta_{\mathrm{e}}$ & mean & $\mathbf{3 3 8 . 5}$ & $\mathbf{3 3 3 . 8}$ & 338.5 \\
$(\mathrm{~K})$ & $\sigma$ & 10.8 & 12.8 & 12.1 \\
& $1 \mathrm{Q}$ & 332.7 & 325.6 & 332.1 \\
& med. & 340.0 & 335.2 & 339.9 \\
& $3 \mathrm{Q}$ & 346.0 & 344.3 & 348.0 \\
\hline
\end{tabular}

The lack of parameters listed in Table 4.17 indicates that there is virtually no discernable difference among the environments of MCSs when classified by the interaction of convective clusters. Only minor differences were found in the temperatures at $200 \mathrm{mb}$ and $850 \mathrm{mb}$. This finding (or lack thereof) suggests that if an environment is favorable for supporting long-lived convection, it is nearly impossible to determine how the convective clusters will interact by examining the environment alone. Perhaps the more important factor in determining how the convective clusters will interact depends on the number of thunderstorms that develop and their proximity to one another. 
Table 4.17: Same as Table 4.13, except for the third radar development classification level: interaction of convective clusters.

\begin{tabular}{llccc}
\hline \hline & & & & \\
Parameter & & Merger & Non-merger & Isolated \\
\hline $200 \mathrm{mb}$ temperature & mean & $\mathbf{2 1 8 . 0}$ & $\mathbf{2 1 5 . 9}$ & 216.9 \\
$(\mathrm{~K})$ & $\sigma$ & 3.4 & 3.4 & 3.8 \\
& $1 \mathrm{Q}$ & 216.0 & 213.7 & 214.1 \\
& med. & 218.7 & 215.3 & 217.4 \\
& 3Q & 220.4 & 218.4 & 220.0 \\
\hline $850 \mathrm{mb}$ temperature & mean & $\mathbf{2 9 2 . 9}$ & 292.4 & $\mathbf{2 9 0 . 8}$ \\
$(\mathrm{K})$ & $\sigma$ & 4.7 & 3.8 & 5.6 \\
& $1 \mathrm{Q}$ & 290.3 & 289.4 & 288.3 \\
& med. & 292.9 & 291.5 & 291.5 \\
& 3Q & 296.3 & 295.0 & 294.5 \\
\hline
\end{tabular}

\subsection{Fixed-point composites}

To gauge the general atmospheric temperature, moisture, and flow patterns across the U.S. on days with and without MCSs, fixed-point composites were created and examined. These composites can be thought of as what a general weather map might look like on a day with or without a MCS. At $200 \mathrm{mb}$, the height, wind, and temperature fields look very different for days with and without MCSs (see Fig. 4.1). Prior to MCS development, a weak, upper-level ridge is present over the central U.S. with a band of minimum temperatures stretching across the middle of the country. The jet stream is centered north of $40^{\circ}$ latitude with the right entrance region of the jet streak encompassing much of the Central Plains. On days without MCSs, there is a stronger ridge over the western U.S. and a trough over the eastern U.S. An inverted temperature ridge extends to the southwest from the Great Lakes. The jet stream is stronger and farther south with the left entrance region of the jet streak over the Central Plains, which is less favorable for the support of convective development. 


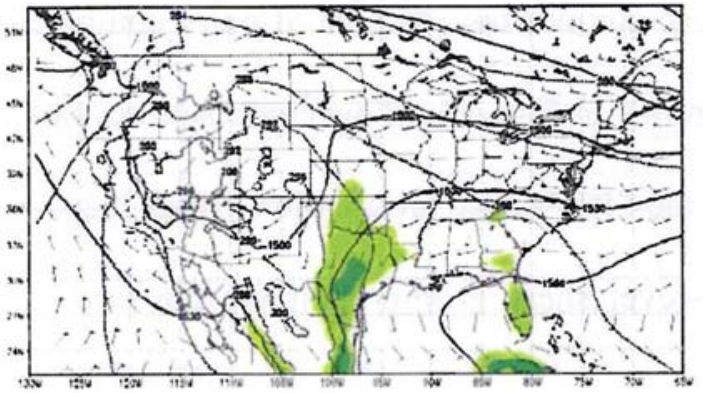

$\cdots+\frac{110}{10}$

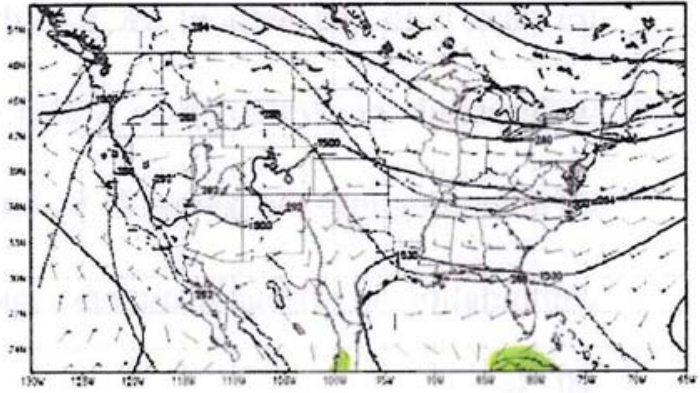

$-\sqrt{1+n}$

Figure 4.4: Same as Fig. 4.2, except for $850 \mathrm{mb}$.

The composite surface map (Fig. 4.5) displays a well-organized trough along the Rocky Mountains generating strong southerly winds through the Central Plains prior to MCS development. On days without MCSs, the surface trough is farther west and the Bermuda High exists farther east resulting in weaker southerly flow into the plains. Hence, the MSLPDIF parameter introduced earlier was created to measure this strong east-west pressure gradient along the Gulf Coast. Clearly, the pressure gradient leads to significant moisture advection into the Mississippi Valley prior to MCS development.

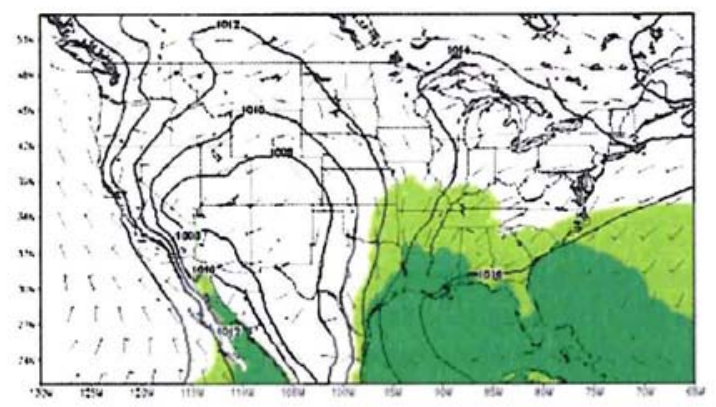

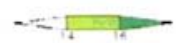
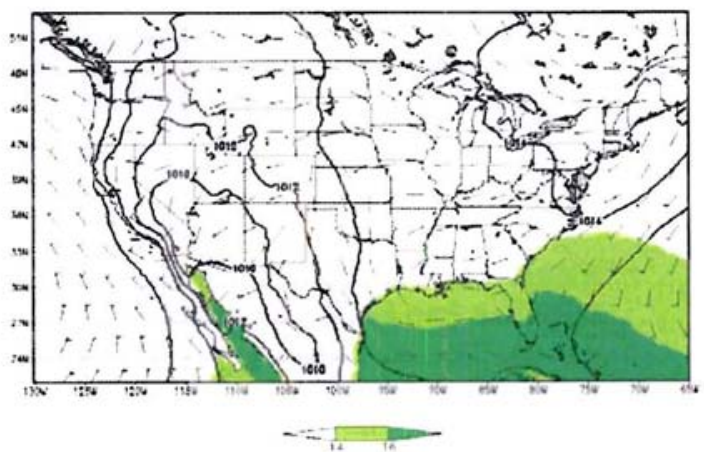

Figure 4.5: Same as Fig. 4.2, except for the surface. The solid lines now represent isobars (mb), and the isotherms are absent.

Composite maps of CAPE (Fig. 4.6) reveal a tongue of unstable air that extends from the Gulf of Mexico into the Central Plains preceding MCS formation that doesn't exist on 
days without MCSs. Interestingly, the values of storm-relative helicity (SRH) are similar for days with and without MCS in these composites. The fixed-point composite for the widespread convection cases is also shown in Fig. 4.6. This composite reveals unstable air extending into the central U.S., but the SRH values are smaller. Thus, it appears that a combination of unstable air and low-level shear is important for the development of MCSs.
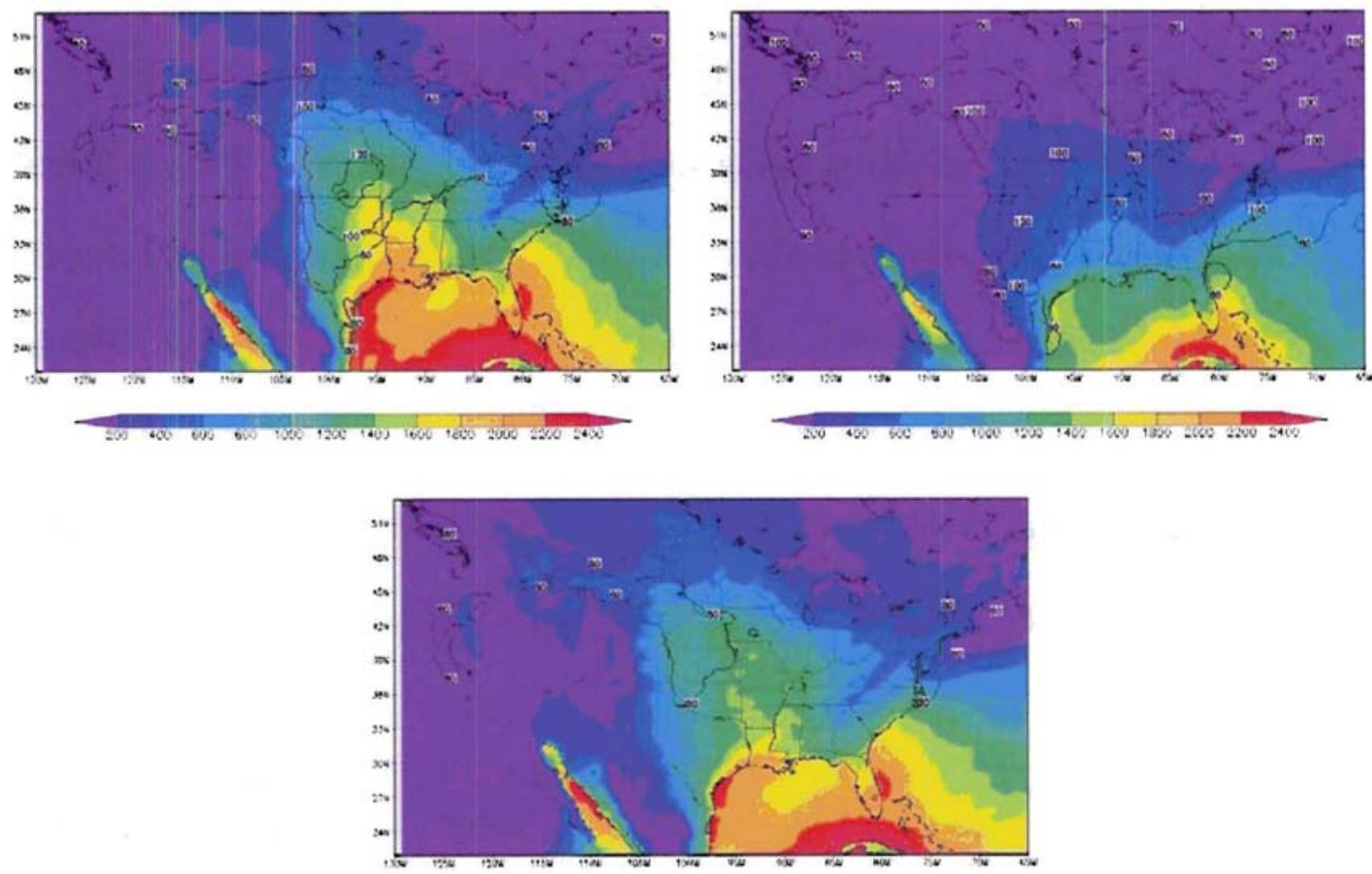

Foure 4.6: Fixed-point composite of CAPE and storm-relative helicity (SRH) for $6 \mathrm{~h}$ prior to MCS initiation (top left panel), times without MCSs (top right panel), and widespread convection (bottom panel). The solid lines represent SRH $\left(\mathrm{m}^{2} \mathrm{~s}^{-2}\right)$, and the shading represents CAPE $\left(\mathrm{J} \mathrm{kg}^{-1}\right)$.

The fixed-point composites for the various MCS classifications do not reveal significant differences among the categories. As expected from the results of the fixedpoint analysis, the greatest difference in fixed-point composites could be seen between 
line and areal systems. The $500 \mathrm{mb}$ composites shown in Fig. 4.7 demonstrate the greatest differences between these types of systems. A ridge is dominant over the central U.S. for areal systems while a ridge resides farther east for line systems. The composites of areal systems are typically moister into the central U.S. than line systems through the mid and lower troposphere while the composites for line systems display stronger winds through the Southern and Central Plains at these levels.

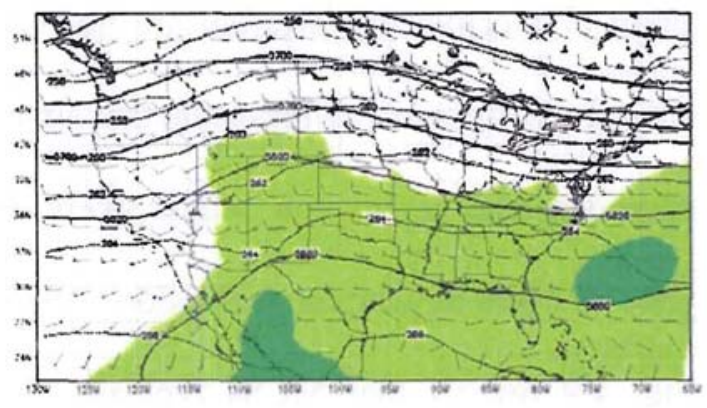

$\cdots \frac{1}{132}$

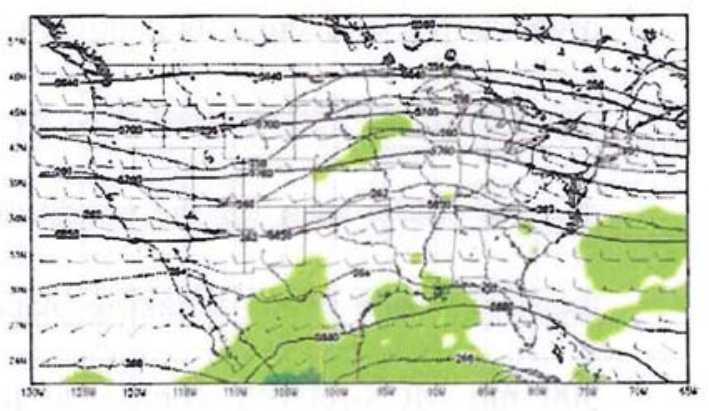

$-\pi$

Figure 4.7: $500 \mathrm{mb}$ fixed-point composite for areal systems (left panel) and line systems (right panel) from the arrangement of convective cells classification level. The solid lines represent height contours $(\mathrm{m})$, the dashed lines represent isotherms $(\mathrm{K})$, and the shading represents specific humidity $\left(\mathrm{g} \mathrm{kg}^{-1}\right)$. Each full wind barb represents $10 \mathrm{~m} \mathrm{~s}^{-1}$.

\subsection{Storm-relative composites}

\subsubsection{MCS and non-MCS composites}

Storm-relative composites allow for the analysis of mesoscale features important to thunderstorm development. Basic fields were composited by averaging data for all MCSs on movable grids $\left(20^{\circ} \times 15^{\circ}\right)$ centered on each system at six hours prior to initiation. The same procedure was also done for the cases of widespread convection at the time of the maximum number of thunderstorms. The basic fields were analyzed along with numerous derived quantities to detect common environmental features for each of these conditions. The map background in these composites does not have any 
physical significance, as systems from all across the central U.S. were included in the composite. However, the map does provide a reference of the size and average initiation location of the MCSs. The average centroid of initiation for MCSs in this sample was $38.38^{\circ} \mathrm{N}$ and $97.38^{\circ} \mathrm{W}$ at $0100 \mathrm{UTC}(6 \mathrm{~h}$ prior $=1900 \mathrm{UTC})$ while the average location of widespread convection was $37.32^{\circ} \mathrm{N}$ and $96.57^{\circ} \mathrm{W}$ at $2130 \mathrm{UTC}$. The storm-relative composites are presented and discussed below starting with the upper troposphere.

At the upper levels, the differences between environments that support convective organization and those that do not support convective organization are not extremely significant. At $200 \mathrm{mb}$ (Fig. 4.8), MCSs typically form in environments that are a couple degrees colder than for the condition of widespread convection, which likely indicates that large-scale lifting is taking place prior to MCS development (Maddox 1983). The $300 \mathrm{mb}$ MCS-relative composite in Fig. 4.9 reveals that MCSs typically form just upstream of an upper-level ridge in an area of modest divergence. The composite of widespread convection also reveals modest divergence, but downstream of a weak ridge. The wind speeds are much slower for unorganized widespread convection without any sign of the jet stream. The jet streak may provide some support to MCS development by inducing upward motion in the right entrance region, which is a favorable region for thunderstorm development (Uccellini and Johnson 1979). 

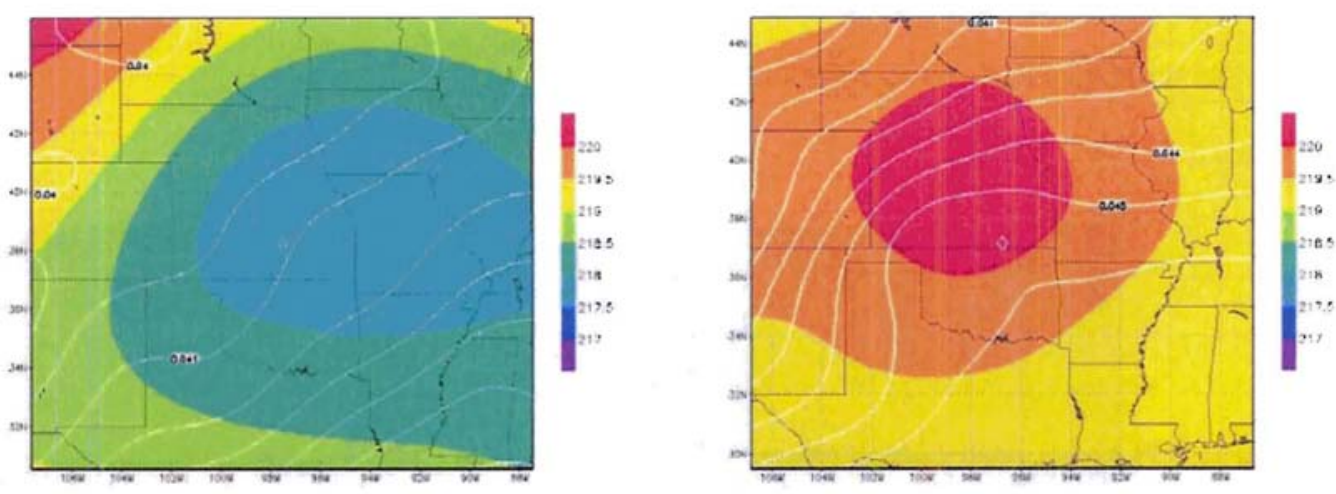

Figure 4.8: Storm-relative composites at $200 \mathrm{mb}$ for $6 \mathrm{~h}$ prior to MCS development (left panel) and widespread convection (right panel). The solid lines represent specific humidity $\left(\mathrm{g} \mathrm{g}^{-1}\right)$, and the shading represents the temperature $(\mathrm{K})$.
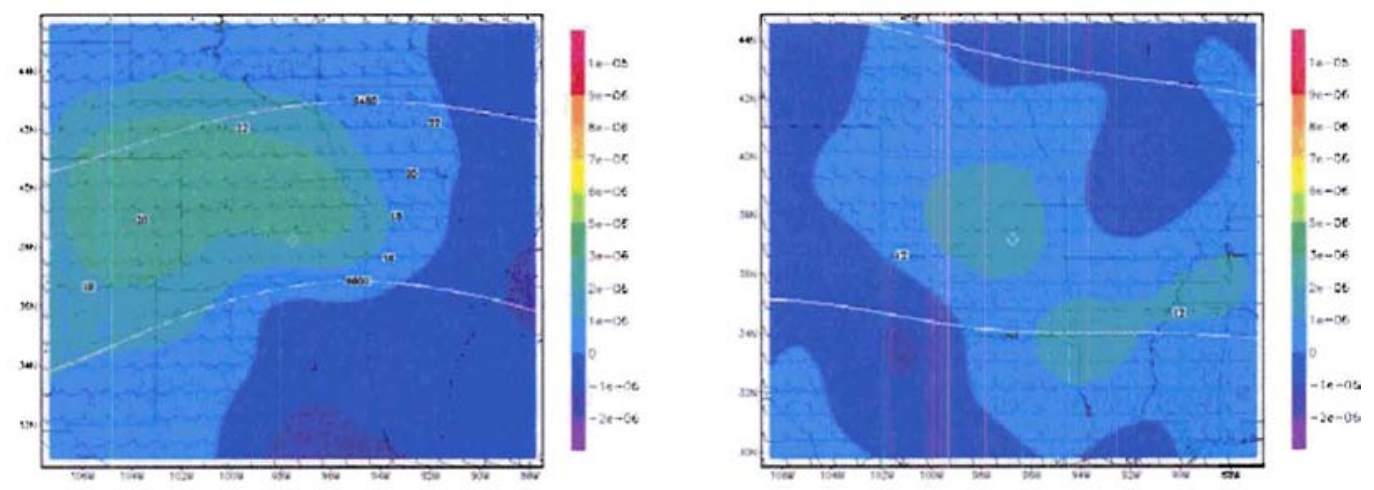

Figure 4.9: Storm-relative composites at $300 \mathrm{mb}$ for $6 \mathrm{~h}$ prior to MCS development (left panel) and widespread convection (right panel). The solid lines represent height contours ( $\mathrm{m}$ ), the dashed lines represent isotachs $\left(\mathrm{m} \mathrm{s}^{-1}\right)$, and the shading represents the divergence $\left(\mathrm{s}^{-1}\right)$. Each full wind barb represents $10 \mathrm{~m} \mathrm{~s}^{-1}$.

In the middle troposphere, the forcing is still weak and does not show a significant difference between the environments. The $500 \mathrm{mb}$ storm-relative composites are shown in Fig. 4.10, which reveals that vorticity advection is actually larger in the center of the widespread convection composite. According to quasi-geostrophic theory, positive vorticity advection contributes to upward vertical motion, so this should benefit convective development. Apparently, however, this forcing is not a common feature prior to MCS development. One other noticeable difference between the composites is 
the much stronger winds to the west and north of the centroid of MCS initiation than in the widespread convection composite.
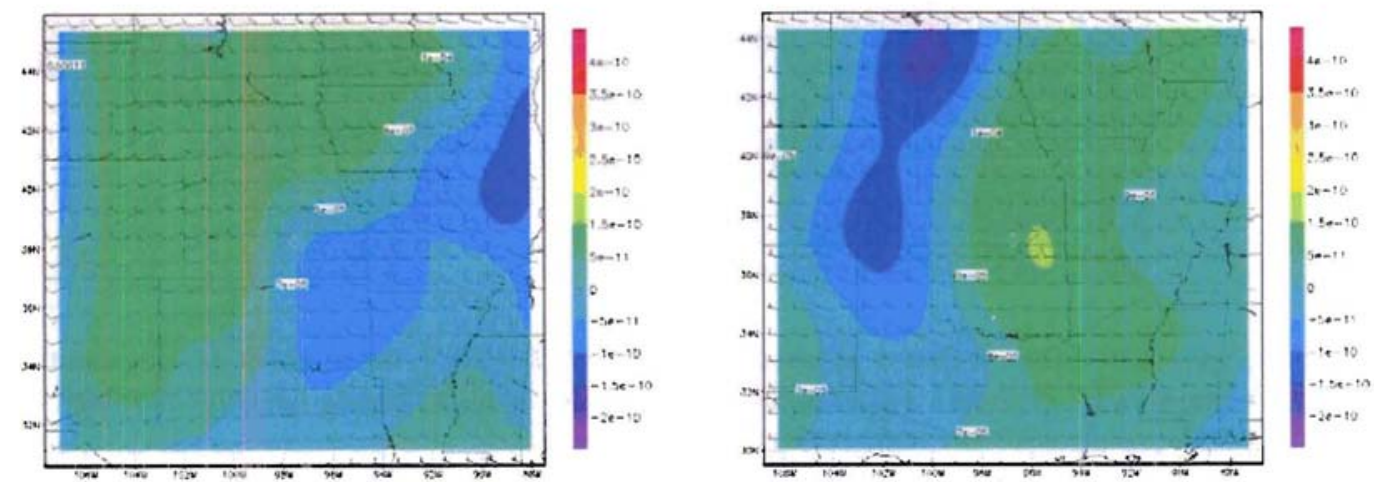

Figure 4.10: Storm-relative composites at $500 \mathrm{mb}$ for $6 \mathrm{~h}$ prior to MCS development (left panel) and widespread convection (right panel). The dashed lines represent absolute vorticity $\left(\mathrm{s}^{-1}\right)$, and the shading represents the vorticity advection $\left(\mathrm{s}^{-2}\right)$. Each full wind barb represents $10 \mathrm{~m} \mathrm{~s}^{-1}$.

A stronger signal is shown in the $700 \mathrm{mb}$ temperature advection field in Fig. 4.11. As Maddox (1983) and others have indicated, low-level warm air advection provides the lifting important for the development and organization of MCSs. Warm air advection at $700 \mathrm{mb}$ appears to be a particularly good indicator, as the maximum coincides with the future location of MCS initiation. In addition, the warm air advection pattern indicates a sharp decrease to the west, but a broad area of high values that extends to the east, which suggests that eastward-moving MCSs will remain in an environment favorable for survival. Widespread unorganized convection also occurs in an area of warm air advection, but the average magnitude is much less than prior to MCS development. The MCS precursor environment again reveals stronger winds in the area of convective organization than for widespread convection. Figure 4.12 provides direct evidence of upward motion by the presence of q-vector convergence in the area of convective 
development. The MCS precursor environment shows stronger q-vector convergence (i.e., upward motion) primarily due to stronger warm air advection.
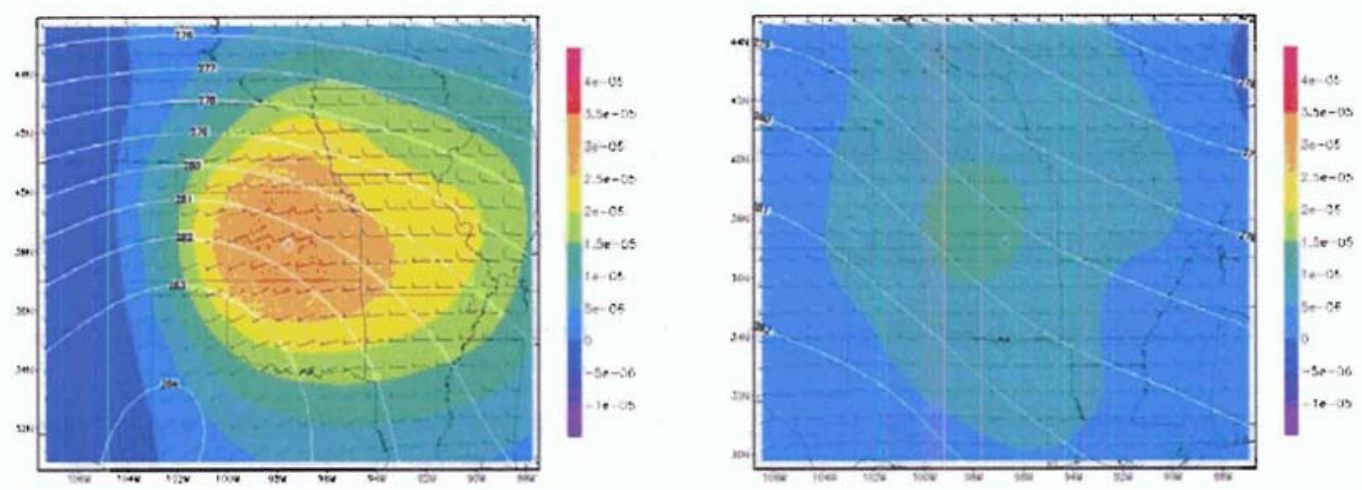

Figure 4.11: Storm-relative composites at $700 \mathrm{mb}$ for $6 \mathrm{~h}$ prior to MCS development (left panel) and widespread convection (right panel). The solid lines are isotherms $(\mathrm{K})$, and the shading represents the temperature advection $\left(\mathrm{K} \mathrm{s}^{-1}\right)$. Each full wind barb represents $10 \mathrm{~m} \mathrm{~s}^{-1}$.
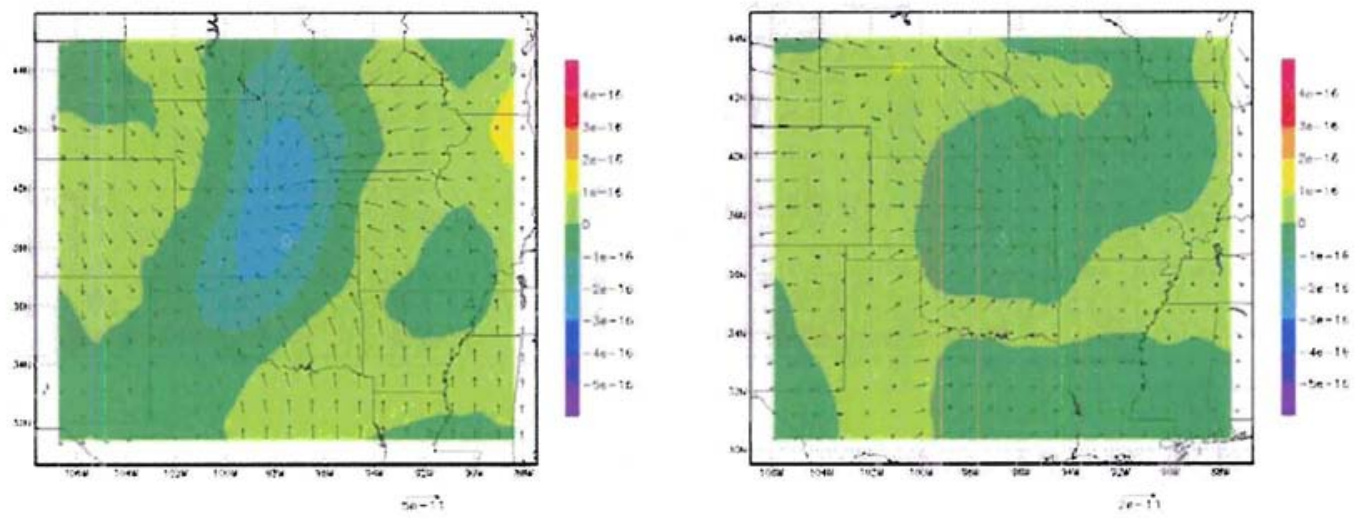

Figure 4.12: Same as Fig. 4.11, except for q-vectors $\left(\mathrm{K} \mathrm{m}^{-1} \mathrm{~s}^{-1}\right)$ and q-vector divergence $\left(\mathrm{K} \mathrm{m}^{-2} \mathrm{~s}^{-1}\right)$ shaded.

At $850 \mathrm{mb}$, a well-defined short-wave trough and its associated convergence are clearly evident prior to MCS development (see Fig. 4.13). Six hours before initiation, the trough and convergence maximum are west of the point of MCS initiation, which suggests that the convergent area at $850 \mathrm{mb}$ may be a preferred location for convective initiation of thunderstorms that move eastward into an area favorable for upscale growth into MCSs. An area of fairly strong convergence is also coincident with the center of the 
widespread convection composite; thus, low-level convergence is also important for convective initiation of thunderstorms that do not organize into a MCS. The biggest difference at this level between the environments can be seen in the wind field. The LLJ, which is often cited as a recurrent feature of the antecedent environment of MCSs (e.g., Maddox 1983; Augustine and Caracena 1994), can be seen feeding into the MCS initiation location. The environment of widespread convection, on the other hand, is absent of the LLJ with much weaker wind speeds throughout the region. Thus, as evidenced by Fig. 4.14, the LLJ is important for the advection of warm, moist air into the region of MCS development.
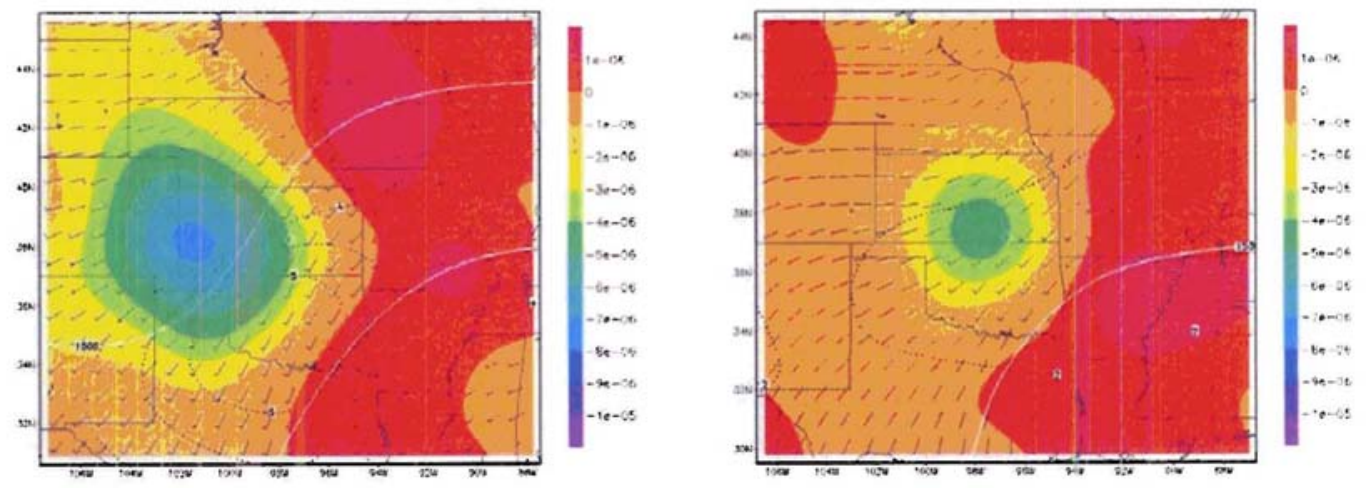

Figure 4.13: Same as Fig. 4.9, except for $850 \mathrm{mb}$.
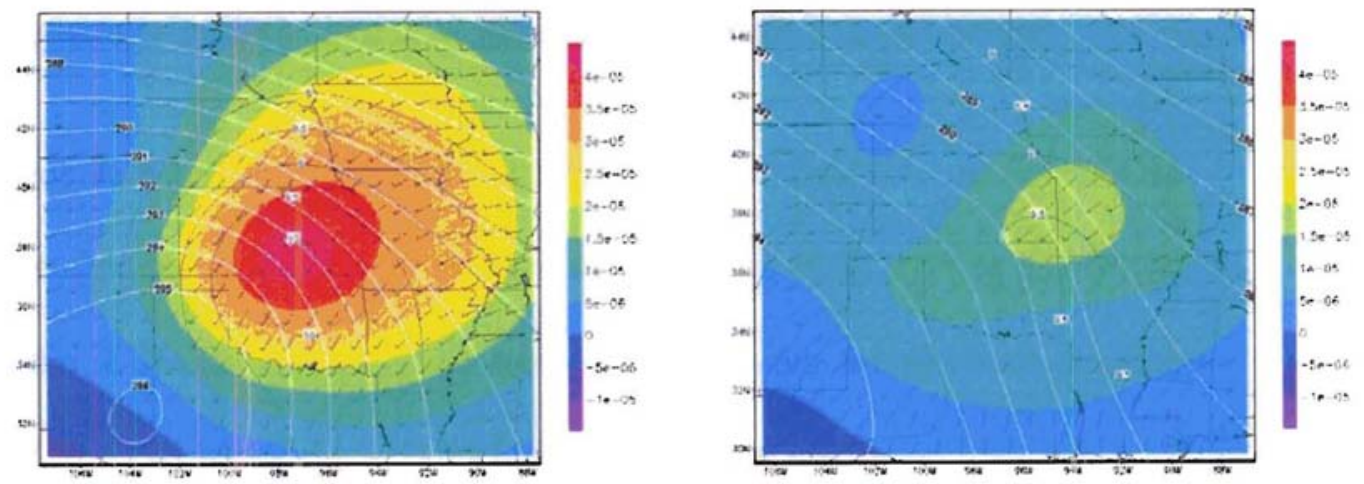

Figure 4.14: Same as Fig. 4.11, except for $850 \mathrm{mb}$. The black, dashed lines represent specific humidity $\left(\mathrm{g} \mathrm{kg}^{-1}\right)$. 
Figure 4.15 shows the composite surface features, which are similar to those at 850 mb. A surface low and trough with their related convergence are located to the west of the MCS initiation location. The pressure and wind fields do not show an obvious eastwest oriented front although a region of enhanced convergence does extend eastward from the convergence maximum. As at $850 \mathrm{mb}$, the surface composite of widespread convection reveals a region of convergence near the center of the storms. The most significant difference at the surface between these environments is the stronger southerly winds that feed into the region of MCS development.
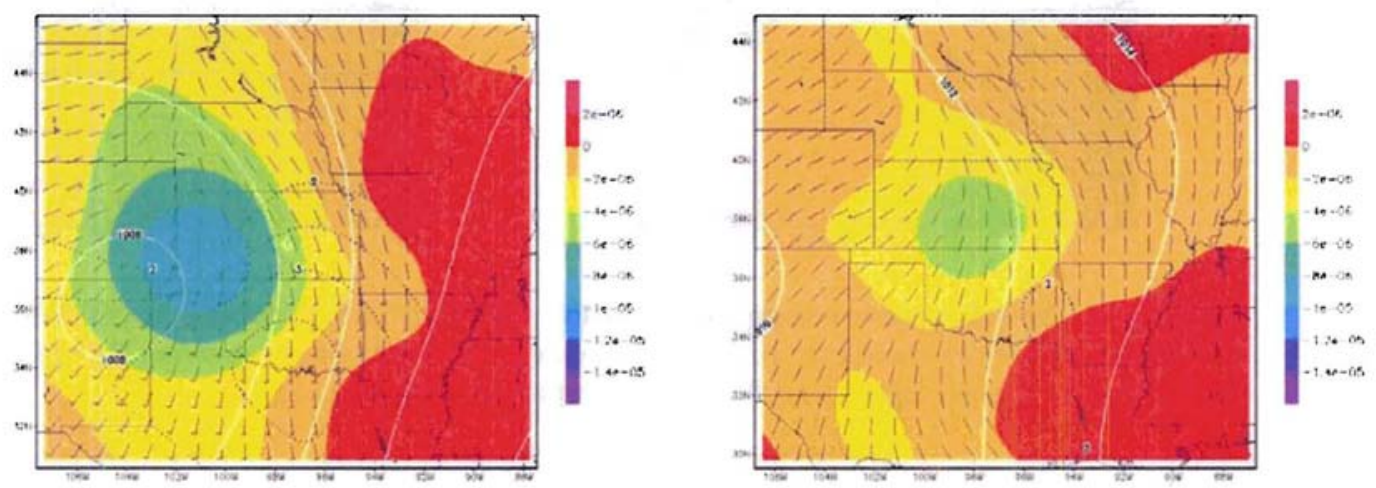

Figure 4.15: Same as Fig. 4.9, except for the surface. The solid lines are now isobars.

The composites for some stability parameters are shown in Fig. 4.16. An unstable pocket of air extends up from the southeast toward the center of each composite. The LI seems to have a better handle on the location of convective development than CAPE, as indicated by the minimum LI value (i.e., most unstable region) extending near the center of the composites. Overall, the MCS precursor environment is more unstable than the environment of widespread convection. The CIN field shows an interesting difference between the environments. The $\mathrm{CNN}$ is actually about twice as large prior to MCS development than for the cases of widespread convection. Perhaps the best explanation is 
that a moderate amount of $\mathrm{CIN}$ helps promote an explosive, simultaneous outbreak of thunderstorms that can improve the chances of convective organization. In some instances if the CIN is too small, as in the cases of widespread convection, then sporadic, random thunderstorms fire up prior to maximum forcing, which is not favorable for storm interaction and convective organization. Of course, if the CIN is too large, convective initiation may be very isolated or may never occur at all.
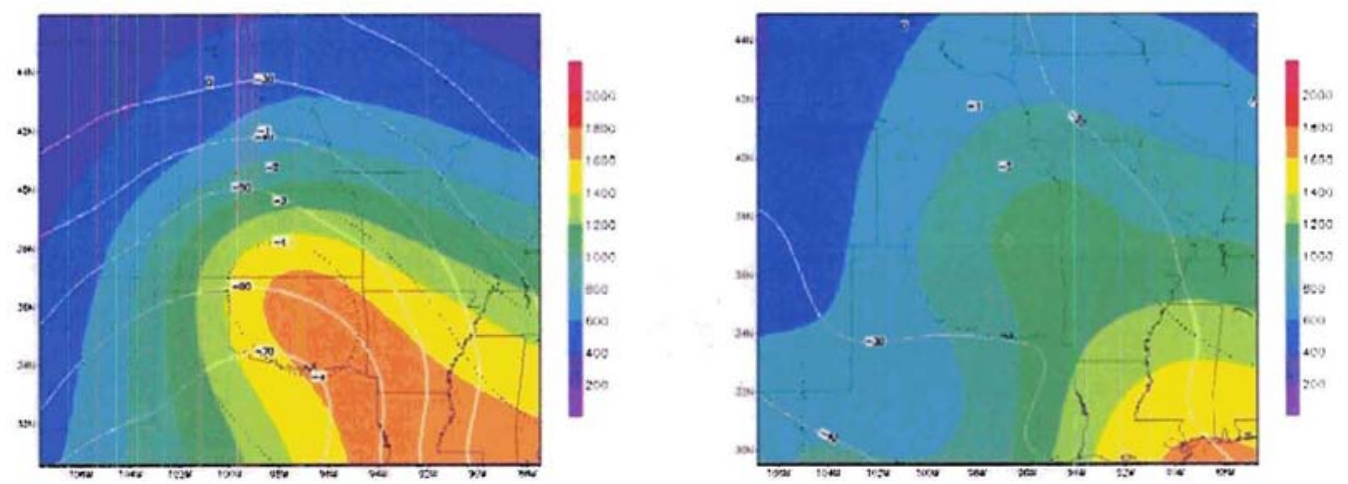

Figure 4.16: Storm-relative composites of CAPE, CIN, and LI for $6 \mathrm{~h}$ prior to MCS development (left panel) and widespread convection (right panel). The solid lines represent CIN ( $\left.\mathrm{J} \mathrm{kg}^{-1}\right)$, the dotted lines represent $L I(K)$ and the shading represents CAPE $\left(\mathrm{J} \mathrm{kg}^{-1}\right)$.

The low-level vertical wind shear of environments that support long-lived organized convection is much greater than that of environments that do not support organized convection. Figure 4.17 shows the $0-3 \mathrm{~km}$ shear and $\mathrm{SRH}$, as well as the $5-10 \mathrm{~km}$ shear. The magnitudes of the $0-3 \mathrm{~km}$ shear vector and SRH have a maximum value very near the location of MCS initiation. The widespread convection composite also reveals a maximum in low-level shear near the center, but the magnitude and outward gradient are much less than for the MCS composite. This suggests that low-level shear is very important for the merging of convection into an organized MCS. The upper-level shear (i.e., $5-10 \mathrm{~km}$ ) is weak for both conditions with near-minimum values at the center of each composite. 

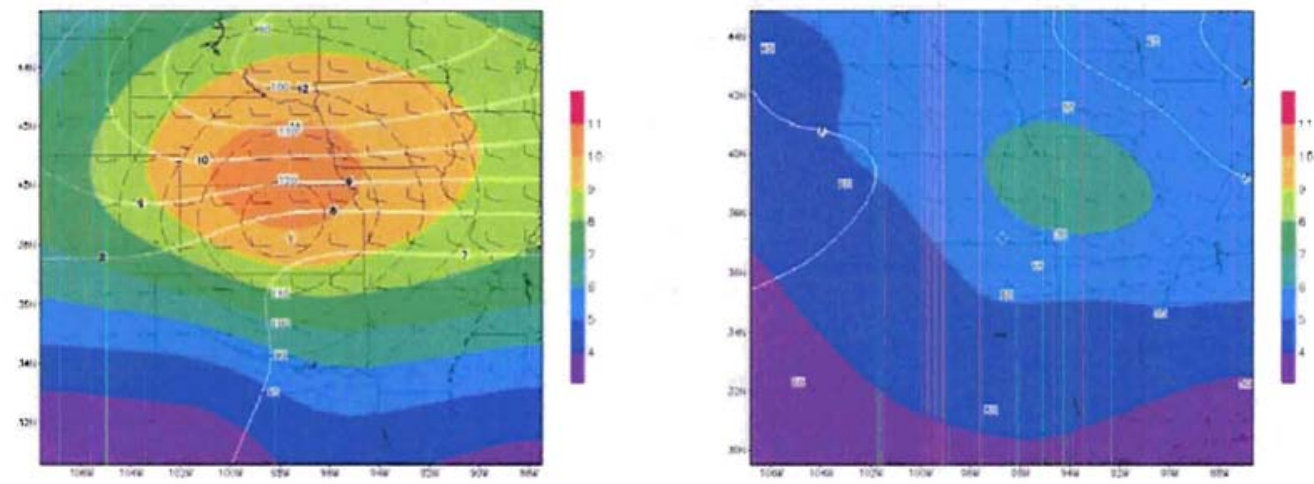

Figure 4.17: Storm-relative composites of 0-3 km shear, $5-10 \mathrm{~km}$ shear, and SRH for $6 \mathrm{~h}$ prior to MCS development (left panel) and widespread convection (right panel). The solid lines represent 5$10 \mathrm{~km}$ shear $\left(\mathrm{m} \mathrm{s}^{-1}\right)$, the dashed lines represent SRH $\left(\mathrm{m}^{2} \mathrm{~s}^{-2}\right)$ and the shading represents $0-3 \mathrm{~km}$ shear $\left(\mathrm{m} \mathrm{s}^{-1}\right)$. The $0-3 \mathrm{~km}$ shear vectors are displayed with a full barb representing $10 \mathrm{~m} \mathrm{~s}^{-1}$.

\subsubsection{Composites of MCS classifications}

An analysis of the MCS-relative composites for the various MCS classifications reveals some differences among the systems. First of all, some notable differences arise among the satellite classifications when looking at the composite fields rather than just point data. Figure 4.18 shows that the magnitude and extent of warm air advection at 700 $\mathrm{mb}$ is larger for the bigger systems (i.e., MCCs and PECSs) than for the smaller, meso- $\beta$ systems (i.e., M $\beta C C S s$ and M $\beta E C S s$ ). Perhaps the size and magnitude of the region of warm air advection at $700 \mathrm{mb}$ could be used to estimate the size of a mature MCS, given that one forms. The magnitude of the low-level shear may also have an influence on the size of quasi-circular systems, as seen in Fig. 4.19. MCCs typically form in regions with much larger 0-3 km shear and helicity than their smaller, shorter-lived counterparts, M $\beta$ CCSs. 

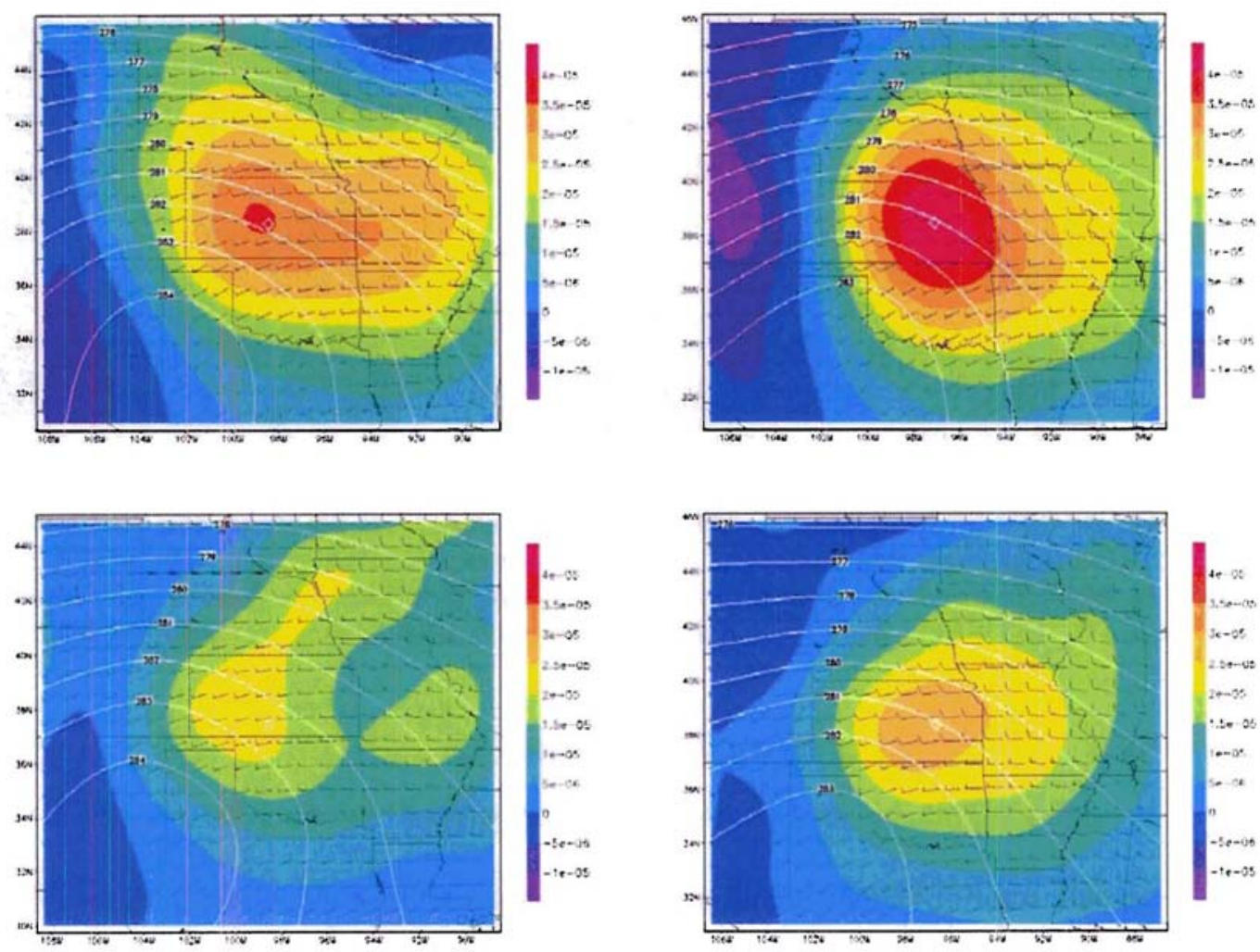

Figure 4.18: MCS-relative composites at $700 \mathrm{mb}$ for MCCs (upper-left panel), PECSs (upper-right panel), M $\beta C C S s$ (lower-left panel), and MBECSs (lower-right panel). The solid lines are isotherms $(K)$, and the shading represents the temperature advection $\left(\mathrm{K} \mathrm{s}^{-1}\right)$. Each full wind barb represents 10 $\mathbf{m ~ s}^{-1}$.
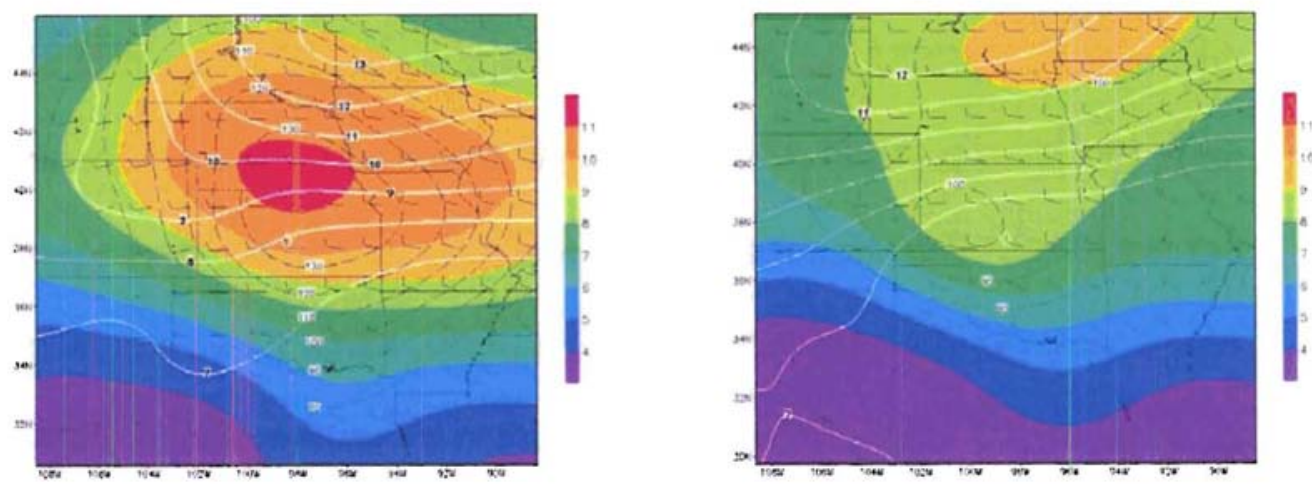

Figure 4.19: Storm-relative composites of 0-3 km shear, 5-10 km shear, and SRH for MCCs (left panel) and M $\mathrm{MCCSs}$ (right panel). The solid lines represent $5-10 \mathrm{~km}$ shear $\left(\mathrm{m} \mathrm{s}^{-1}\right)$, the dashed lines represent $\mathrm{SRH}\left(\mathrm{m}^{2} \mathrm{~s}^{-2}\right)$ and the shading represents $0-3 \mathrm{~km}$ shear $\left(\mathrm{m} \mathrm{s}^{-1}\right)$. The $0-3 \mathrm{~km}$ shear vectors are displayed with a full barb representing $10 \mathrm{~m} \mathrm{~s}^{-1}$. 
Systems classified by the presence of stratiform precipitation also showed differences in their composites. The precursor environment of embedded systems revealed much stronger upper-level forcing than non-embedded systems, as seen in the divergence field in Fig. 4.20. The divergence maximum is very pronounced just upstream of the ridge in the right entrance region of the jet streak. Systems that did not develop in the presence of stratiform precipitation also formed in a region of divergence, but much weaker in magnitude. Figure 4.21 also displays the differences in stability of the precursor environments of embedded and non-embedded systems. Clearly, instability is greater for systems that develop in an area without stratiform precipitation.
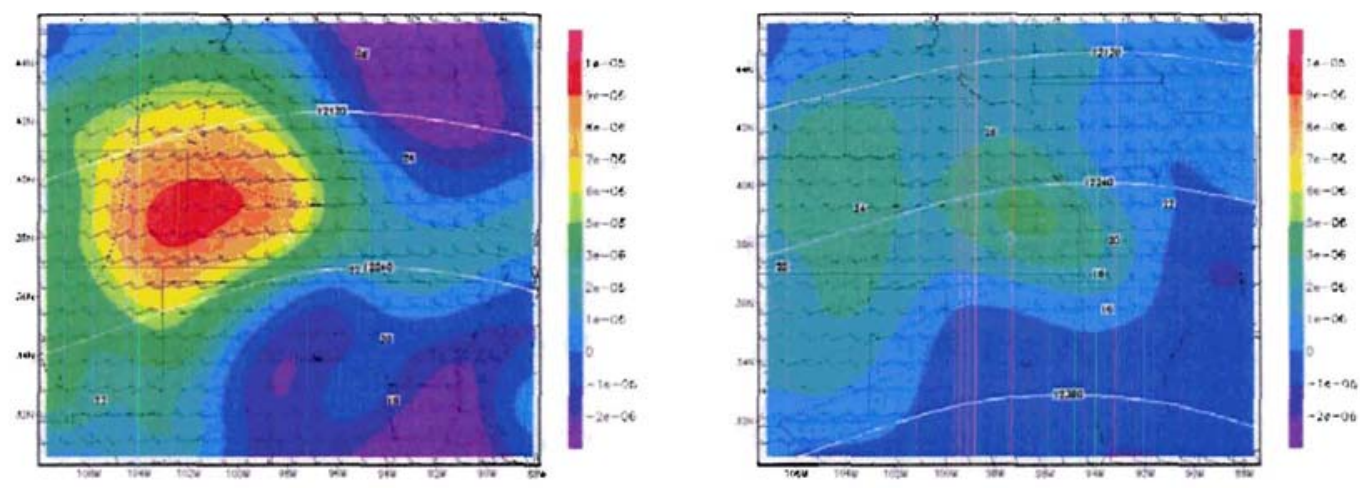

Figure 4.20: MCS-relative composites at $200 \mathrm{mb}$ for embedded (left panel) and non-embedded (right panel) systems. The solid lines represent height contours $(m)$, the dashed lines represent isotachs $(m$ $\mathrm{s}^{-1}$ ), and the shading represents the divergence $\left(\mathrm{s}^{-1}\right)$. Each full wind barb represents $10 \mathrm{~m} \mathrm{~s}^{-1}$. 

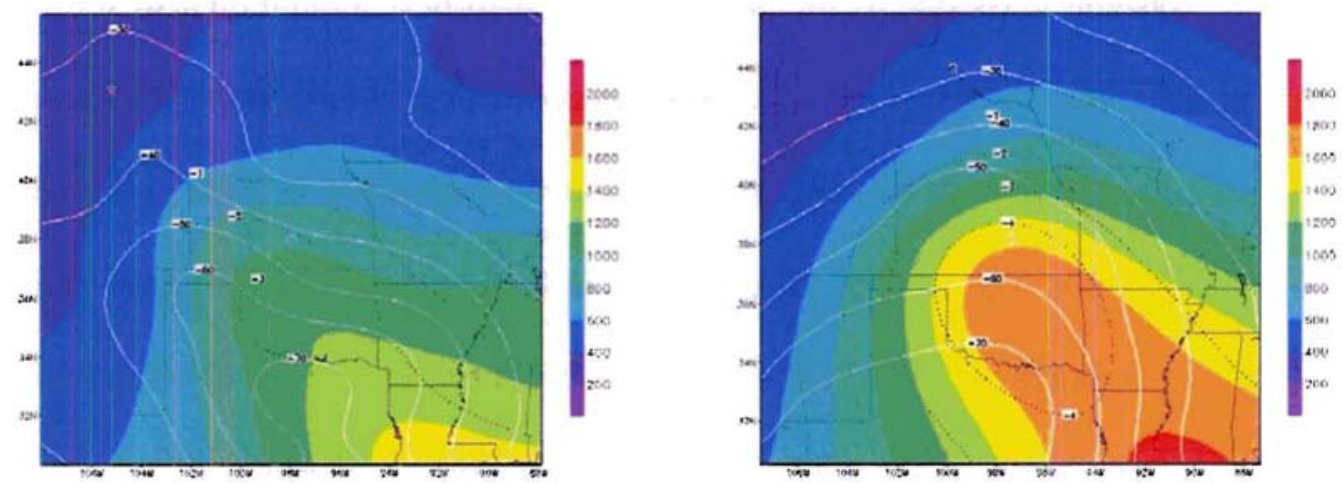

Figure 4.21: MCS-relative composites of CAPE, CIN, and LI for embedded (left panel) and nonembedded (right panel) systems. The solid lines represent $\mathrm{CIN}\left(\mathrm{J} \mathrm{kg}^{-1}\right)$, the dotted lines represent $\mathrm{LI}$ (K) and the shading represents CAPE $\left(\mathrm{J} \mathrm{kg}^{-1}\right)$.

Very significant differences are also evident in the environments of MCSs when classified by the arrangement of convective cells. The $700 \mathrm{mb}$ composites in Fig. 4.22 reveal a maximum of warm air advection centered on the location of MCS initiation for both categories of MCSs. However, the magnitude of warm air advection is much greater for line systems. In addition, the gradient of temperature advection is significantly larger for line systems than areal systems to the west of MCS initiation, going from strong warm air advection to moderate cold air advection over a few hundred kilometers. At $850 \mathrm{mb}$ (see Fig. 4.23), both types of systems develop just east of a region of convergence associated with a well-defined trough. Convergence is slightly stronger for line systems than areal systems, but the most prominent difference is the strength of the winds extending through and east of the region of MCS development. Line systems have a very distinct and significant LLJ stretching through the precursor environment while the winds are much weaker without a clearly defined LLJ prior to the development of areal systems. As expected from the analysis of the point-value data, Fig. 4.24 shows that line systems generally develop in a region of stronger $0-3 \mathrm{~km}$ shear and helicity than areal systems. Although the environments of both systems are obviously favorable for 
supporting MCS development, there are enough significant differences between them to develop an idea of which type of system might form, leading to information about the size, duration, and severity of the MCS.
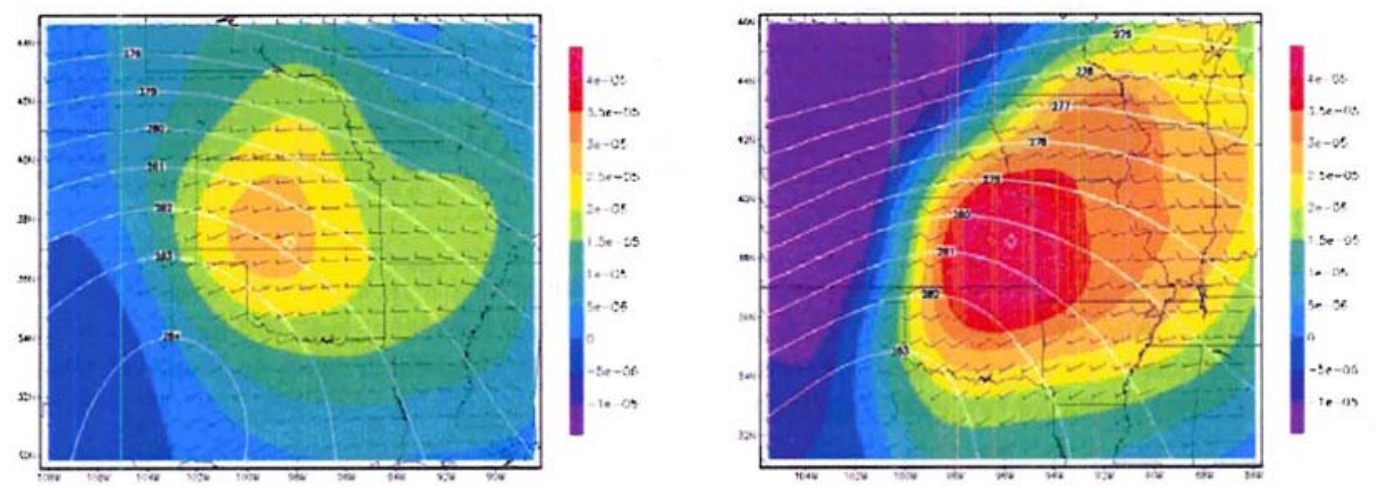

Figure 4.22: MCS-relative composites at $700 \mathrm{mb}$ for areal (left panel) and line (right panel) systems. The solid lines are isotherms $(\mathrm{K})$, and the shading represents the temperature advection $\left(\mathrm{K} \mathrm{s}^{-1}\right)$. Each full wind barb represents $10 \mathrm{~m} \mathrm{~s}^{-1}$.
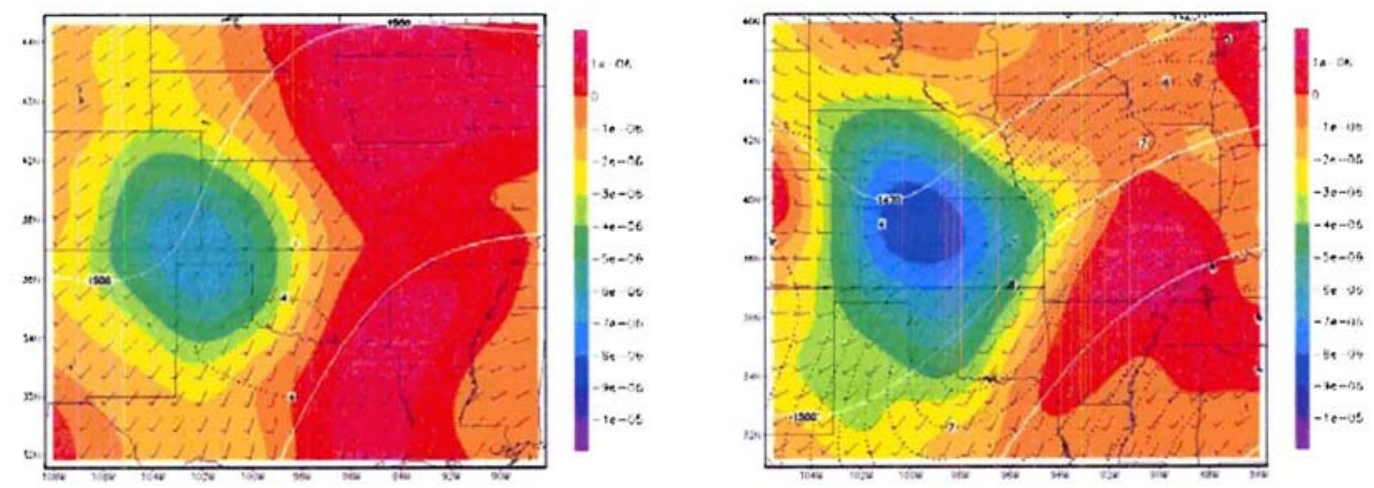

Figure 4.23: MCS-relative composites at $850 \mathrm{mb}$ for areal (left panel) and line (right panel) systems. The solid lines represent height contours $(\mathrm{m})$, the dashed lines represent isotachs $\left(\mathrm{m} \mathrm{s}^{-1}\right)$, and the shading represents the divergence $\left(\mathrm{s}^{-1}\right)$. Each full wind barb represents $10 \mathrm{~m} \mathrm{~s}^{-1}$. 

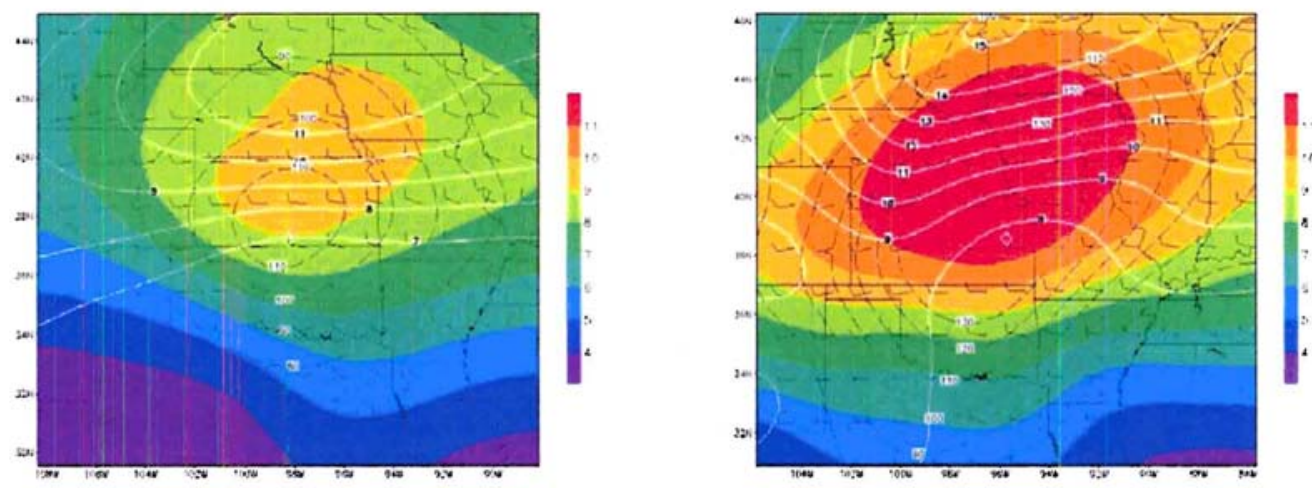

Figure 4.24: Storm-relative composites of 0-3 km shear, 5-10 km shear, and SRH for areal (left panel) and line (right panel) systems. The solid lines represent $5-10 \mathrm{~km}$ shear $\left(\mathrm{m} \mathrm{s}^{-1}\right)$, the dashed lines represent SRH $\left(\mathrm{m}^{2} \mathrm{~s}^{-2}\right)$ and the shading represents $0-3 \mathrm{~km}$ shear $\left(\mathrm{m} \mathrm{s}^{-1}\right)$. The $0-3 \mathrm{~km}$ shear vectors are displayed with a full barb representing $10 \mathrm{~m} \mathrm{~s}^{-1}$.

\subsection{Parameter evaluation}

To further objectively evaluate parameters in their ability to aid in the forecasting of MCSs, a binary forecasting method was employed to quantify their skill. This method involves providing a "yes" or "no" forecast based on a threshold value of a given parameter and recording whether or not the event occurred. As mentioned in Section 3.2, numerous terms can be calculated once the $2 \times 2$ contingency table has been created. Rasmussen and Blanchard (1998) utilized this method to discriminate among the environments of tornadic versus supercell thunderstorms and supercell versus ordinary thunderstorms. A similar approach is used here to discriminate between MCS precursor environments and widespread convection environments, as well as between days with and without MCSs.

The Heidke skill score (HSS), threat score (TS), probability of detection (POD), false alarm rate (FAR), and bias (B) were calculated over a range of values for each parameter. The Heidke Skill Score (HSS) was considered to be the most appropriate measure of 
forecast skill since it gives credit to correct forecasts of non-events, but also takes the false alarm rate into account (Doswell et al. 1990). Therefore, the parameters with the highest HSS are considered the best indicators of distinguishing the MCS precursor environments from other conditions.

Table 4.18 lists the parameters with the ten highest HSSs for distinguishing between MCS precursor environments and environments of widespread convection. For example, SRH had the highest HSS, where a MCS would be forecast if the SRH was greater than $60 \mathrm{~m}^{2} \mathrm{~s}^{-2}$ given that highly concentrated thunderstorms had formed. Otherwise, convection would not be expected to organize into a MCS for lesser values of SRH. Generally, the values listed in the table are as good as or better than the results from the studies of Rasmussen and Blanchard (1998) and Rasmussen (2003), regarding supercell and tornado forecast parameters. The FAR is especially lower in this study as opposed to the tornado studies, where the minimum FAR was generally greater than 0.40 . Shear parameters tend to be the best at distinguishing between MCS environments and environments that support widespread unorganized convection. Five out of the top ten parameters are based on vertical wind shear including the SWEAT index since it is heavily weighted by wind shear. Three of the remaining four parameters are based on stability with MCSs being likely to form in more unstable environments with a moderate cap to convection. 
Table 4.18: Parameters with the highest HSS for distinguishing between MCS precursor environments and environments of widespread convection. The optimal value at the maximum HSS for each parameter is listed, as well as the TS, POD, FAR, and B calculated at that optimal value. An asterisk (*) indicates that a "yes" forecast is given for values less than the optimal value.

\begin{tabular}{lcccccc}
\hline & HSS & Optimal Value & TS & POD & FAR & B \\
\hline SRH & 0.42 & $60 \mathrm{~m}^{2} \mathrm{~s}^{-2}$ & 0.61 & 0.78 & 0.27 & 1.07 \\
$0-3 \mathrm{~km}$ shcar & 0.36 & $8 \mathrm{~m} \mathrm{~s}^{-1}$ & 0.57 & 0.74 & 0.29 & 1.04 \\
CIN $*$ & 0.36 & $-10 \mathrm{~J} \mathrm{~kg}^{-1}$ & 0.55 & 0.69 & 0.27 & 0.95 \\
$0-6 \mathrm{~km}$ shear & 0.35 & $12 \mathrm{~m} \mathrm{~s}^{-1}$ & 0.55 & 0.70 & 0.29 & 0.99 \\
$700 \mathrm{mb}$ temp. adv. & 0.33 & $2 \times 10^{-5} \mathrm{~K} \mathrm{~s}^{-1}$ & 0.50 & 0.61 & 0.26 & 0.81 \\
SWEAT index & 0.33 & 275 & 0.49 & 0.59 & 0.25 & 0.79 \\
$0-1 \mathrm{~km}$ shear & 0.32 & $3 \mathrm{~m} \mathrm{~s}^{-1}$ & 0.52 & 0.67 & 0.29 & 0.93 \\
LI $*$ & 0.27 & $-4 \mathrm{~K}^{2}$ & 0.49 & 0.62 & 0.30 & 0.88 \\
$200 \mathrm{mb}$ temperature $*$ & 0.26 & $219 \mathrm{~K}^{*}$ & 0.46 & 0.58 & 0.30 & 0.82 \\
CAPE & 0.24 & $1400 \mathrm{~J} \mathrm{~kg}^{-1}$ & 0.44 & 0.55 & 0.30 & 0.79 \\
\hline
\end{tabular}

The top parameters in distinguishing between MCS precursor environments and nonMCS environments are shown in Tables 4.19 and 4.20. The data for the non-MCS environments in Table 4.19 were extracted from the domain maximum SWEAT index, which typically is large prior to MCS development. The best parameter in distinguishing MCS from non-MCS environments is MSLPDIF. Please note that this parameter is different from all other parameters listed in the table in that it is taken at fixed locations; thus, it only provides information on whether a MCS will form within the domain, not the exact location of MCS formation. When the surface pressure in Jacksonville, FL, becomes more than $6 \mathrm{mb}$ larger than in El Paso, TX, MCS development over the central U.S. becomes more likely. Three of the other top parameters indicate that MCS development is more likely with moister conditions throughout the depth of the troposphere. Examination of $5-10 \mathrm{~km}$ shear reveals that MCSs are likely to develop in 
weaker upper-level shear, as strong $5-10 \mathrm{~km}$ shear is not favorable for long-lived MCSs (Coniglio et al. 2004).

Table 4.19: Same as Table 4.18, except for distinguishing between MCS precursor environments and days without MCSs based on the location of the maximum SWEAT index.

\begin{tabular}{|c|c|c|c|c|c|c|}
\hline & HSS & Optimal Value & $\mathrm{TS}$ & POD & FAR & $\mathrm{B}$ \\
\hline MSLPDIF & 0.37 & $6 \mathrm{mb}$ & 0.65 & 0.80 & 0.23 & 1.04 \\
\hline Surface spec. humid. & 0.24 & $10 \mathrm{~g} \mathrm{~kg}^{-1}$ & 0.62 & 0.81 & 0.28 & 1.13 \\
\hline $500 \mathrm{mb}$ spec. humid. & 0.24 & $1.3 \mathrm{~g} \mathrm{~kg}^{-1}$ & 0.59 & 0.76 & 0.27 & 1.04 \\
\hline $200 \mathrm{mb}$ temperature $*$ & 0.23 & $221 \mathrm{~K}$ & 0.62 & 0.83 & 0.29 & 1.16 \\
\hline $5-10 \mathrm{~km} \mathrm{shear} *$ & 0.19 & $10 \mathrm{~m} \mathrm{~s}^{-1}$ & 0.46 & 0.55 & 0.25 & 0.74 \\
\hline Precipitable water & 0.17 & $20 \mathrm{~mm}$ & 0.64 & 0.91 & 0.31 & 1.32 \\
\hline CAPE & 0.17 & $1400 \mathrm{~J} \mathrm{~kg}^{-1}$ & 0.46 & 0.55 & 0.26 & 0.74 \\
\hline $850 \mathrm{mb}$ temp. adv. & 0.11 & $-2.5 \mathrm{E}-5 \mathrm{~K} \mathrm{~s}^{-1}$ & 0.60 & 0.85 & 0.33 & 1.26 \\
\hline $850 \mathrm{mb}$ moist. div. * & 0.10 & $2 \mathrm{E}-7 \mathrm{~g} \mathrm{~g}^{-1} \mathrm{~s}^{-1}$ & 0.62 & 0.89 & 0.33 & 1.33 \\
\hline $700 \mathrm{mb}$ q-vector div.* & 0.08 & $3 \mathrm{E}-15 \mathrm{~K} \mathrm{~m}^{-2} \mathrm{~s}^{-1}$ & 0.59 & 0.84 & 0.33 & 1.26 \\
\hline
\end{tabular}

Table 4.20 shows results from another analysis of MCS versus non-MCS environments using data taken from the location of maximum CAPE over land. Strong low-level warm air advection is an important feature of the MCS precursor environment that is not as common in unstable environments that do not produce MCSs. Strong lowlevel shear is another significant feature of MCS environments, as four of the top ten parameters are based on shear. Finally, even though the non-MCS environment is very unstable based on the nature of how the data were collected, the total totals index (TT) is still appreciably larger for the MCS precursor environment. TT takes into account 850 $\mathrm{mb}$ moisture and the lapse rate between $850 \mathrm{mb}$ and $500 \mathrm{mb}$; thereforc, larger lowertropospheric lapse rates must be an important feature of the MCS precursor environment. 
Table 4.20: Same as Table 4.18, except for distinguishing between MCS precursor environments and days without MCSs based on the location of the maximum CAPE.

\begin{tabular}{lcccccc}
\hline & HSS & Optimal Value & TS & POD & FAR & B \\
\hline MSLPDIF & 0.37 & $6 \mathrm{mb}^{2}$ & 0.65 & 0.80 & 0.23 & 1.04 \\
500 mb spec. humid. & 0.29 & $1.1 \mathrm{~g} \mathrm{~kg}^{-1}$ & 0.69 & 0.83 & 0.27 & 1.12 \\
700 mb tcmp. adv. & 0.26 & $0 \mathrm{~K} \mathrm{~s}^{-1}$ & 0.61 & 0.79 & 0.27 & 1.08 \\
SWEAT index & 0.26 & 225 & 0.58 & 0.74 & 0.26 & 1.00 \\
850 mb moist. div. ${ }^{*}$ & 0.25 & $0 \mathrm{~g} \mathrm{~g}^{-1} \mathrm{~s}^{-1}$ & 0.50 & 0.59 & 0.23 & 0.77 \\
Total totals index & 0.22 & 49 & 0.54 & 0.68 & 0.27 & 0.92 \\
$850 \mathrm{mb}$ temp. adv. & 0.21 & $2.5{\mathrm{E}-5 \mathrm{~K} \mathrm{~s}^{-1}}$ & 0.43 & 0.49 & 0.22 & 0.63 \\
0-6 km shear & 0.21 & $8 \mathrm{~m} \mathrm{~s}^{-1}$ & 0.64 & 0.87 & 0.30 & 1.25 \\
0-3 km shear & 0.19 & $8 \mathrm{~m} \mathrm{~s}^{-1}$ & 0.57 & 0.74 & 0.29 & 1.04 \\
SRH & 0.19 & $80 \mathrm{~m}^{2} \mathrm{~s}^{-2}$ & 0.52 & 0.64 & 0.27 & 0.89 \\
\hline
\end{tabular}

In summary, the analysis of the various environmental conditions led to the discovery of significant differences between environments that support organized convective systems and those that do not favor convective organization. First of all, triggering mechanisms were identified for each system:

- Around half of the MCSs developed along stationary or cold fronts.

- Widespread convection was most commonly initiated by troughs, but about onethird of the cases did not have a discernable convective trigger.

- Drylines did not commonly trigger convection that led to MCS development. The systems that did develop along a dryline tended to be smaller with less common merging of convective clusters.

- More than three-fourths of the systems that developed along a cold front were elongated systems (i.e., PECS or M $\beta E C S$ ). 
The composite analysis of these conditions revealed differences from a fixed and storm-relative sense:

- MCS development typically occurs just upstream of a weak mid- and upper-level ridge in a region of modest divergence.

- The low levels exhibited a stronger signal than the upper levels prior to MCS development. Moist, unstable conditions exist in an area of convergence, strong winds, and warm air advection at low levels.

- The MCS precursor environment revealed a much larger east-west surface pressure gradient across the Gulf Coast as opposed to environments in which MCSs do not develop.

- The maxima of low-level temperature advection and wind shear in the MCSrelative composites showed excellent agreement with the location of MCS initiation and much larger values than the widespread convection composites.

A statistical analysis of point-value data demonstrated the usefulness of various parameters in forecasting MCSs:

- Embedded systems generally developed in regions of larger mid- and upper-level PV and weaker instability than non-embedded systems.

- Line systems typically formed in environments with stronger winds, vertical wind shear, and low-level warm air advection than areal systems.

- MSLPDIF performed well in identifying whether or not a MCS would form on a given day over the central U.S.

- Mid-level PV was larger on average for unorganized convection than for convection that organized into a MCS. 
- Low-level temperature advection, low-level vertical wind shear, and instability were the best parameters in distinguishing between environments of widespread convection and MCSs. 


\section{Chapter 5}

\section{MCS Index}

The previous chapter provided detailed information about the environments that are both favorable and unfavorable for MCS development. The results portrayed in that chapter offer tremendous insight into environmental features that help determine whether convection will evolve into a MCS. This information, in itself, is valuable to forecasters in predicting MCSs. However, these results would be even more useful to forecasters if they could be directly applied to MCS forecasting through an index. Like other weather indices, a MCS index would just be a tool to help forecasters in making difficult decisions about the possible development of MCSs. Given the difficulty of forecasting convective initiation, a MCS index would not be expected to accurately forecast every MCS and may overpredict MCSs in some situations. The MCS index introduced in this chapter simply indicates areas that are favorable for MCS development and sustenance given that a group of highly concentrated thunderstorms have formed.

\subsection{Definition of the MCS index}

The analysis of environmental conditions discussed earlier focused on the conditions six hours prior to MCS initiation. Consequently, the MCS index defined here inherently provides a forecast out to six hours for MCS development. Of course, given that an operational forecast model does well in forecasting the parameters found in the index, 
then MCS forecasts could be made for an entire model run. It is worth noting that since the MCS index indicates areas favorable for the development of MCSs, it also indicates areas that are favorable for sustaining MCSs.

The MCS index was formulated to be as simple as possible, yet comprehensive enough to work in a varicty of situations. A few key parameters had to be included, such as low-level moisture, instability, and forcing, to ensure that convection was likely to develop and sustain itself over time. The MCS index is defined below:

$$
M C S \text { Index }=\frac{-(L I+4.4)}{3.3}+\frac{\left(0-3 \mathrm{~km} \text { shear }-11.5 \mathrm{~ms}^{-1}\right)}{5 \mathrm{~ms}^{-1}}+\frac{\left(700 \mathrm{mb} T A-4.5 \times 10^{-5} \mathrm{Ks}^{-1}\right)}{7.3 \times 10^{-5} K \mathrm{~K}^{-1}}
$$

where the MCS index is defined only if the following conditions are met:

- MSLPDIF $>0 \mathrm{mb}$,

- surface specific humidity $>8 \mathrm{~g} \mathrm{~kg}^{-1}$,

- $T T>44$,

- $850 m b v$-wind $>-1 \mathrm{~ms}^{-1}$, and

- $5-10 \mathrm{~km}$ shear $<20 \mathrm{~m} \mathrm{~s}^{-1}$.

Equation 5.1: MCS index equation and conditional terms.

The following subsections describe the terms that comprise the MCS index equation and explain why they were included in the index.

\subsubsection{Conditional terms}

The conditional terms listed in Eq. 5.1 are necessary to make certain that the MCS index does not indicate that a region is favorable for MCS development when convective development is unlikely. For example, an environment can have very strong low-level shear without being unstable. Therefore, these conditional terms are used to define areas where convection is at least possible and sustainable. These terms were specifically derived from the analysis of the MCS versus non-MCS environments discussed in Chapter 4. All of the conditional values for these terms, except for MSLPDIF, are simply 
the $10^{\text {th }}$ percentile values of the MCS point-value data. In this way, nearly all environments that support MCSs are considered, meanwhile removing a significant portion of unfavorable environments.

\section{(a) MSLPDIF}

This parameter is a very good starting point when determining whether or not a MCS will form over the central U.S. on a given day. MSLPDIF is statistically much larger on average prior to MCS development than on days when MCSs do not form and had the largest HSS for distinguishing MCS from non-MCS environments. A positive MSLPDIF means that higher surface pressure exists on the southeast U.S. coast than in the lee of the southern Rocky Mountains in part due to the Bermuda high being west of its mean position (Augustine and Howard 1991) (see Fig. 4.2). This east-west pressure gradient along the Gulf Coast leads to the advection of warm, moist air by southeasterly to southerly winds over the Southern and Central Plains, which is favorable for MCS development.

\section{(b) Surface specific humidity}

Moist conditions near the surface are also important for the development of thunderstorms. Specific humidity at the surface was significantly larger on average prior to MCS development than on days without MCSs based on data taken from the maximum SWEAT inclex. This resulted in a large HSS for these conditions (see Table 4.19). For a given temperature profile, an increase in surface moisture results in the destabilization of the atmosphere, increasing the chance of thunderstorm development. This parameter is included to prevent insignificantly-large values of the MCS index in moisture-deprived areas with very large shear and/or temperature advection. 
(c) Total totals index

The MCS precursor environment must be unstable enough to support long-lived deep convection. TT is a stability parameter based on the specific humidity at $850 \mathrm{mb}$ and the lapse rate between $850 \mathrm{mb}$ and $500 \mathrm{mb}$. TT distinguishes fairly well between MCS precursor environments and non-MCS environments compared to CAPE, as shown by its high HSS (see Table 4.20). This parameter is particularly useful in preventing maritime locations with large surface-based instability, but drier $850 \mathrm{mb}$ conditions and weaker $850 \mathrm{mb}$ - $500 \mathrm{mb}$ lapse rates, from having a defined MCS index.

\section{(d) $850 \mathrm{mb}$ meridional wind}

The recurrent nature of the southerly LLJ in MCS precursor environments has been well-documented. In addition, this study has shown that southerly winds were present at $850 \mathrm{mb}$ six hours prior to the initiation for more than three-fourths of the MCSs. Fixedpoint and MCS-relative composites at $850 \mathrm{mb}$ have also revealed strong winds with a southerly component in the region of MCS development. Therefore, this parameter was added to ensure that the MCS index would not be defined in regions with strong northerly-component winds, which generally would result in unfavorable moisture and temperature advection.

\section{(e) $5-10 \mathrm{~km}$ shear}

Coniglio et al. (2004) showed through a modeling study of MCSs that very large upper-level shear is not conducive to large vertical parcel displacements, thus being unfavorable for supporting long-lived MCSs. Indeed, the MCS precursor environments 
in this study typically revealed intermediate values $\left(\sim 10 \mathrm{~m} \mathrm{~s}^{-1}\right)$ of $5-10 \mathrm{~km}$ shear, as opposed to larger values in the non-MCS environments. The MCS-relative composites also reveal a preference for systems to develop in regions of weaker upper-level shear; thus, this parameter guarantees that the index will not be defined where the upper-level shear is too strong to support long-lived organized convection.

\subsubsection{Equation terms}

While the conditional terms delineate where the MCS index is defined, the terms in Eq. 5.1 determine the value of the MCS index. Essentially, anywhere the MCS index is defined, convection is possible; therefore, the value the index takes should reflect the likelihood of convection to develop into a MCS. Consequently, the parameters selected to be a numerical part of the MCS index were chosen based on the analysis of the MCS precursor environment versus the environment of widespread convection, as presented in Chapter 4. These parameters are expected to be a maximum at or near the location of MCS initiation in order to maximize the value of the MCS index. In Eq. 5.1, the MCS sample mean of each parameter is subtracted from its value at a given location and divided by the sample standard deviation, resulting in a unitless index. In this way, the MCS index is a reflection of the number of standard deviations the environment varies from the average MCS precursor environment.

\section{(a) Lifted index}

A stability parameter certainly needs to be included in the MCS index to accurately predict the environments that are capable of generating and supporting MCSs. Basically, there were two logical choices of stability parameters based on the analysis: CAPE and LI. The LI was chosen because it has a slightly higher HSS than CAPE in distinguishing 
MCS environments from unorganized widespread convection (see Table 4.18). The MCS-relative composites revealed that the location of MCS initiation is better encompassed by the minimum value of the LI than the maximum value of CAPE (see Fig. 4.16). In addition, the LI provides a continuous range of values even as the atmosphere becomes more stable unlike CAPE. Finally, the LI gencrated by the Eta model is actually the best (i.e., most unstable) LI of four layers within $180 \mathrm{mb}$ of the surface. Thus, the LI formulated in this manner performs better when there is an elevated layer of more unstable air, which is common for nocturnal systems like MCSs.

\section{(b) $700 \mathrm{mb}$ temperature advection}

Much like the LLJ, warm air advection at $700 \mathrm{mb}$ has been fairly well documented as a recurrent feature of the MCS precursor environment. As mentioned previously, it signals an area of ambient rising motion, which is beneficial for thunderstorm generation and organization. The results from this study do indeed show that MCSs develop in areas of significantly stronger warm air advection at $700 \mathrm{mb}$ than for thunderstorms that do not evolve into a MCS (see Table 4.18). In addition, the maximum in the composite $700 \mathrm{mb}$ temperature advection field is perfectly collocated with the location of MCS initiation (see Fig. 4.11). The $850 \mathrm{mb}$ temperature composite also shows a maximum in warm air advection coincident with the location of MCS initiation; however, fewer MCSs overall have warm air advection at $850 \mathrm{mb}$ prior to their development. Additionally, warm air advection at $850 \mathrm{mb}$ is not statistically as good at distinguishing MCS environments from widespread convection as temperature advection at $700 \mathrm{mb}$. Therefore, the $700 \mathrm{mb}$ level was chosen to diagnose temperature advection due to better overall results for a variety of situations. 


\section{(c) $0-3 \mathrm{~km}$ shear}

Examination of Table 4.18 reveals that lower-tropospheric shear over many depths is very good at determining whether convection will organize into a MCS. Evidently, lowlevel shear is not only important for promoting long-lived convective systems through the enhanced lifting that results at the leading edge of the storm's outflow (Rotunno et al. 1988; Weisman 1992; Weisman and Rotunno 2004), but also for promoting convective organization through the merger of convective cells along the leading edge of the cold pool where there is enhanced uniform lifting. As compared to other parameters mentioned previously, shear has been relatively overlooked in previous studies of the precursor environments of MCSs. The results strongly suggest that low-level shear should be included in the MCS index, so the only issue resides in deciding which shear parameter to use since each of them would likely work reasonably well. One choice would be to use SRH, which has the largest HSS; however, it is not directly obvious why SRH would be important to MCS development. Traditionally, SRH has been used to identify environments favorable for supercell formation and determining their rotational characteristics (Davies-Jones 1984; Weisman and Rotunno 2000). Apparently, large values of SRH prịor to MCS development indicate a combination of two factors: a large magnitude of the ambient shear vector, which enhances the lifting at the leading edge of the cold pool to aid convective development and sustenance, and veering winds with height, which suggest warm air advection through this layer for the geostrophic component of flow. Due to the complex nature of separating these effects, it is preferable to include separate terms for temperature advection and shear in the MCS index. In addition, abstaining from the use of SRH eliminates the ambiguity that arises from having 
to estimate storm motion, which certainly is desirable when forecasting storms that are yet to form.

The $0-1 \mathrm{~km}, 0-3 \mathrm{~km}$, and 0-6 km shear composites all look very similar with maxima very near the location of MCS initiation, and the shear magnitude for each depth is greater for the MCS precursor environment than for widespread convection at the $99 \%$ confidence level. The $0-3 \mathrm{~km}$ shear has only a slightly larger HSS than shear over the other depths, but was ultimately chosen to be included in the MCS index. Inclusion of shear over the lowest $3 \mathrm{~km}$ is more desirable than over just the lowest $1 \mathrm{~km}$, especially for instances of elevated convection. The $0-3 \mathrm{~km}$ shear is more preferable than the $0-6$ $\mathrm{km}$ shear due to its more intimate relationship to the nocturnal LLJ. Accordingly, the 0-3 $\mathrm{km}$ shear shows a strong diurnal cycle with a nighttime (i.e., 0600 UTC) maximum (see Fig. 5.1) while the 0-6 km shear shows a weaker diurnal cycle with an evening (i.e., 0000 UTC) maximum (see Fig. 5.2). Additionally, the diurnal cycle of $0-3 \mathrm{~km}$ shear reveals a clear eastward and southward extension of relatively large shear values into the night. These diumal characteristics of the $0-3 \mathrm{~km}$ shear resemble the diurnal behavior of MCSs, hinting at the importance of shear through this layer in supporting long-lived convective systems. 

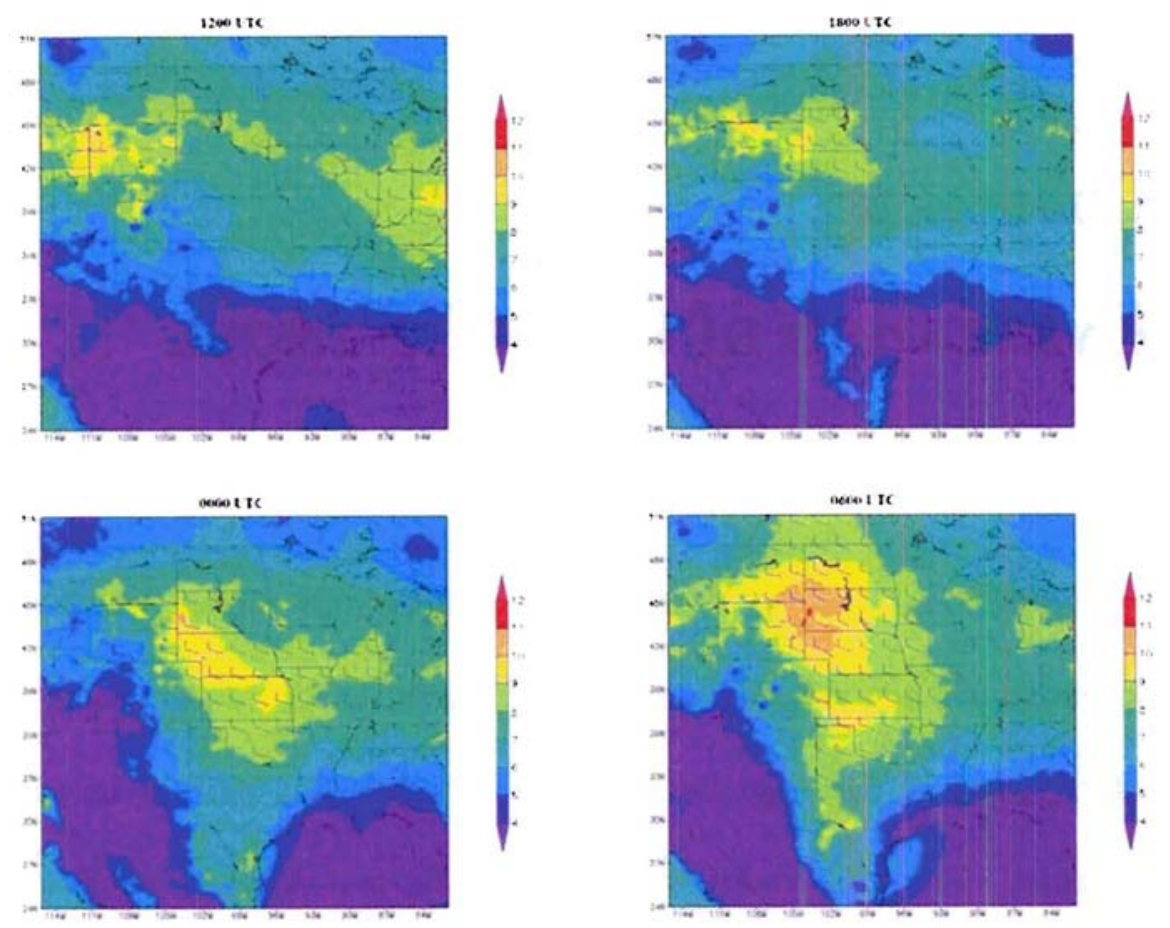

Figure 5.1: Diurnal cycle of 0-3 km shear (shaded) as shown by fixed-point composites during initial study period at 6-hour intervals throughout the day. The shear vectors are displayed with a full barb representing $10 \mathrm{~m} \mathrm{~s}^{-1}$.
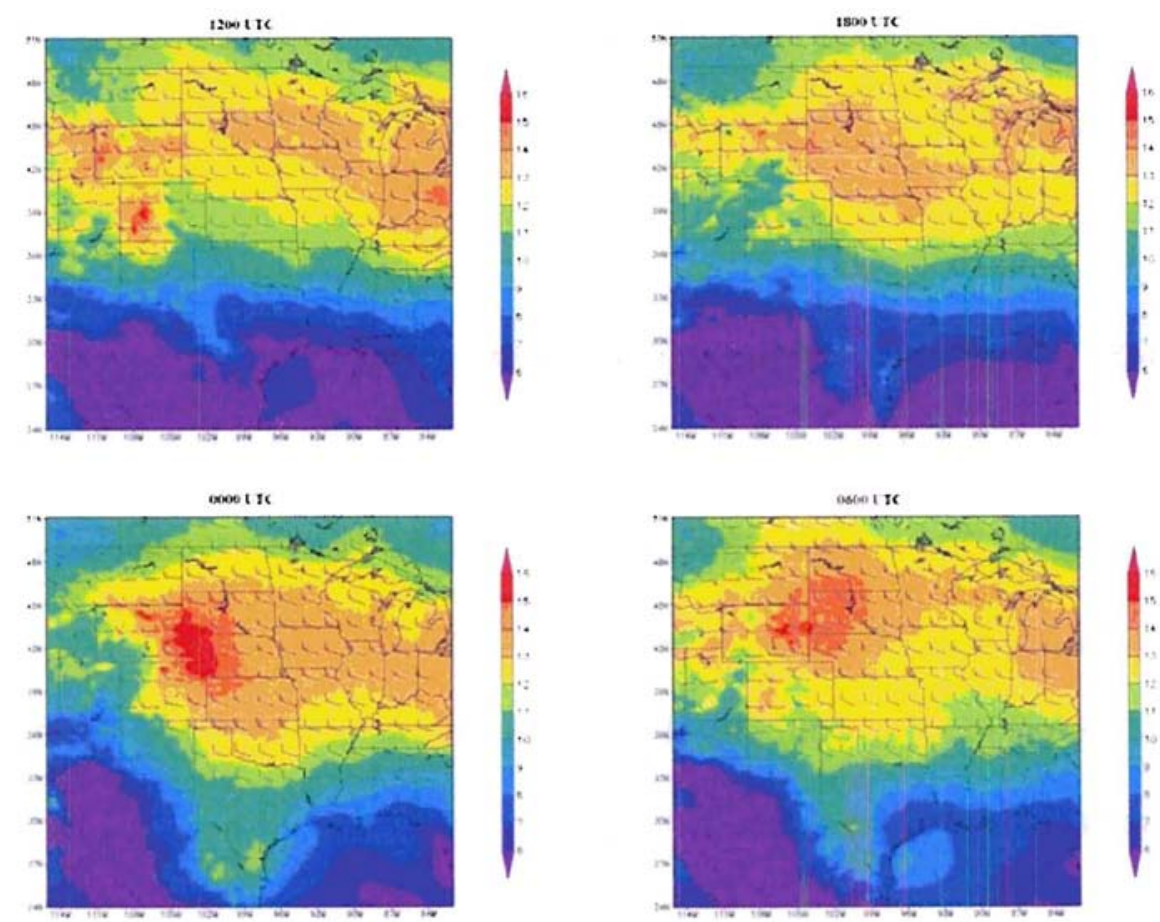

Figure 5.2: Same as Fig. 5.1, except for 0-6 km shear. 


\section{Chapter 6}

\section{Evaluation of the MCS index}

Even though the MCS index was carefully formulated based on results from the observational analysis of hundreds of MCSs, it would be useful to demonstrate the effectiveness of the index by assessing its forecasting performance and other important attributes. The MCS index was evaluated for two different periods: the original study period from which the index was derived and an independent convective period during BAMEX. Several different methods were employed to examine the forecast skill and behavior of the MCS index, including binary forecasting and compositing techniques. In addition, a discussion of forecasting the type of MCS is provided along with examples of the utility of the MCS index.

\subsection{Evaluation during original study period}

As a reminder, the original study period covers April through August of 1996, 1997, and 1998. The sample includes 387 MCSs, 300 cases of widespread convection, and 209 instances when MCSs were not present over the central U.S. The forecast skill of the MCS index is investigated along with diurnal, seasonal, and episodic cycles that are characteristic of the index. 


\subsubsection{Binary forecasting technique}

The binary forecasting technique is applied exactly as before when evaluating the skill of individual parameters in Section 4.5, except now the MCS index is the parameter being evaluated in forecasting MCSs. Table 6.1 reveals the skill of the MCS index in differentiating among the different conditions. The MCS index performs very well in distinguishing between MCS precursor environments and environments of unorganized widespread convection. Thus, given that a group of highly concentrated thunderstorms develop in an area with a MCS index greater than -1.5 , a forecaster could predict the development of a MCS with much confidence. Notice that the HSS is greater for the MCS index than for any of the individual parameters examined previously (cf. Table 4.18). Therefore, combining the best individual predictors into an index does improve the overall forecasting skill.

The MCS index does not do as well in determining MCS from non-MCS environments without having knowledge of whether thunderstorms develop (see Table 6.1). The HSS for the MCS versus no-MCS condition based on the location of maximum CAPE is, however, larger for the MCS index than for the other comparable individual parameters examined (cf. Table 4.20). Therefore, the MCS index does provide some skill in distinguishing MCS environments from high CAPE environments that are unlikely to generate MCSs. Similarly, the HSS is relatively high for the MCS index for the MCS vs. no-MCS condition based on the maximum SWEAT index compared to individual parameters (cf. Table 4.19). Not surprisingly, the HSS is not as high in this instance since some of the parameters included in the MCS index are a part of the SWEAT index (e.g., TT and vertical wind shear). Remember that the analysis of the MCS versus nonMCS environments was used to generate the conditional terms of the MCS index. Thus, 
it is encouraging that the optimal value of the MCS index for these conditions is simply just having a defined value of the index. Therefore, the conditional terms of the MCS index perform the job they were intended to do by excluding large regions that are unlikely to produce MCSs.

Of course, other more stringent tests can be performed to further assess the skill of the MCS index in forecasting MCSs. For example, Table 6.1 shows the results of the MCS index for the MCS precursor environment versus the domain maximum of the index on days without MCSs. Although the MCS index still shows skill in forecasting MCSs (i.e., HSS $>0$ ), the maximum HSS for this scenario is fairly low compared to other results presented previously. This indicates that forecaster intervention is still important in using the MCS index due to the complexity of convective initiation.

Table 6.1: Skill of MCS index for distinguishing between MCS precursor environments and other environments. The optimal value at the maximum HSS for each condition is listed, as well as the TS, POD, FAR, and B calculated at that optimal value.

\begin{tabular}{lcccccc}
\hline & HSS & $\begin{array}{c}\text { Optimal } \\
\text { Value }\end{array}$ & TS & POD & FAR & B \\
\hline MCS vs. widespread convection & 0.49 & -1.5 & 0.66 & 0.85 & 0.25 & 1.14 \\
MCS vs. No MCS (Max. CAPE) & 0.31 & defined & 0.57 & 0.69 & 0.23 & 0.90 \\
MCS vs. No MCS (Max. SWEAT) & 0.22 & defined & 0.55 & 0.70 & 0.27 & 0.96 \\
MCS vs. No MCS (Domain Max.) & 0.14 & -1.5 & 0.63 & 0.91 & 0.32 & 1.34 \\
\hline
\end{tabular}

Clearly, the greatest utility of the MCS index is determining the likelihood that a MCS will develop given that a highly-concentrated group of thunderstorms are present. Therefore, the MCS index signifies areas that are favorable or unfavorable for MCS development contingent upon the initiation of widespread convection. Based on the results presented in Table 6.1 and the nature in which the MCS index is calculated, guidelines for the likelihood of MCS development are presented in Table 6.2. Since the 
MCS index is calculated based on the number of standard deviations that a given parameter is above or below the mean, the contribution from each term indicates how similar the conditions are to an average MCS precursor environment. Thus, values of the index close to zero represent typical conditions prior to MCS development.

Table 6.2: Guidelines for the likelihood of MCS development based on the MCS index.

$\begin{array}{cc}\text { MCS index }<-1.5 \text { or undefined } & \text { unfavorable } \\ -1.5<\text { MCS index }<0 & \text { marginal } \\ 0<\text { MCS index }<3 & \text { favorable } \\ \text { MCS index }>3 & \text { very favorable }\end{array}$

\subsubsection{Diurnal and seasonal cycles}

MCSs have a distinct diurnal cycle, as seen in Fig. 6.1. MCSs typically form in the late afternoon and evening hours, reach a maximum size during the night, and dissipate in the morning hours (Maddox 1980; Jirak et al. 2003). This unique nocturnal behavior of MCSs must also then be present in an index that attempts to predict these systems. To show the diurnal cycle of the MCS index presented in this thesis, fixed-point composites of the index were created for the entire study period at three-hour intervals. Figure 6.2 shows the diurnal cycle of the MCS index starting when the index is at a minimum at 1200 UTC (i.e., early morning). The magnitude of the MCS index increases steadily throughout the day to the east of the Rocky Mountains until it reaches a maximum at 0300 UTC (i.e., late evening) and then decreases into the morning hours. Thus, the diurnal cycle of the MCS index closely resembles the diurnal cycle of MCSs, which indicates that the index can at least replicate the daily cycle. 


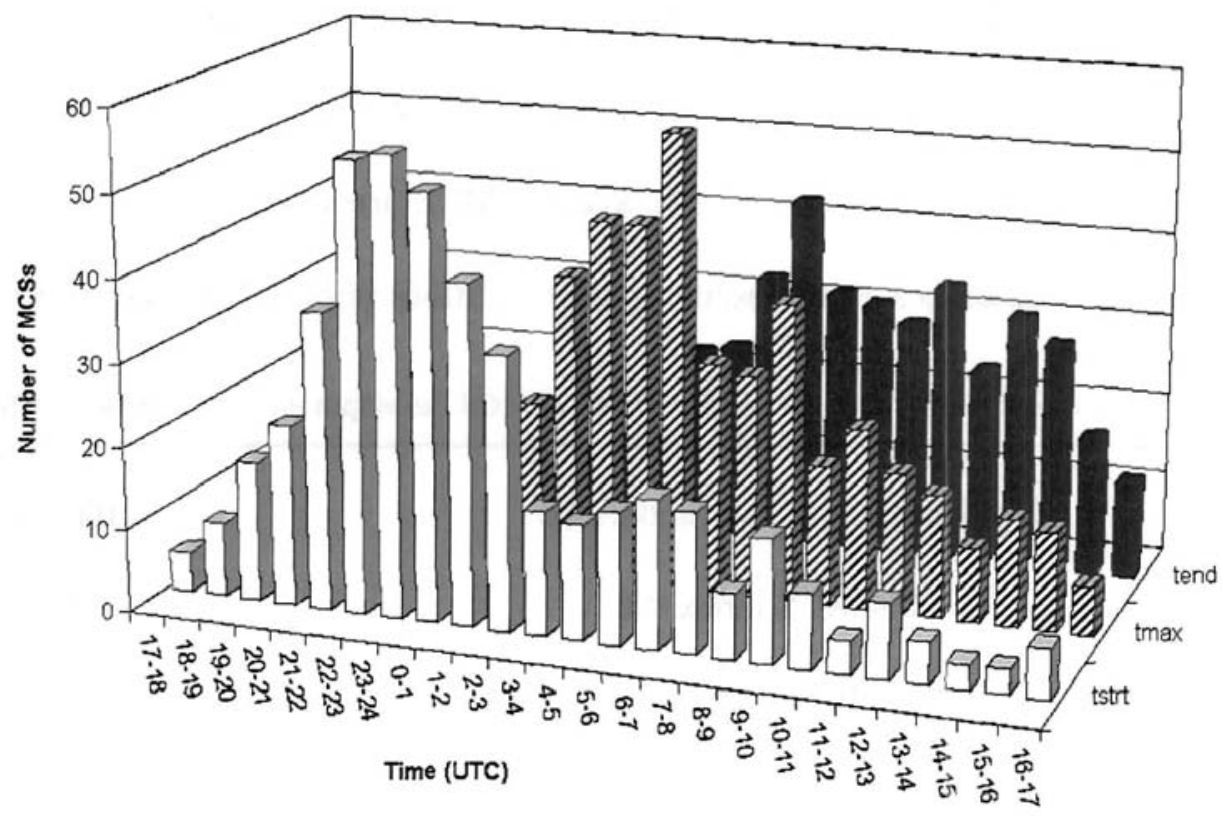

Figure 6.1: Distribution of MCSs from the Jirak et al. (2003) study as a function of initiation time (tstrt), time of maximum extent (tmax), and termination time (tend). [From Jirak et al. 2003]

The MCS index was created by looking at data six hours prior to MCS initiation; therefore, the index inherently provides a forecast out six hours into the future. Thus, the MCS index at 0300 UTC provides the likelihood of MCS development from 0300 UTC to 0900 UTC. This time range nicely encompasses when the majority of systems reach their maximum size, as seen in Fig. 6.1. Therefore, it is fairly safe to say that the MCS index not only indicates areas that are favorable for MCS development, but also areas that are favorable for sustaining systems that have already formed. The diurnal cycle of the MCS index suggests that the most active period of MCS development and sustenance occurs from 2100 UTC through 1200 UTC. Indeed, observations of MCS lifecycles indicate that this is the most active period while the time range from $1200 \mathrm{UTC}$ through $2100 \mathrm{UTC}$ is a relatively inactive period of MCS development and growth primarily dominated by the dissipation of systems. 

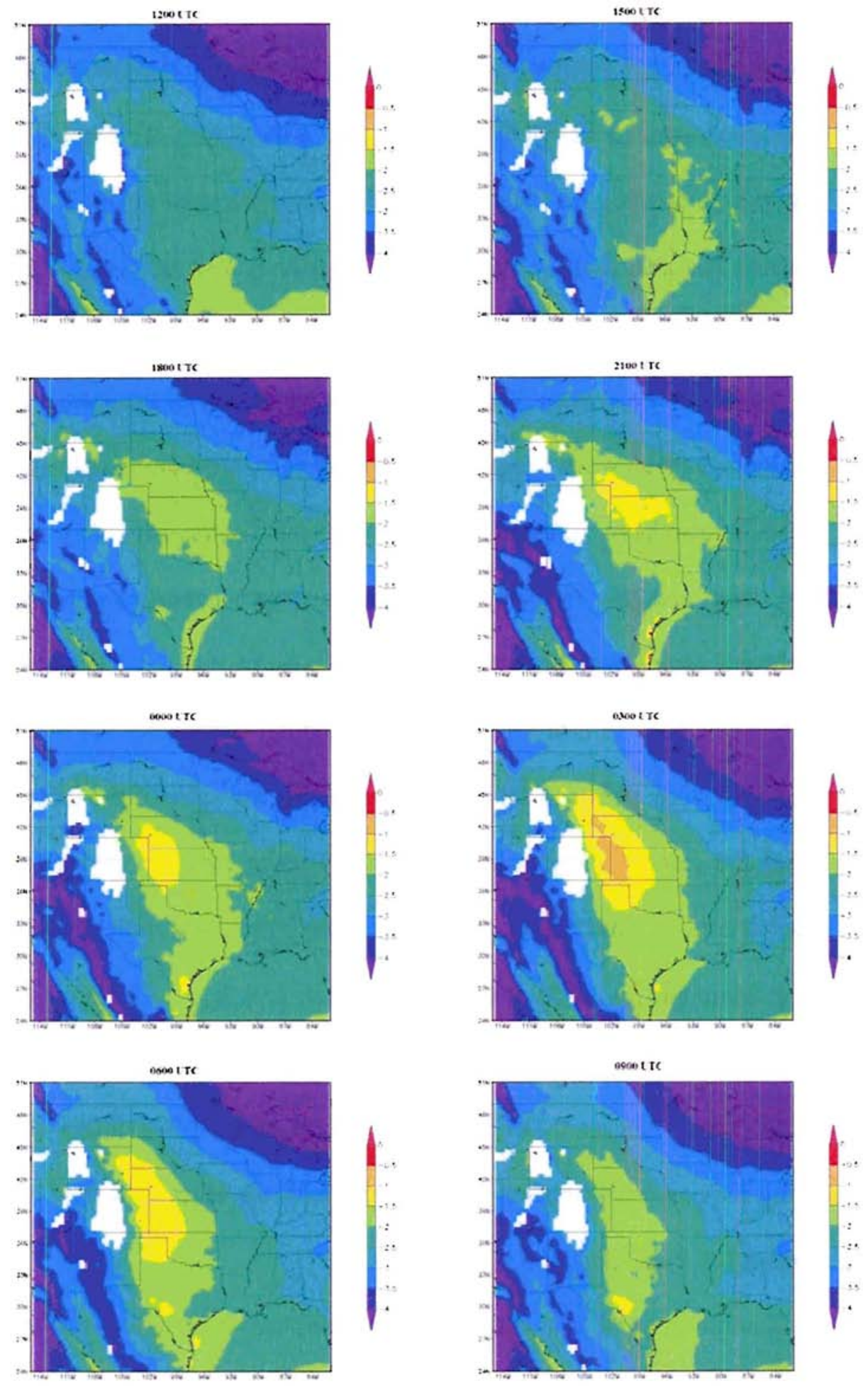

Figure 6.2: Diurnal cycle of the MCS index as shown by fixed-point composites of the index during initial study period at 3-hour intervals throughout the day. High elevations (i.e., above $750 \mathrm{mb}$ ) are blocked out from calculations of the MCS index due to insignificantly large values of $700 \mathrm{mb}$ temperature advection. 
Examination of the diurnal cycle of the MCS index through the use of fixed-point composites brings out features that are fixed over time, such as topography. The MCS index maximizes in the High Plains just east of the Rocky Mountains in these composites (Fig. 6.2), indicating that this is generally a favorable area for MCS development. Other transient features, such as fronts, get averaged out over this long-term mean; thus, they are undetectable in these composites. Interestingly, the values of the MCS index in Fig. 6.2 reveal that the average High Plains environment is still marginally favorable for MCS development even when examining every day over a few entire convective seasons.

MCSs also have a distinct seasonal cycle with the majority of systems forming during May, June, and July (see Fig. 6.3). The average location of initiation gradually shifts northward during the convective season, as seen in Fig. 6.3. The seasonal cycle of the MCS index was examined by creating fixed-point composites for cach month during the three-year study period at the time of the maximum value of the index (i.c., 0300 UTC). Figure 6.4 shows the composites of the MCS index for April through August. The MCS index is at a minimum over the plains during April, and then conditions become much more favorable for MCSs during May, June, and July. The areal extent of marginal values of the index decreases in August, which agrees with the observation of fewer MCSs during August. The maximum values of the MCS index also shift northward during the convective season in agreement with the northward shift of MCSs during the summer (cf. Figs. 6.3 and 6.4).

In addition to the seasonal cycle of convective systems over the central U.S., another seasonal feature can be seen in the monthly composites in Fig. 6.4. The influence of the North American monsoon is evident in the MCS index beginning in June and increases in 
magnitude and extent in July and August over northwestern Mexico and the southwest U.S. In fact, the onset of the North American monsoon typically occurs in June over northwest Mexico and spreads into the southwestern U.S. during July and August (Douglas et al. 1993). Although MCSs are not well documented in this region, they are known to occur (e.g., McCollum et al. 1995) during the monsoon season. Certainly, this area has a pronounced rainfall maximum during the monsoon season due to increased convective storms (Douglas 1993; Saleeby and Cotton 2004). The MCS index indicates that this region becomes more favorable to support organized, long-lived convection during this period; hence, MCSs may be a common mode of convection leading to this seasonal precipitation maximum. The monsoon ridge is also a very obvious feature in Fig. 6.4 that builds in over central Texas during July making the region unfavorable for MCS development.

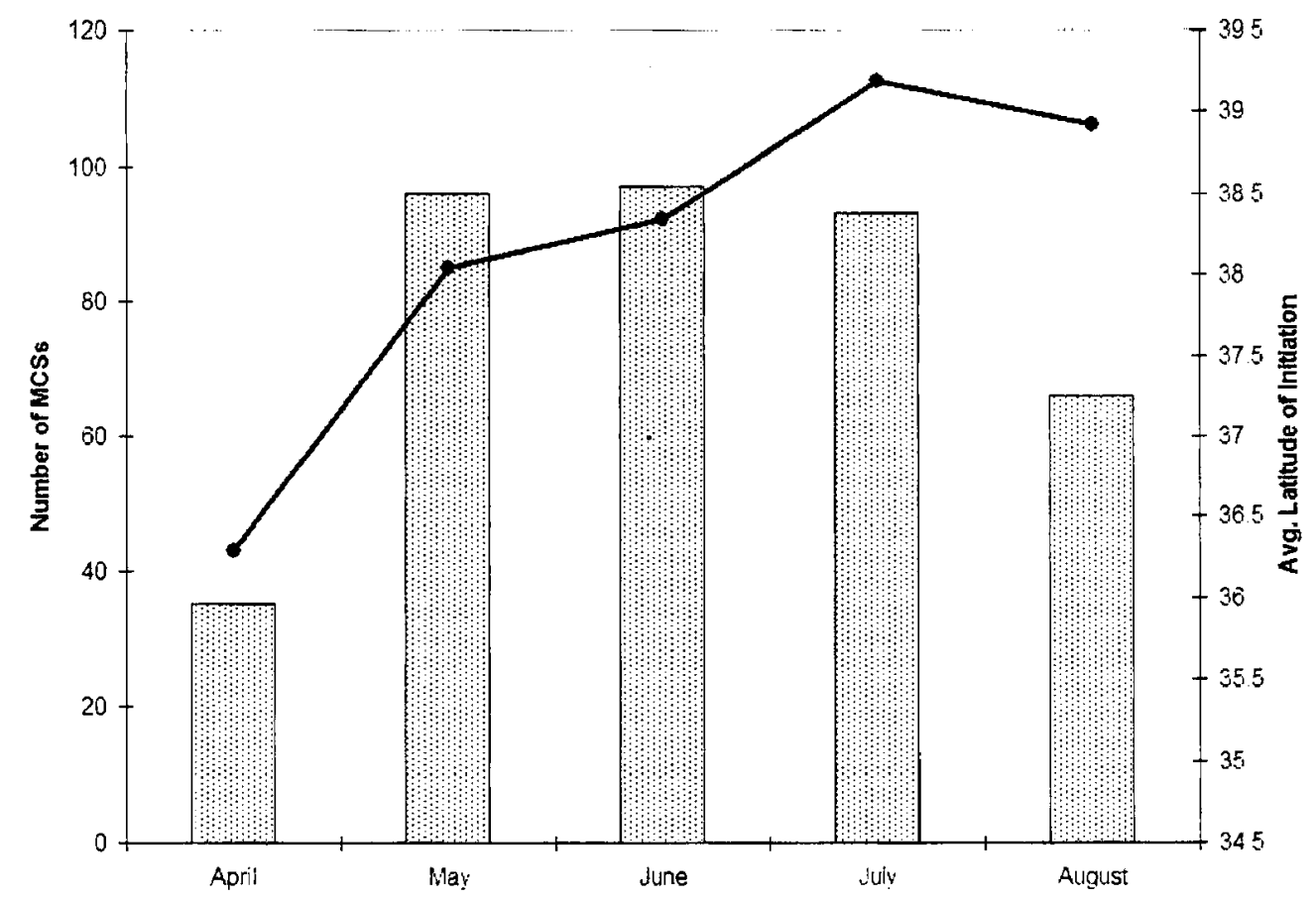

Figure 6.3: Distribution (bars) and average latitude of initiation (line) by month of all MCSs studied. 

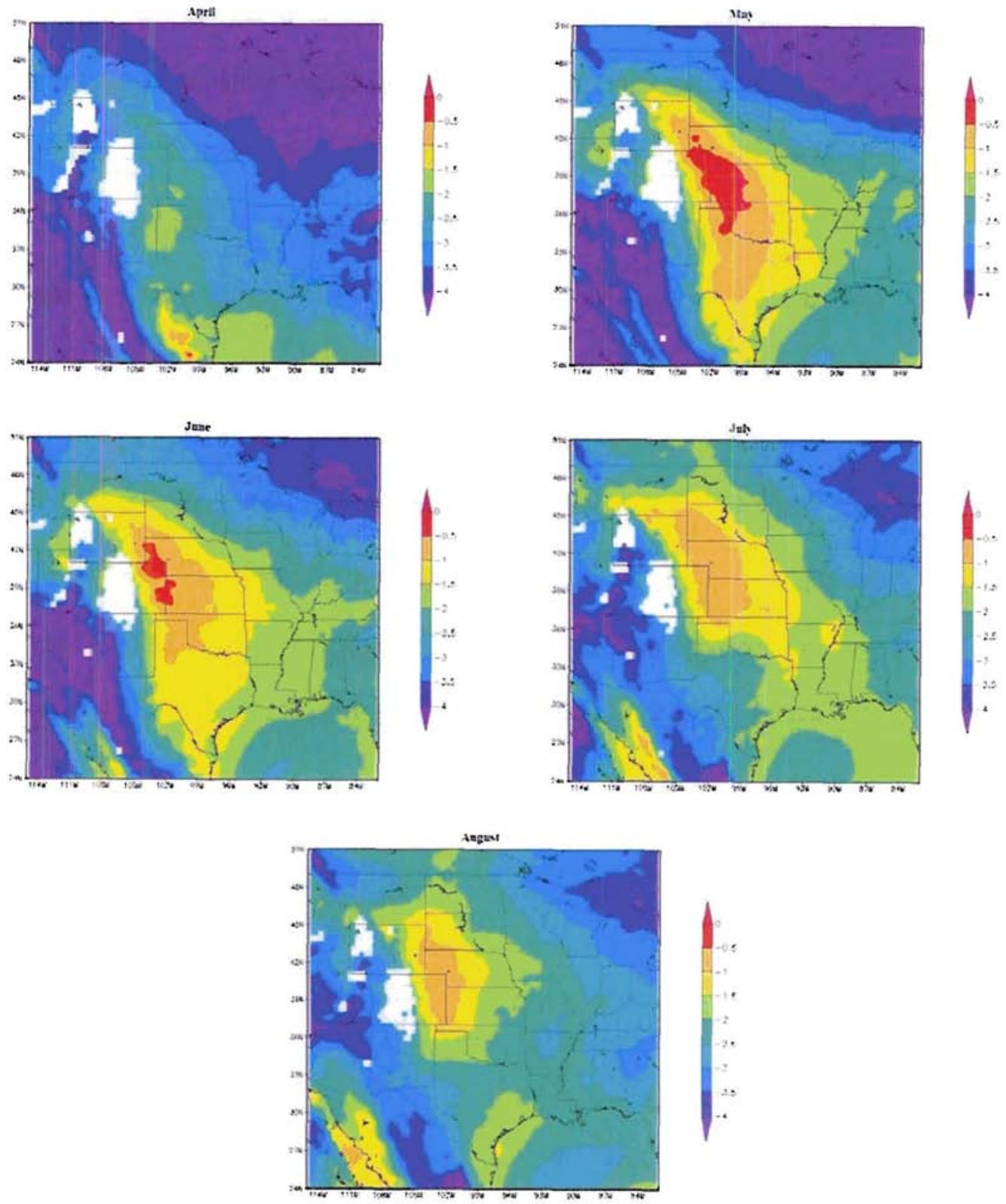

Figure 6.4: Seasonal cycle of the MCS index as shown by fixed-point composites of the index at 0300 UTC during initial study period for each month. High elevations (i.e., above $750 \mathrm{mb}$ ) are blocked out from calculations of the MCS index due to insignificantly large values of $700 \mathrm{mb}$ temperature advection.

\subsubsection{Warm season precipitation episodes}

The characteristics of the MCS index are similar to MCS characteristics in an averaged sense, but what about on a case-to-case basis? Warm season precipitation 
episodes have been documented (Cotton et al. 1983; Carbone et al. 2002) as coherent sequences of MCSs that traverse the U.S. for periods of more than one day. Carbone et al. (2002) focused on precipitation events that occur under weakly-forced midsummer conditions due to the low skill in predicting convective precipitation by numerical weather models during this regime. They show that precipitation episodes are highly inphase with baroclinic waves during the springtime when stronger synoptic forcing is present; however, they found the midsummer precipitation episodes to be highly unrelated to synoptic disturbances. To investigate the ability of the MCS index to forecast these episodes, the index is compared to radar-derived rain-rate Hovmöller diagrams from the Carbone et al. (2002) study.

Figures 6.5 and 6.6 reveal Hovmöller diagrams of the MCS index and rain rate for two different summertime fortnights. The Hovmöller diagrams simply vary in time (increasing upward in these plots) and longitude with the data being averaged from $30^{\circ}$ to $48^{\circ} \mathrm{N}$ latitude. Thus, any coherent pattern sloping from the lower-left to the upper-right portion of the plots indicates an eastward propagating feature with time. Several precipitation episodes can be seen in the right-hand panels of Figs. 6.5 and 6.6 as coherent eastward-propagating features that typically cover around $1500 \mathrm{~km}$ over a $20-40$ hour period. These episodes are very repetitive features that begin east of the Continental Divide $\left(\sim 105^{\circ} \mathrm{W}\right)$ due to afternoon thermal forcing and propagate eastward overnight into the plains where the LLJ helps sustain the systems until thermal forcing kicks in the following day for convective regeneration.

If the MCS index is compared to specific midsummer precipitation episodes, it shows good correspondence with the timing and propagation of MCSs. Four different 
precipitation episodes are highlighted in Figs. 6.5 and 6.6 that demonstrate the association of coherent precipitation events and the MCS index. For example, the precipitation episode that started around 0000 UTC on 17 June 1997 along the eastern slopes of the Rocky Mountains and propagated eastward to the Appalachians by 0000 UTC on 19 June 1997 is nicely associated with a region of maximum values of the MCS index. Notice that the absence of a precipitation episode initiating in the west on the following day corresponds with a streak of minimum values in the MCS index. The other three highlighted precipitation episodes also show a very strong correlation between precipitation episodes and strips of maximum values of the MCS index, indicating that coherent, propagating convection often occurs where the index is favorable.

Many other precipitation episodes and features in these figures are also consistent with the MCS index. Even with the excellent overall agreement between the MCS index and precipitation episodes, there are certainly some differences between them. Keep in mind that the rain rate diagrams include the precipitation from all types of storms, which complicates the comparison with an index that focuses solely on MCSs. In addition, the data are averaged over a large latitudinal band reducing the sensitivity of the index in some instances to areas favorable for MCS development and sustenance. In fact, that is why the MCS index rarely reaches the favorable range outlined in Table 6.2. Of course, the usefulness of the MCS index is also contingent on convective initiation. 


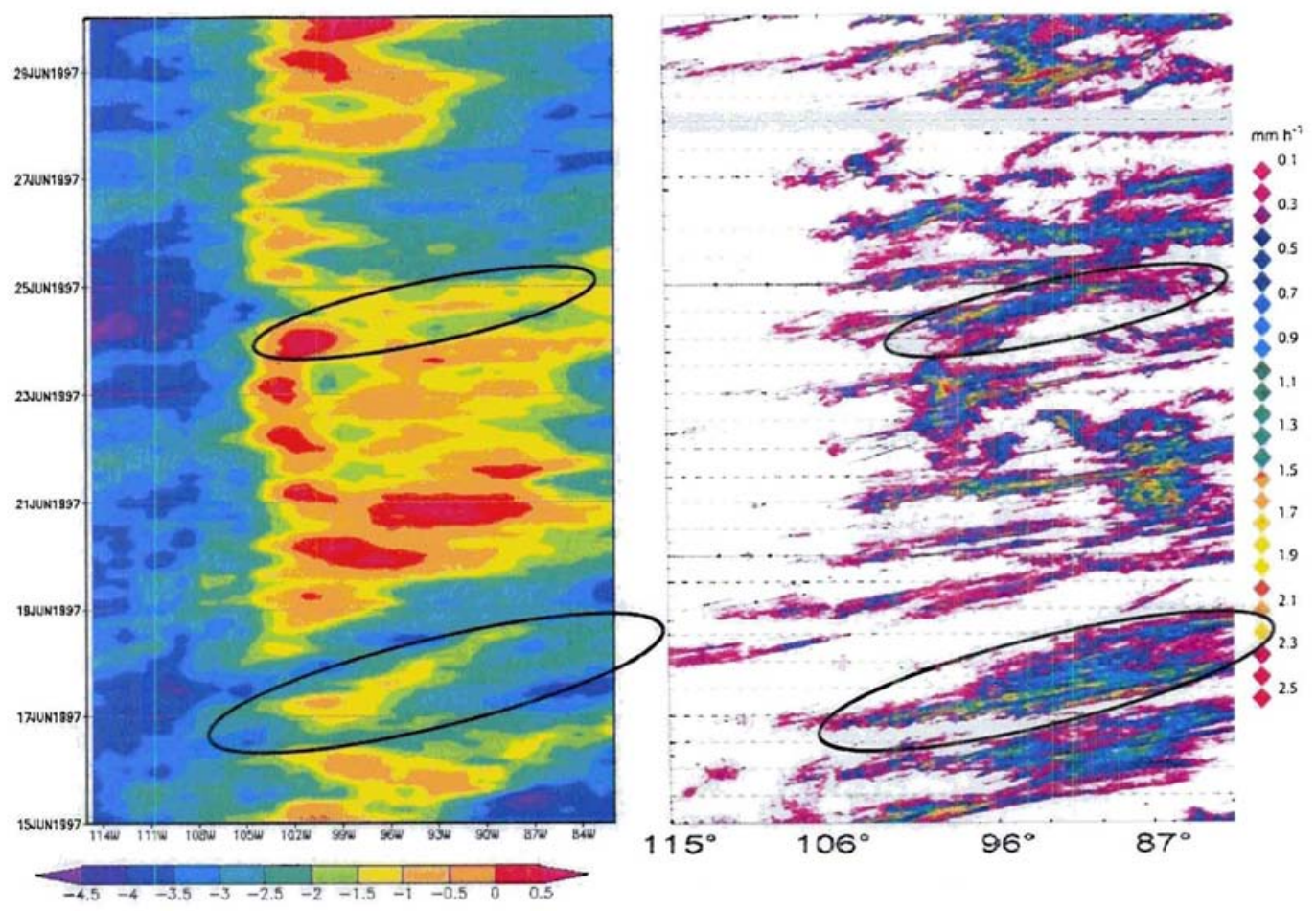

Figure 6.5: Hovmöller diagrams for 15-29 June 1997 (in UTC) of the MCS index (left panel) and the radar-derived rain rate in $\mathrm{mm} \mathrm{h}^{-1}$ (right panel) [modified from Carbone et al. 2002]. The elliptical areas encompass examples of precipitation episodes and the corresponding values of the MCS index.

Overall, the MCS index shows several promising features with regard to the forecasting of precipitation episodes. The index shows a definite diurnal cycle with a maximum typically occurring just after 0000 UTC. This maximum is often followed by continued large values farther east overnight across the plains in response to the larger shear and advection due to the development of the LLJ. Finally, large values of the index are occasionally found near the Appalachians in response to decreased daytime stability. Certainly, the MCS index is not expected to continuously "propagate" as a MCS would since it indicates areas favorable for development over a $6 \mathrm{~h}$ period. It should, however, indicate a relatively wide longitude range favorable for development followed later by a wide range farther east. This can be seen in the Hovmöller diagrams 
of the MCS index as a "tiered" structure of large values that encompasses the more smoothly propagating precipitation episodes. Essentially, the MCS index provides a good indication of the likelihood of midsummer precipitation episodes simply by identifying areas that are favorable for the development and sustenance of MCSs. This finding does not address the physical mechanism by which convective (re)generation occurs (i.e., a convective initiation issue), but it does imply that convective instability, low-level shear, and low-level warm air advection are very important to the existence of coherent, propagating precipitation systems.
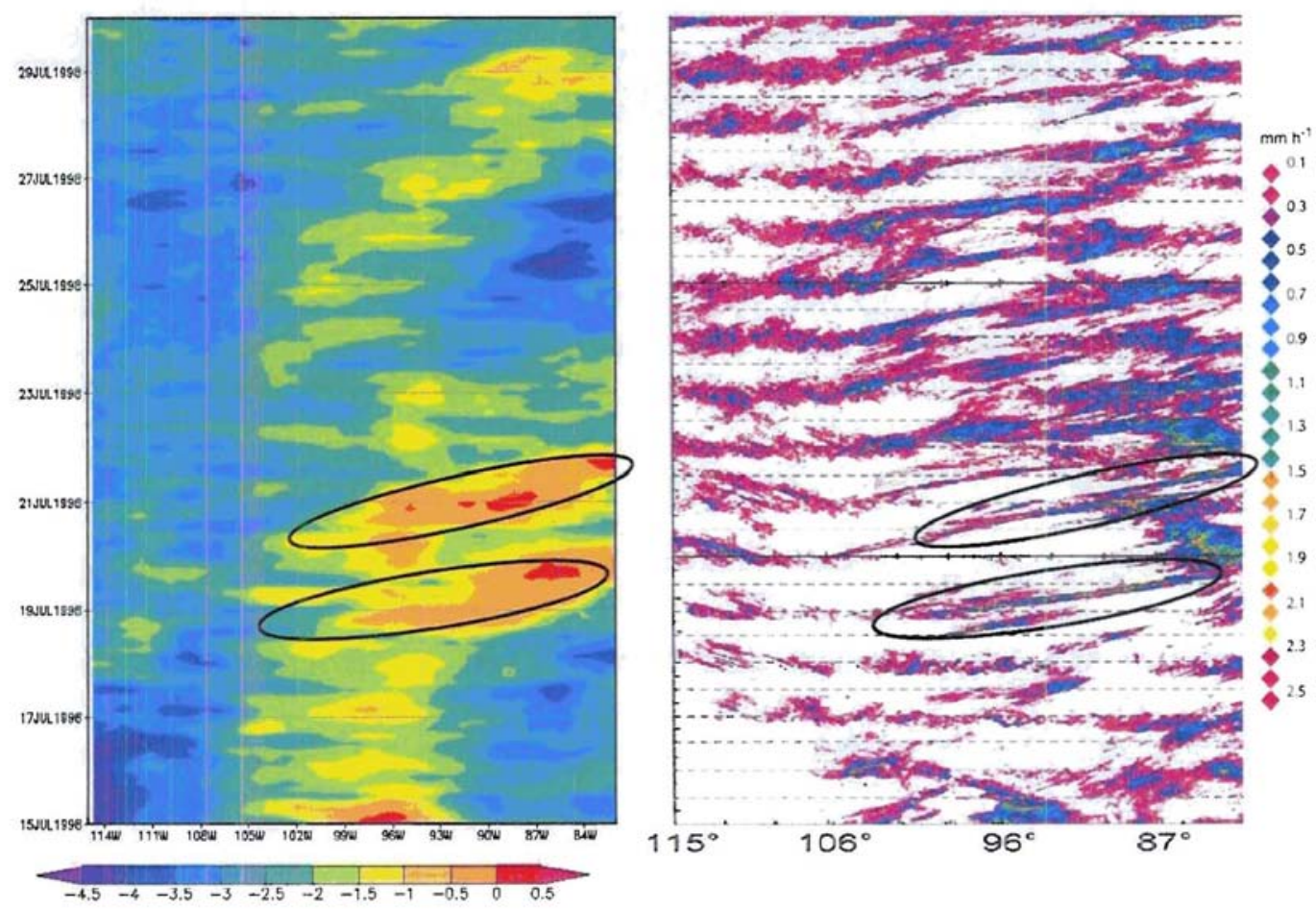

Figure 6.6: Same as Fig. 6.5, except for 15-29 July 1998.

\subsubsection{Determination of MCS type}

The MCS index introduced here shows skill in forecasting MCSs in general, but it has not been discussed whether the index can be helpful in discerning the type of MCS that 
will form. The individual terms of the MCS index, as well as the index itself, was evaluated with respect to the various MCS classifications. Table 6.3 provides information about typical index values for the MCS satellite classifications. As expected from the analysis done in Section 4.2, the MCS index is not statistically different at a high confidence level among the MCS satellite categories. The larger systems, especially MCCs, do reveal slightly higher values of the MCS index on average than the smaller meso- $\beta$ systems. MCCs usually form in environments with larger low-level shear and temperature advection than their smaller counterparts. In fact, the contribution of the LI to the MCS index is significantly larger than the contribution from the $700 \mathrm{mb}$ temperature advection prior to the development of M $\beta C C S s$, suggesting that instability is more important than thermal forcing to these small quasi-circular systems.

Table 6.3: Point-value data of the MCS index and its respective terms for the satellite classifications. For each classification the mean, standard deviation $(\sigma), 1^{\text {st }}$ quartile value $(1 Q)$, median, and $3^{\text {rd }}$ quartile value $(3 \mathrm{Q})$ are listed. Bold numbers indicate that the means for the classifications are different at the $95 \%$ confidence level while italicized numbers indicated that the means for the terms of a given classification are different at the $95 \%$ confidence level.

\begin{tabular}{llcccc}
\hline MCS Category & & LI & $0-3 \mathrm{~km}$ shear & $700 \mathrm{mb}$ TA & \\
& & term & $\begin{array}{c}\text { term } \\
\text { term }\end{array}$ & MCS index \\
\hline MCC & mean & 0.05 & 0.23 & 0.04 & 0.32 \\
& $\sigma$ & 0.99 & 0.96 & 0.94 & 1.45 \\
& $1 \mathrm{Q}$ & -0.51 & -0.51 & -0.50 & -0.75 \\
& med. & 0.21 & 0.12 & -0.06 & 0.29 \\
& $3 \mathrm{Q}$ & 0.70 & 0.89 & 0.45 & 1.21 \\
\hline PECS & mean & 0.02 & -0.04 & 0.08 & 0.06 \\
& $\sigma$ & 0.97 & 1.00 & 1.13 & 1.68 \\
& $1 \mathrm{Q}$ & -0.48 & -0.68 & -0.57 & -1.05 \\
& med. & 0.15 & -0.16 & -0.21 & -0.15 \\
& $3 \mathrm{Q}$ & 0.67 & 0.54 & 0.45 & 0.85 \\
\hline MBCCS & mean & 0.17 & -0.16 & -0.27 & -0.26 \\
& $\sigma$ & 0.83 & 0.79 & 0.77 & 1.42 \\
& $1 \mathrm{Q}$ & -0.33 & -0.66 & -0.69 & -1.13 \\
& med. & 0.26 & -0.16 & -0.29 & -0.25 \\
& $3 \mathrm{Q}$ & 0.73 & 0.30 & 0.03 & 0.67 \\
\hline MBECS & mean & -0.23 & 0.01 & -0.02 & -0.24 \\
& $\sigma$ & 1.16 & 0.98 & 0.92 & 1.54 \\
& $1 \mathrm{Q}$ & -0.62 & -0.77 & -0.55 & -1.34 \\
& med. & -0.01 & -0.04 & -0.26 & -0.38 \\
& $3 \mathrm{Q}$ & 0.56 & 0.75 & 0.27 & 0.66 \\
\hline
\end{tabular}


More significant differences can be found among MCSs when classified by their development. Table 6.4 lists the statistics of each category for all three levels of classification. As expected, the LI term is larger on average for non-embedded systems than for embedded systems, but that disparity does not result in a statistically significant difference in the overall value of the MCS index. For embedded systems, the contributions from each term to the MCS index indicate that they depend on stronger forcing to survive in the weakly unstable environments. Line systems also tend to rely on stronger forcing than instability, as shown by a significantly lower contribution to the index from the LI term. They do show a statistically-significant larger average value of the MCS index than areal systems due to larger low-level shear and warm air advection. Essentially, this suggests that larger values of the MCS index are more likely to lead to larger, longer-lived, more severe, and rainier MCSs than lower values of the index.

Even though the MCS index is statistically larger on average for line systems than areal systems, there is still little skill in using this fact to predict the type of MCS that will form. The same can also be said for the other MCS classifications, which had even less significant differences among their respective categories. CART (described in Section 3.2) was used in an attempt to try to forecast the type of MCS that will form based on the conditions of the precursor environment (60 variables were examined). In the end, this procedure was unable to develop a set of rules that could forecast the MCS classification better than by simply predicting the most common mode. For example, by forecasting an areal system to always form, one would misclassify $48 \%$ (187/387) of the systems while the cross-validation procedure revealed that the decision tree could not reduce the number of misclassifications. 
Table 6.4: Same as Table 6.3, except for the radar classifications of MCS development.

\begin{tabular}{|c|c|c|c|c|c|}
\hline MCS Category & & $\begin{array}{c}\mathrm{LI} \\
\text { term }\end{array}$ & $\begin{array}{c}0-3 \mathrm{~km} \text { shear } \\
\text { term }\end{array}$ & $\begin{array}{c}700 \mathrm{mb} \text { TA } \\
\text { term }\end{array}$ & MCS index \\
\hline \multirow[t]{5}{*}{ Embedded } & mean & -0.62 & 0.09 & 0.22 & -0.32 \\
\hline & $\sigma$ & 1.18 & 0.96 & 1.13 & 1.55 \\
\hline & $1 Q$ & -1.31 & -0.58 & -0.40 & -1.15 \\
\hline & med. & -0.45 & 0.07 & 0.01 & -0.49 \\
\hline & $3 Q$ & 0.10 & 0.61 & 0.73 & 0.43 \\
\hline \multirow[t]{5}{*}{ Not Embedded } & mean & 0.12 & 0.00 & -0.06 & 0.06 \\
\hline & $\sigma$ & 0.91 & 0.96 & 0.96 & 1.56 \\
\hline & $1 Q$ & -0.33 & -0.68 & -0.57 & -1.07 \\
\hline & med. & 0.22 & -0.12 & -0.26 & -0.05 \\
\hline & $3 Q$ & 0.71 & 0.60 & 0.26 & 0.86 \\
\hline \multirow[t]{5}{*}{ Areal } & mean & 0.00 & -0.15 & -0.12 & -0.26 \\
\hline & $\sigma$ & 0.88 & 0.90 & 0.77 & 1.35 \\
\hline & $1 \mathrm{Q}$ & -0.43 & -0.80 & -0.55 & -1.15 \\
\hline & med. & 0.12 & -0.19 & -0.26 & -0.36 \\
\hline & $3 Q$ & 0.60 & 0.39 & 0.20 & 0.52 \\
\hline \multirow[t]{5}{*}{ Line } & mean & -0.28 & 0.36 & 0.44 & 0.52 \\
\hline & $\sigma$ & 1.16 & 1.07 & 1.39 & 1.97 \\
\hline & $1 Q$ & -1.01 & -0.38 & -0.43 & -0.87 \\
\hline & med. & -0.17 & 0.30 & -0.08 & 0.37 \\
\hline & $3 Q$ & 0.52 & 1.05 & 0.82 & 1.56 \\
\hline \multirow[t]{5}{*}{ Combination } & mean & 0.14 & 0.12 & -0.07 & 0.20 \\
\hline & $\sigma$ & 1.04 & 0.96 & 0.99 & 1.54 \\
\hline & $1 Q$ & -0.29 & -0.49 & -0.62 & -0.80 \\
\hline & med. & 0.22 & -0.07 & -0.27 & 0.20 \\
\hline & $3 Q$ & 0.80 & 0.69 & 0.32 & 0.93 \\
\hline \multirow[t]{5}{*}{ Merger } & mean & 0.04 & -0.03 & 0.00 & 0.01 \\
\hline & $\sigma$ & 0.97 & 0.95 & 1.00 & 1.55 \\
\hline & $1 Q$ & -0.38 & -0.69 & -0.56 & -1.10 \\
\hline & med. & 0.15 & -0.13 & -0.21 & -0.07 \\
\hline & $3 Q$ & 0.67 & 0.60 & 0.34 & 0.84 \\
\hline \multirow[t]{5}{*}{ Non-merger } & mean & -0.11 & -0.03 & -0.09 & -0.22 \\
\hline & $\sigma$ & 0.77 & 0.78 & 0.68 & 1.30 \\
\hline & $1 \mathrm{Q}$ & -0.74 & -0.55 & -0.49 & -1.03 \\
\hline & med. & 0.06 & 0.03 & -0.16 & -0.37 \\
\hline & $3 Q$ & 0.38 & 0.43 & 0.37 & 0.49 \\
\hline \multirow[t]{5}{*}{ Isolated } & mean & -0.13 & 0.22 & 0.01 & 0.10 \\
\hline & $\sigma$ & 1.14 & 1.07 & 1.04 & 1.69 \\
\hline & $1 Q$ & -1.02 & -0.59 & -0.55 & -1.08 \\
\hline & med. & 0.16 & 0.23 & -0.29 & -0.18 \\
\hline & $3 Q$ & 0.83 & 0.71 & 0.30 & 1.24 \\
\hline
\end{tabular}

Even when picking a threshold of the MCS index in merely forecasting between line and areal systems, there is essentially no improvement over picking the most common classification for a sample of MCSs due to the much higher frequency of occurrence of areal systems. A constant forecast of areal systems results in a misclassification of $24 \%$ 
(63/261) where the best forecast using the MCS index (value of 3.34) still results in misclassifying over $21 \%$ of the systems. Therefore, with the assumption that the distribution of MCS types in this sample is representative of the total population of MCSs, the precursor environment cannot provide much help in determining the type of MCS that will form. However, this does not change the fact that if a forecaster were to predict for a line system to develop that a more successful forecast would result for higher values of the MCS index. For example, the percentage of line systems increases from $24 \%$ for a MCS index of -3 to $42 \%$ for a MCS index of 1 ; therefore, the index does at least provide some guidance for when it would be best to forecast a line system.

\subsubsection{Examples}

Examination of more than $300 \mathrm{MCSs}$ over a 15-month period results in a multitude of possible examples to illustrate the utility of the MCS index. A few representative examples were selected to demonstrate the usefulness and effectiveness of the MCS index in forecasting MCSs for a variety of situations. These examples bring out several important features of the MCS index: an agreement between the location of MCS development and large values of the MCS index, a lack of organization of widespread convection in areas with small values of the MCS index, and the dissipation of MCSs as they move into areas with small or undefined values of the MCS index.

The first example is a sequence of MCSs that occurred on consecutive days from 2100 UTC on 7 July 1997 to 1500 UTC on 9 July 1997 (see Fig. 6.7). In Fig. 6.7a, there is remnant stratiform precipitation in Minnesota from a MCS that formed on the preceding night. The MCS index shows favorable conditions (i.e., values $>0$ ) for MCS development stretching from Minnesota to north Texas. By 0000 UTC on 8 July, 
convection breaks out from southern Minnesota to central Nebraska along a cold front in a region mostly favorable for MCS development. Meanwhile, orographically-induced convection over eastern Colorado and New Mexico forms in areas unfavorable (i.e., MCS index $<-1.5$ or undefined) for MCS development and quickly dissipates without undergoing convective organization. The convection along the cold front, however, does indeed begin to organize over the next several hours into two distinct MCSs: one over eastern Kansas and one over southern Wisconsin. Interestingly, the MCS index also reveals two favorable locations of MCS development with very close correspondence to the location of the two MCSs separated by a region marginally favorable (i.e., $-1.5<$ MCS index < 0) for MCS development. These systems weakened into the morning hours, as the environment became more marginal for supporting organized convection. However, both systems showed reintensification during the following afternoon as the conditions became favorable once again for MCS development. Finally, these systems completely dissipated on the morning of 9 July with predominantly unfavorable conditions for MCS development over the central U.S.

While the two MCS from 8 July were going through their regeneration stage around 0000 UTC on 9 July, convection also developed in response to orographic forcing along the Rocky Mountains and surface convergence along a trough extending through southern Kansas. The convection that moved into or developed in regions favorable for MCS development underwent convective organization into MCSs with the largest system forming in southeast Kansas. The systems dissipated into the morning hours as the overall conditions became less favorable for supporting MCSs. 

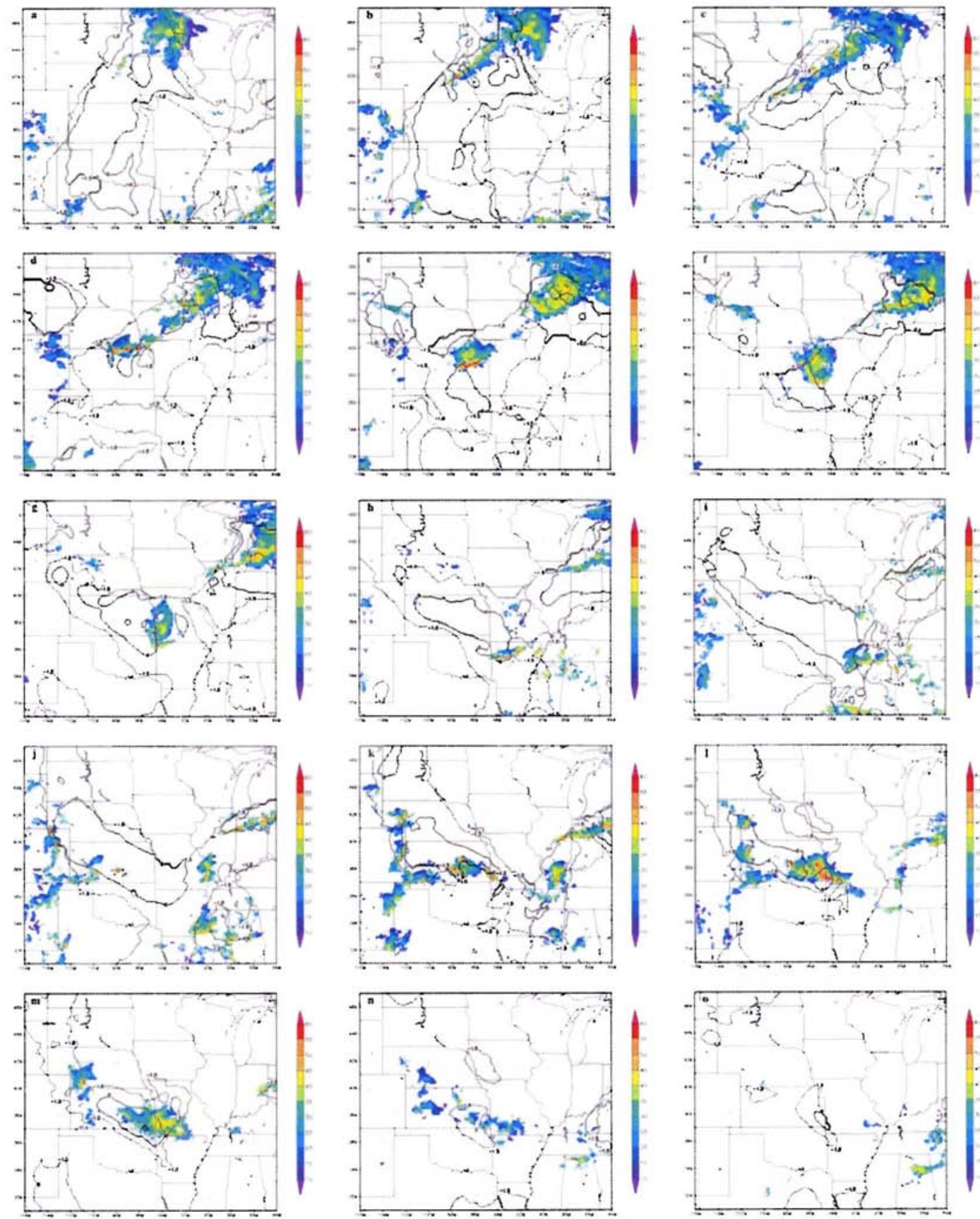

Figure 6.7: Radar reflectivity (shaded) and MCS index (contoured) over a two-day period from 7-9 July 1997. The images are from: (a) 2100 UTC 7 July 1997, (b) 0000, (c) 0300, (d) 0600, (e) 0900, (f) 1200 , (g) 1500 , (h) 1800 , (i) 2100 UTC 8 July 1997, (j) 0000, (k) 0300, (l) 0600, (m) 0900, (n) 1200, and (o) 1500 UTC 9 July 1997.

Another example of the utility of the MCS index is provided in Fig. 6.8. This system formed over eastern Nebraska and Kansas on 12 May 1998. Once again, the remains of 
earlier MCS can be seen in South Dakota as a region of stratiform precipitation. By 0000 UTC, a nice line of thunderstorms has formed along a cold front on the western boundary of the region favorable for MCS development. As this convection advances eastward, it enters an area primarily favorable for MCS development and organizes into a narrow, leading-line/trailing-stratiform system. As the linear MCS propagates eastward, the region of favorable values of the MCS index for supporting this system remains nearly stationary; therefore, the system advances into a more unfavorable environment and dissipates. Thus, the two examples shown here provide evidence that the MCS index can also provide some skill in helping to forecast the dissipation of MCSs.
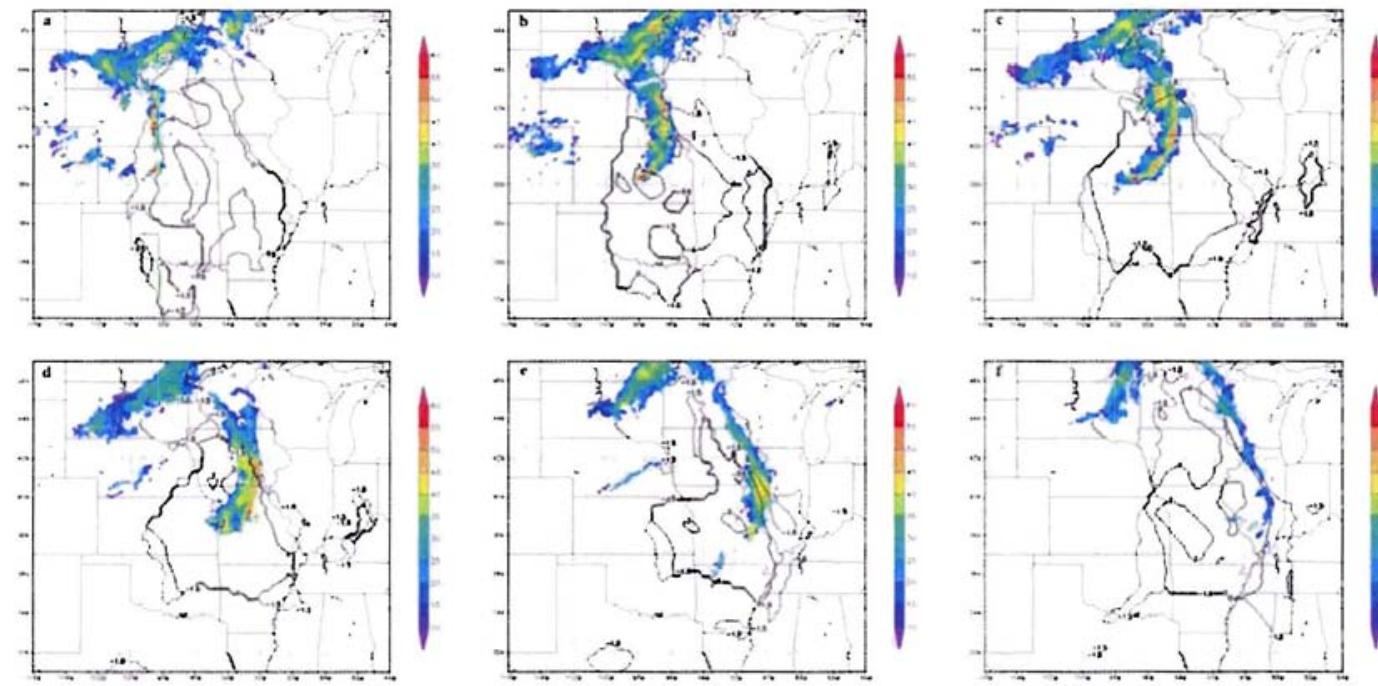

Figure 6.8: Radar reflectivity (shaded) and MCS index (contoured) on 12 May 1998. The images are from: (a) 0000, (b) 0300, (c) 0600, (d) 0900, (e) 1200, and (f) 1500 UTC 12 May 1998.

The third example is a three-day period of June 1998 with significant MCSs forming each day (Figs. 6.9 and 6.10). By 0000 UTC on 22 June, convective initiation has occurred in northeast Colorado and the Nebraska panhandle, as well as along a dryline in Texas. The convection in Colorado advances into a region favorable for MCS development and quickly organizes and intensifies. The convection in Texas, on the 
other hand, remains in marginally-favorable conditions at best for MCS development and quickly dissipates. Additional convection fires up at 0300 UTC in central Kansas along a stationary front in favorable conditions and rapidly organizes into a convective line. Two bow echoes form across Kansas and Missouri by 1200 UTC on 22 June primarily propagating through a region favorable for supporting MCSs. The trailing bow echo falls apart as conditions become less favorable in the wake of the first system by morning while the leading system survives through the morning by remaining in at least a marginally-favorable environment.

The focus on the afternoon of 22 June has now shifted back toward the Central Plains and northern High Plains where the MCS index shows a large area with values greater than zero. By 0300 UTC on 23 June, convection has erupted along higher terrain aided by a lee tough and along a stationary front draped across the central U.S. In addition, convection also breaks out along the dryline in the Texas panhandle in better conditions than on the previous day. As a result, the northernmost storms survive and eventually merge with the developing MCS while the southern portion of the convection in Texas never organizes as it remains in marginally-favorable MCS conditions. Meanwhile, several convective clusters form over the plains within the band of large values of the MCS index. All but the casternmost cluster eventually merge by morning on 23 June over the Central Plains. This large system dissipates rapidly through the morning even though it remains on the edge of somewhat favorable conditions.

The region of interest for possible MCS development on the evening of 23 June has advanced slightly to the northeast. Convection begins to develop along a series of fronts and troughs over the plains by 0000 UTC on 24 June. The convection quickly organizes 
into a MCS over northwestern Iowa by 0300 UTC in a very favorable region of MCS development. The system remains well-organized until 1200 UTC when it advances northeastward out of the region favorable for supporting MCSs.
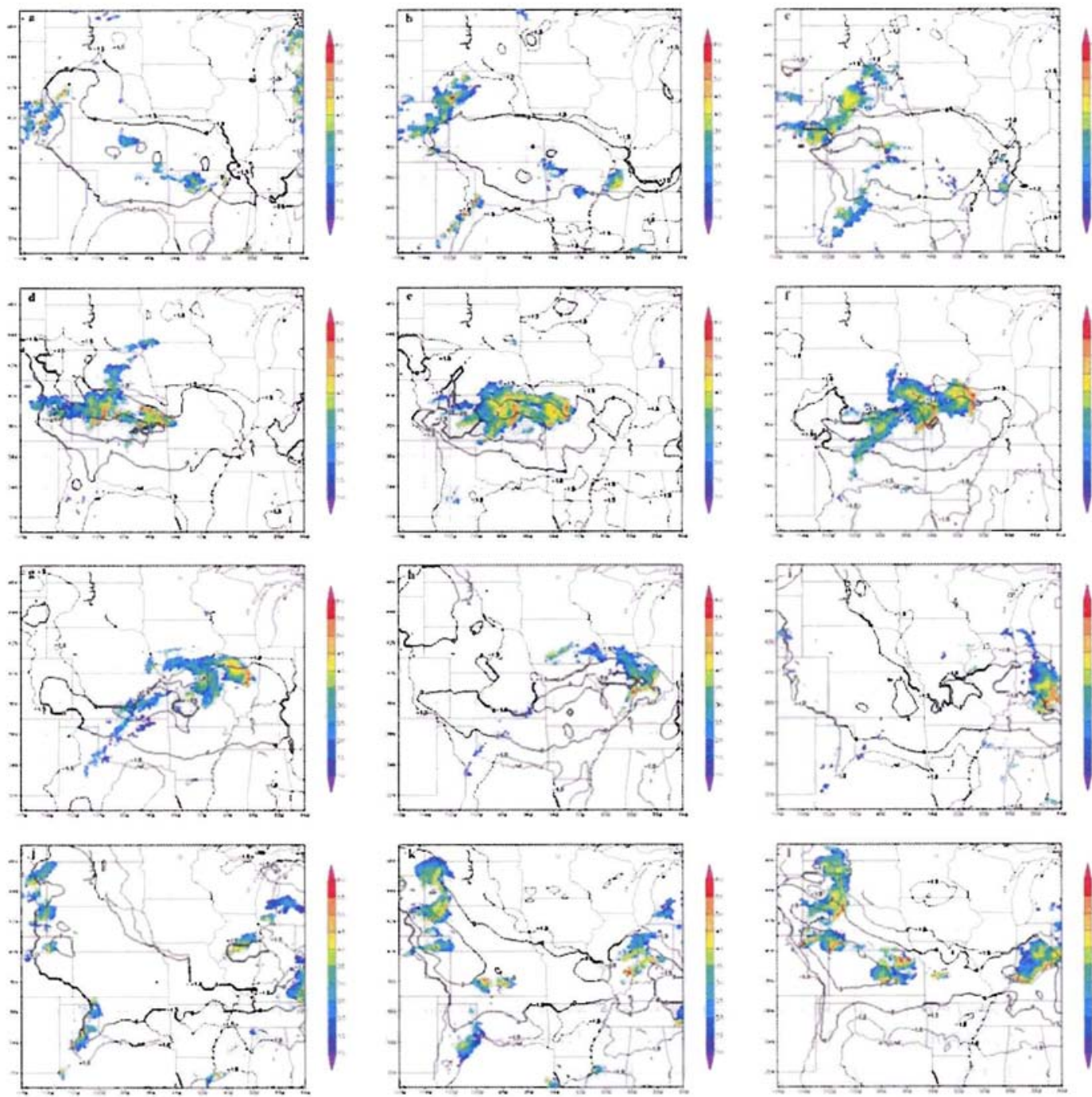

Figure 6.9: Radar reflectivity (shaded) and MCS index (contoured) during 21-23 June 1998. The images are from: (a) 2100 UTC 21 June 1998, (b) 0000, (c) 0300, (d) 0600, (c) 0900, (f) 1200, (g) 1500, (h) 1800, (i) 2100 UTC 22 June 1998, (j) 0000, (k) 0300, and (l) 0600 UTC 23 June 1998. 

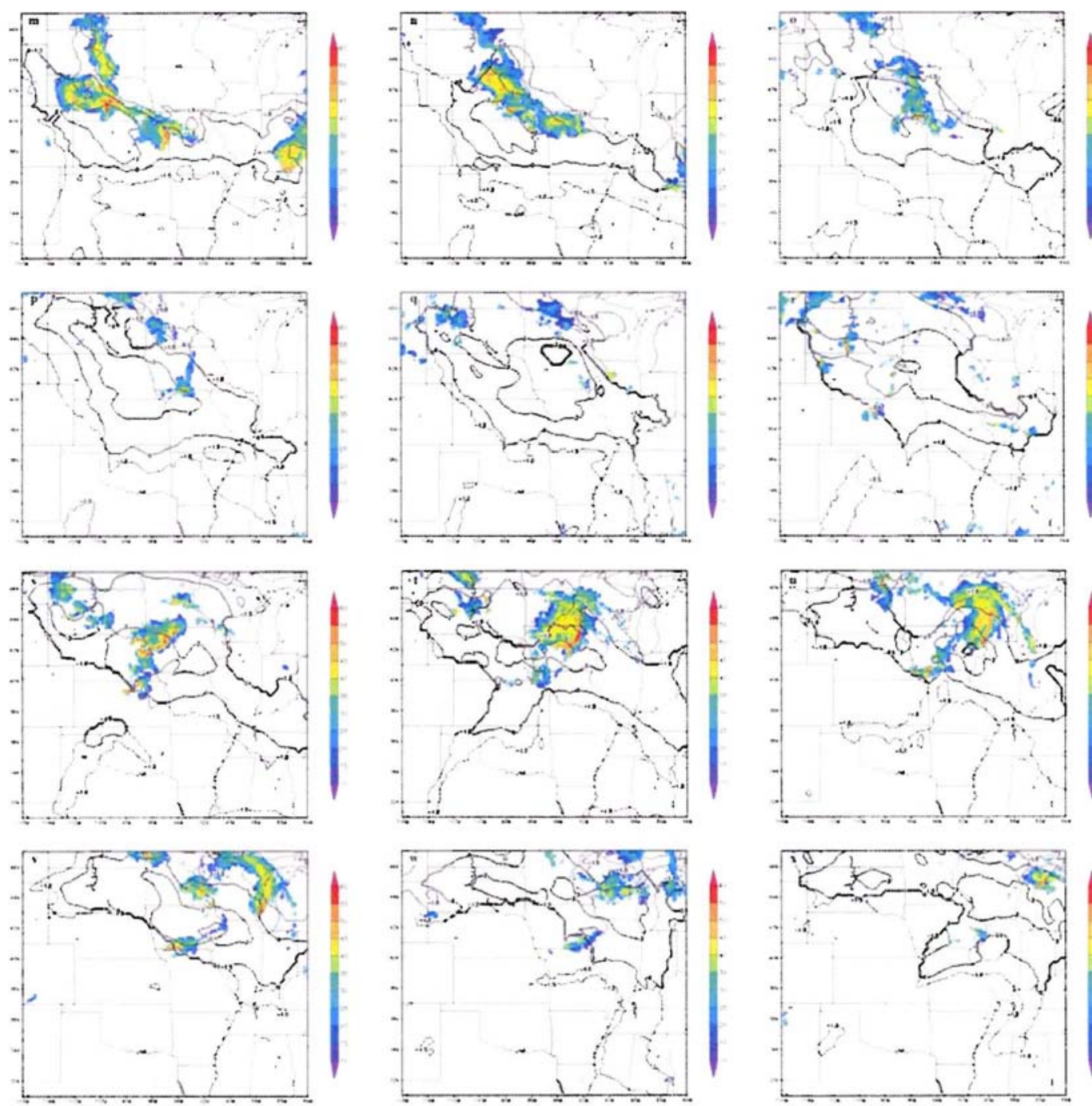

Figure 6.10: Continuation of Fig. 6.9 for 23-24 June 1998. The images are from: (m) 0900, (n) 1200, (o) 1500, (p) 1800, (q) 2100 UTC 23 June 1998, (r) 0000, (s) 0300, (t) 0600, (u) 0900, (v) 1200, (w) 1500 , and (x) 1800 UTC 24 June 1998.

The examples were provided to give an idea of the usefulness and flexibility of the MCS index in forecasting MCSs. The MCS index provides a significant amount of skill in determining where a MCS will develop given that convection has been initiated. The examples showed several instances where a favorable value of the MCS index could distinguish convection that would organize into a larger convective system from 
convection that would rapidly dissipate. In addition, the examples revealed that MCSs that stay in at least marginally-favorable conditions tend to remain strong and well organized. Whereas, when MCSs move out of favorable conditions, they tend to weaken and eventually dissipate. Other features of the MCS index that have not been explicitly mentioned include the boundaries and shape of the index that provide some information on the extent and orientation of the MCSs that form. Overall, the MCS index provides skill in determining whether widespread convection will organize into a coherent system and whether an existing MCS is likely to endure or dissipate.

\subsection{Evaluation during BAMEX}

The MCS index possesses skill in forecasting MCSs during the time period from which it was created, so it would be useful to show that the index performs equally as well during an independent convective season. The period of 20 May through 6 July 2003 was chosen to further test the MCS index due to the documentation of MCS forecasting that took place during BAMEX. During this period, a total of $50 \mathrm{MCSs}$ were objectively identified by IR satellite using the same methodology as Jirak et al. (2003). In addition, 33 instances of widespread convection were identified along with 20 times when MCSs were not present over the central U.S. Identification of these different conditions allows for a direct comparison of the skill of the MCS index during BAMEX with the original study period. A few examples are also provided to demonstrate how the MCS index would have been useful to forecasters during BAMEX.

\subsubsection{Binary forecasting technique}

The binary forecasting technique was applied to the BAMEX data in the same manner as was done during the original study period. The only difference is that the data 
used during BAMEX were available operationally at the time forecasts were being made. Therefore, Eta model analyses and forecasts were used in this comparison rather than reanalyses. Table 6.5 reveals the performance of the MCS index during BAMEX for analyses and forecasts. The analysis time was simply taken as the first $6 \mathrm{~h}$ period (i.c., $0000,0600,1200$, and 1800 UTC) prior to convective development. All of the forecasts are valid at the time of the analyses; thus, analyses at 1800 UTC would have $6,18,30$, 42 , and $54 \mathrm{~h}$ forecasts valid at that time while analyses for 0000 UTC would have 12,24 , 36,48 , and $60 \mathrm{~h}$ forecasts valid at that time based on the 0000 and 1200 UTC Eta model runs. Comparison of the data in Tables 6.1 and 6.5 reveals that the MCS index performs at least slightly better for all conditions during the BAMEX period than during the original study period. This result reassures that the MCS index can be applicable and useful for all convective seasons and is not just an artifact of the convective seasons from which it was formed.

The MCS index is essentially just a complex combination of the wind, temperature and moisture fields weighted heavily in the lower-troposphere. Therefore, if an operational forecast model can accurately predict these fields, then forecasts of MCSs can be made several days in advance using the MCS index. A measure of the ability of the Eta model in forecasting these fields for forecasts of varying lead times out to $60 \mathrm{~h}$ is also shown in Table 6.5. As expected, the overall skill of the MCS index decreases as the forecast lead time increases. However, the MCS index still shows considerable skill in distinguishing between MCS precursor environments and unorganized widespread convection for forecasts out to $60 \mathrm{~h}$. The $60 \mathrm{~h}$ forecast exhibits only a slightly higher FAR and misses only $10 \%$ more of the MCSs (i.e., POD decreases from 0.74 to 0.64 ) than the 
analysis. Evidently, the model produces very good short-range forecasts of lowertropospheric wind, temperature, and moisture fields resulting in proficient MCS forecasts. A.t present, this appears to be a very good approach to forecasting MCSs as opposed to depending on operational forecast models, which exhibit low skill in predicting warm season precipitation (Olson et al. 1995; Fritsch et al. 1998), to parameterize convection and resolve the development and organization of MCSs.

Table 6.5: Skill of MCS index during BAMEX in distinguishing between MCS precursor environments and other environments for analyses and forecasts out to $60 \mathrm{~h}$. The optimal value at the maximum HSS for each condition is listed, as well as the TS, POD, FAR, and B calculated at that optimal value.

\begin{tabular}{|c|c|c|c|c|c|c|c|}
\hline Condition & Time & HSS & $\begin{array}{c}\text { Optimal } \\
\text { Value }\end{array}$ & TS & POD & FAR & $\mathrm{B}$ \\
\hline MCS vs. & analysis & 0.54 & -1.0 & 0.66 & 0.74 & 0.14 & 0.86 \\
\hline Widespread & $6-12 \mathrm{~h} \mathrm{fcst}$ & 0.59 & -1.5 & 0.69 & 0.74 & 0.10 & 0.82 \\
\hline \multirow[t]{4}{*}{ Convection } & $18-24 \mathrm{~h} \mathrm{fcst}$ & 0.51 & -1.5 & 0.65 & 0.74 & 0.16 & 0.88 \\
\hline & $30-36 \mathrm{~h} \mathrm{fcst}$ & 0.41 & -1.5 & 0.55 & 0.62 & 0.16 & 0.74 \\
\hline & $42-48 \mathrm{~h} \mathrm{fcst}$ & 0.41 & -2.0 & 0.63 & 0.80 & 0.25 & 1.06 \\
\hline & $54-60 \mathrm{~h}$ fcst & 0.43 & -1.5 & 0.57 & 0.64 & 0.16 & 0.76 \\
\hline MCS vs. No MCS & analysis & 0.67 & defined & 0.81 & 0.86 & 0.07 & 0.92 \\
\hline \multirow[t]{5}{*}{ (Max. CAPE) } & $6-12 \mathrm{~h} \mathrm{fcst}$ & 0.58 & defined & 0.73 & 0.74 & 0.03 & 0.76 \\
\hline & $18-24 \mathrm{~h} \mathrm{fcst}$ & 0.46 & defined & 0.63 & 0.66 & 0.06 & 0.70 \\
\hline & $30-36 \mathrm{~h} \mathrm{fcst}$ & 0.32 & defined & 0.56 & 0.60 & 0.12 & 0.68 \\
\hline & $42-48 \mathrm{~h}$ fest & 0.33 & defined & 0.58 & 0.64 & 0.14 & 0.74 \\
\hline & $54-60 \mathrm{~h} \mathrm{fcst}$ & 0.48 & defined & 0.65 & 0.68 & 0.06 & 0.72 \\
\hline MCS vs. No MCS & analysis & 0.28 & defined & 0.69 & 0.86 & 0.22 & 1.10 \\
\hline \multirow[t]{5}{*}{ (Max. SWEAT) } & $6-12 \mathrm{~h} \mathrm{fcst}$ & 0.27 & defined & 0.63 & 0.74 & 0.20 & 0.92 \\
\hline & $18-24 \mathrm{~h} \mathrm{fcst}$ & 0.19 & -2.0 & 0.51 & 0.58 & 0.19 & 0.72 \\
\hline & $30-36 \mathrm{~h}$ fest & 0.17 & -2.5 & 0.49 & 0.56 & 0.20 & 0.70 \\
\hline & $42-48 \mathrm{~h} \mathrm{fcst}$ & 0.17 & -2.0 & 0.52 & 0.60 & 0.25 & 0.80 \\
\hline & $54-60 \mathrm{~h} \mathrm{fest}$ & 0.13 & 0 & 0.32 & 0.34 & 0.15 & 0.40 \\
\hline MCS vs. No MCS & analysis & 0.15 & 3.0 & 0.34 & 0.36 & 0.14 & 0.42 \\
\hline \multirow[t]{5}{*}{ (Domain Max.) } & $6-12 \mathrm{~h} \mathrm{fcst}$ & 0.15 & 3.0 & 0.31 & 0.32 & 0.11 & 0.36 \\
\hline & $18-24 \mathrm{~h} \mathrm{fcst}$ & 0.16 & 0.5 & 0.63 & 0.80 & 0.25 & 1.06 \\
\hline & $30-36 \mathrm{~h}$ fest & 0.11 & 2.5 & 0.36 & 0.40 & 0.20 & 0.50 \\
\hline & $42-48 \mathrm{~h} \mathrm{fcst}$ & 0.11 & 3.0 & 0.33 & 0.36 & 0.18 & 0.44 \\
\hline & $54-60 \mathrm{~h} \mathrm{fcst}$ & 0.05 & 2.5 & 0.29 & 0.32 & 0.24 & 0.42 \\
\hline
\end{tabular}

\subsubsection{Examples}

During BAMEX, the viewpoint changes somewhat to focus on whether the MCS index would have been of assistance to forecasters if it had been available during the field project. The primary objective of the experiment is to study bow echoes and mesoscale 
convective vortices (MCVs) within a $650 \mathrm{~km}$ radius of St. Louis, Missouri. Therefore, some of the decisions made on whether to attempt to get measurements of a system are based not only on whether a MCS will form, but whether a MCS will form within the domain of interest. The following examples demonstrate situations in which the MCS index would have been helpful to forecasters in making these difficult decisions.

The BAMEX forecasters were fairly certain that a MCS would form overnight (i.e., 0000-1200 UTC) on 5 June 2003 in the southern Oklahoma/northern Texas area (see Fig. 6.11), but the issue was whether the MCS would be worth pursuing since they questioned whether it would enter the southwest portion of the BAMEX domain. In fact, the operations plan from 2132 UTC on 4 June stated that they were planning to get measurements of this system. Examination of the Eta model forecasts of the MCS index in Fig. 6.12 reveals that starting with the $36 \mathrm{~h}$ forecast favorable conditions for MCS development were not expected within the BAMEX domain at 0000 UTC on 5 June. The updated forecasts started to focus on the Texas panhandle and the area to the south, which is outside of the BAMEX area. Thus, forecasts of the MCS index with as much as $36 \mathrm{~h}$ lead time suggest that a MCS would likely not enter the BAMEX domain. Verification of this forecast is provided in Fig. 6.13. The 0000 UTC analysis of the MCS index still targets the Texas panhandle and the region to the south for MCS development. Indeed, convection forms and organizes in the Texas panhandle and advances to the southeast toward central Texas as a very nice asymmetric bow echo. The location of favorable values of the MCS index tracks the movement of the system very well and decreases in areal extent through the night. Ultimately, this system was not studied by the BAMEX researchers, which was probably a good thing considering that it stayed outside of the 
primary region of interest. The forecasters did report that the models were having a 100$150 \mathrm{~km}$ northeastward bias in representing MCS development. Interestingly, one of the very same models was able to produce an accurate forecast location of MCS development through the MCS index by identifying areas favorable for MCS genesis and sustenance. In this instance, the MCS index could have been used to reassure forecasters that a MCS would not enter the BAMEX domain.

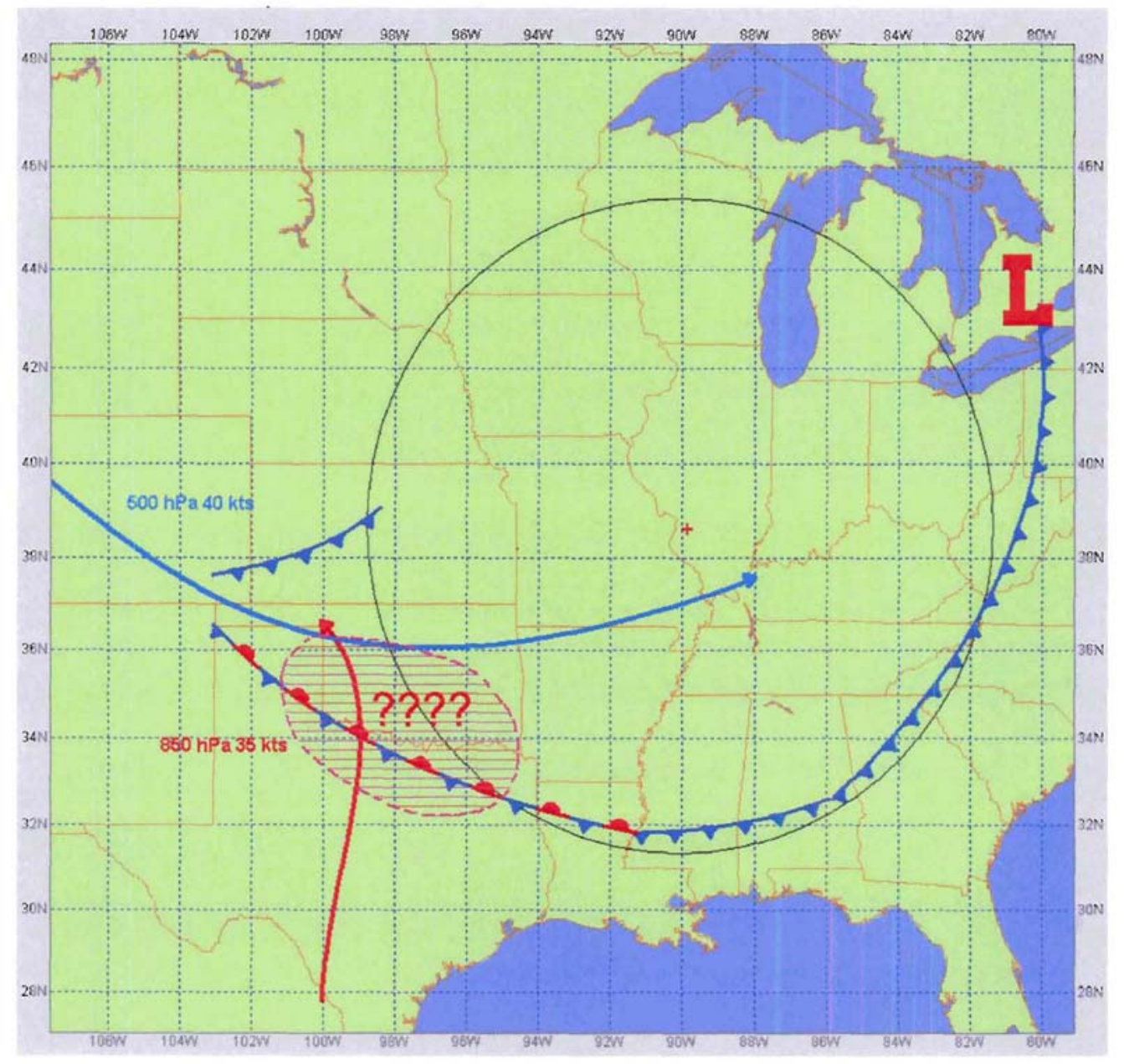

Figure 6.11: MCS forecast made by BAMEX forecasters made at 2245 UTC on 4 June 2003 valid for 0000-1200 UTC on 5 June. Surface fronts are depicted with the usual symbols along with wind speed maxima at $500 \mathrm{mb}$ (blue arrow) and $850 \mathrm{mb}$ (red arrow). The hatched pink region identifies the MCS forecast location, and the black circle identifies the BAMEX domain with a red cross denoting the operation center just east of St. Louis, Missouri. 

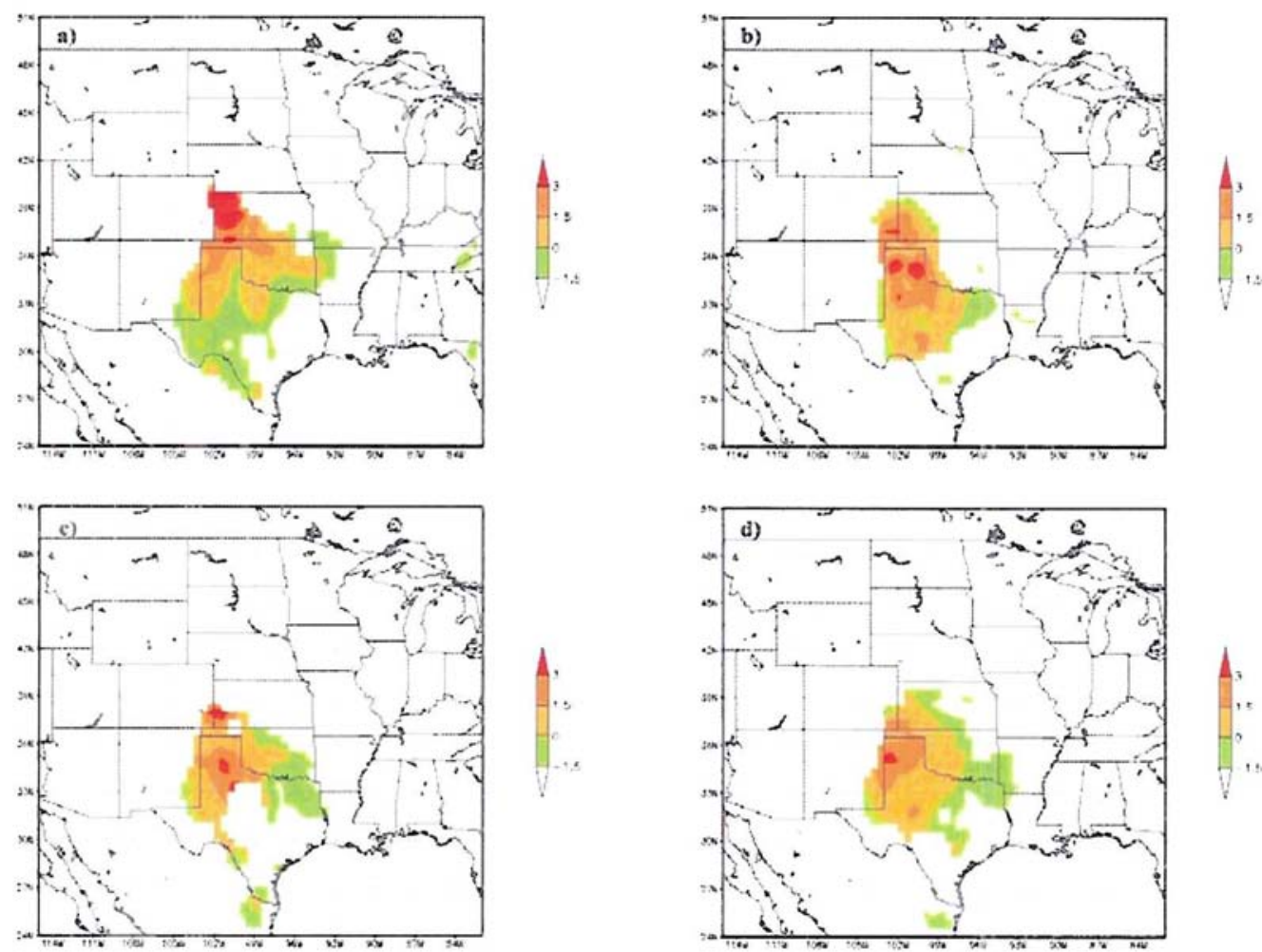

Figure 6.12: MCS index a) 48h, b) 36h, c) $24 \mathrm{~h}$, and d) $12 \mathrm{~h}$ Eta model forecasts valid at 0000 UTC on 5 June 2003. 


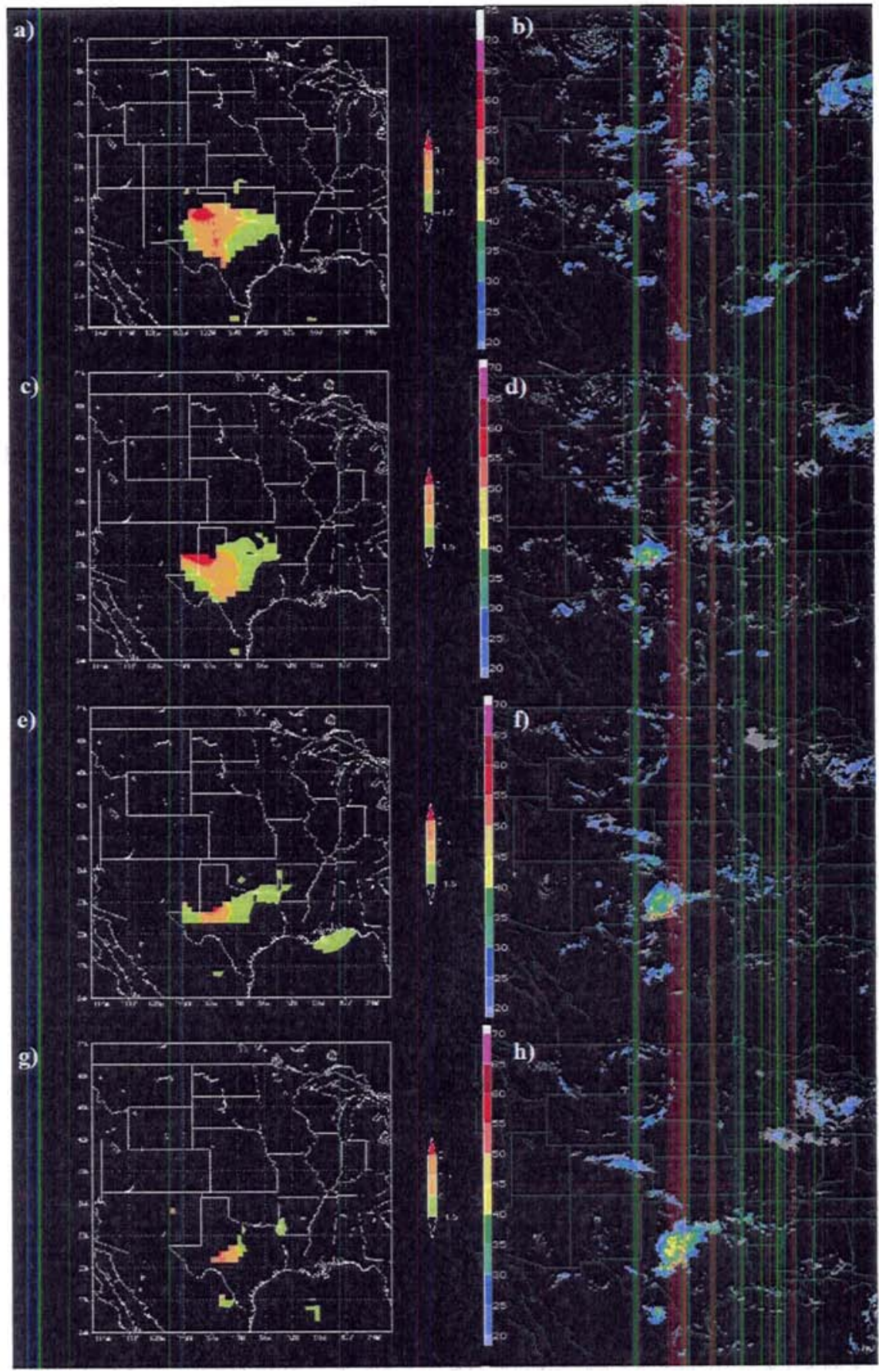

Figure 6.13: MCS index (left panels) and composite radar reflectivity (right panels) from 0000 UTC to 0900 UTC on 5 June 2003. The MCS index analyses are from a) 0000 , c) 0300 , e) 0600 and, g) 0900 UTC while the radar images are from b) 0030, d) 0300, f) 0600, and h) 0900 UTC. 
Another example is taken from 12 June 2003 in which no operations were planned overnight (i.e., 0000-1200 UTC on 12 June). The BAMEX forecasters did not expect significant MCS development within the region of interest. The forecasts of the MCS index shown in Fig. 6.14, which show a large area favorable for MCS development over the plains, seem inconsistent with the forecasters' expectations of no significant MCS development within the BAMEX domain. Although the model forecasts change somewhat with time, southeastern Oklahoma appears to be a consistently favorable area for MCS development at 0000 UTC on 12 June. Regardless, even though this area is within the BAMEX domain, it is never mentioned as a possible region of bow echo development. The scenario, as it played out overnight, is shown in Fig. 6.15. At 0000 UTC, convection is initiated on a multitude of boundaries throughout the plains primarily in regions favorable for MCS development. By 0300 UTC, two dominant MCSs have formed over the plains: one over southern Nebraska/northern Kansas and the other over southern Oklahoma/northern Texas. Even though the northernmost MCS remains only in a marginally favorable environment, it develops into a well-organized bow echo by 0600 UTC in northern Kansas on the western boundary of the BAMEX domain. The southernmost MCS remains in mostly favorable conditions and exhibits bowing along its convective line through its lifecycle although it never becomes as well organized as the MCS in Kansas. Nevertheless, much of the lifecycle of this system was within the BAMEX domain and should have been at least considered for study and likely would have been considered if forecasts of the MCS index would have been available. 

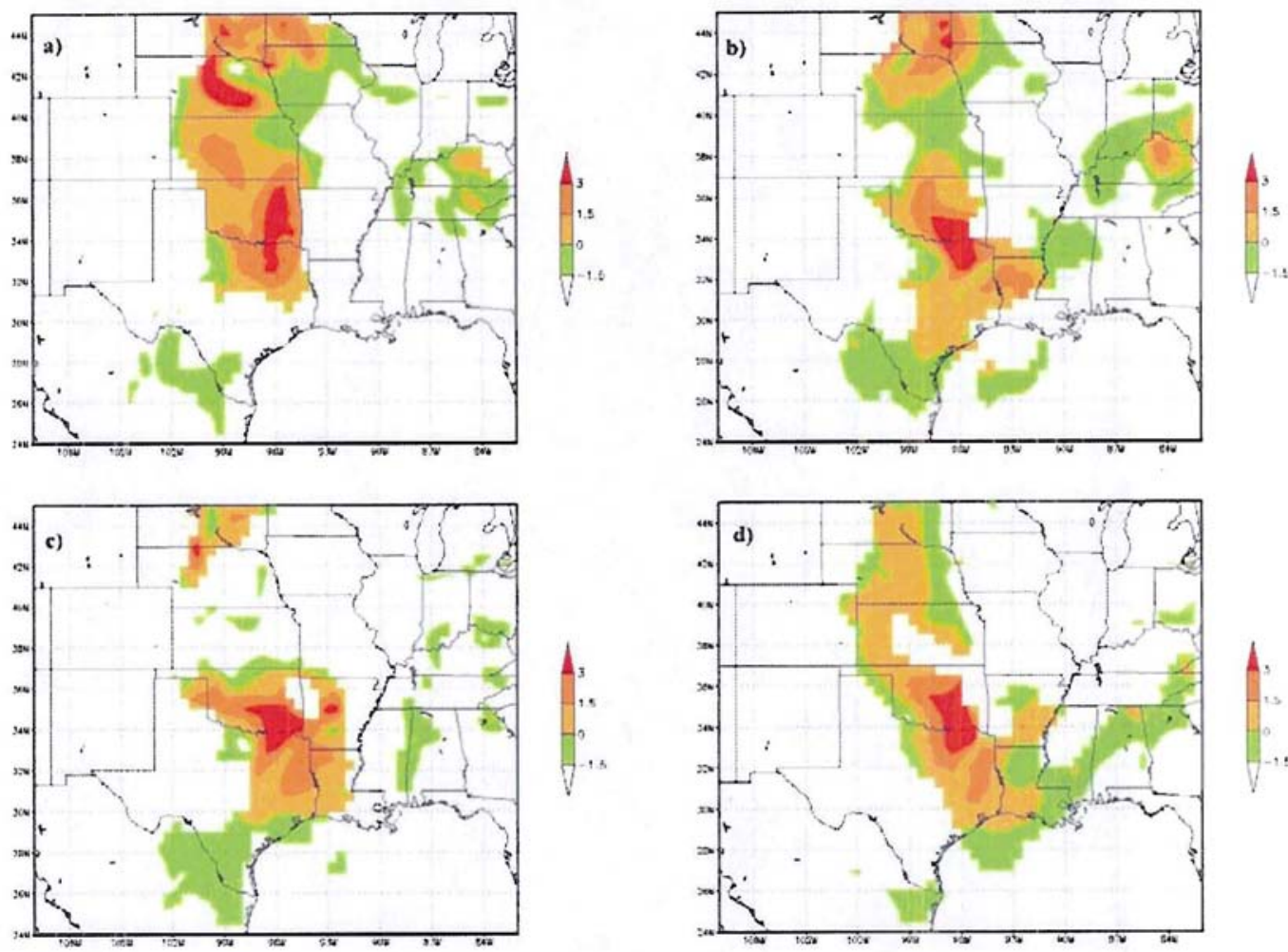

Figure 6.14: MCS index a) 48h, b) 36h, c) 24h, and d) 12h Eta model forecasts valid at 0000 UTC on 12 June 2003. 


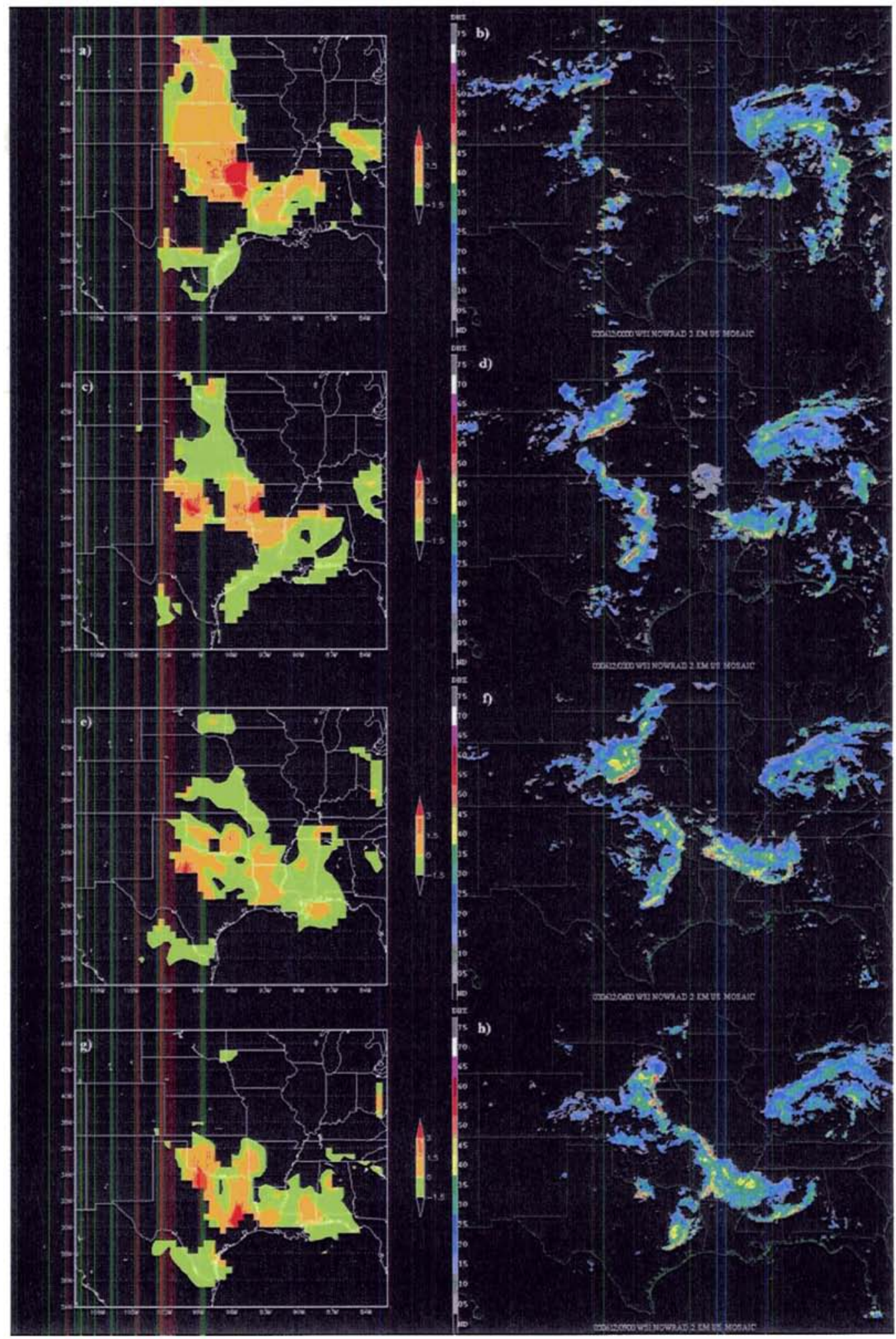

Figure 6.15: MCS index (left panels) and composite radar reflectivity (right panels) from 0000 UTC to 0600 UTC on 12 June 2003. The MCS index analyses are from a) 0000 , c) 0300 , e) 0600 and, g) 0900 UTC while the radar images are from b) $0000, d) 0300, f) 0600$, and h) 0900 UTC. 
Finally, the last example is of a system that was studied during BAMEX that did not develop in a region with a large MCS index. The forecasters targeted Illinois as a possible location of bow echo development on 26 June 2003 out ahead of an advancing cold front. The analysis of the MCS index from 0000 UTC on 26 June 2003 in Fig. 6.16a shows that even if convection did form along the cold front, the environment was only marginally favorable at best for supporting a long-lived convective system. The radar images of western Illinois in Fig. 6.16 show that a line of strong convection did develop along the cold front. However, as the convection advances well ahead of the front and enters unfavorable conditions, the system rapidly dissipates before it can become wellorganized. In this instance, the MCS index could have been used to identify the fact that the environment out ahead of the cold front was not favorable enough to support longlived organized convection even though significant convection formed.

All in all, the MCS index is not a perfect index, but it does provide a forecaster with an additional skillful tool in predicting MCSs. The index will not accurately predict the timing and location of all MCSs and may overestimate MCS development in some instances, especially if highly concentrated thunderstorms do not form. However, the analysis and examples discussed in this chapter reveal that the index does show significant skill in determining whether convection will organize into a MCS and whether existing systems will be able to survive. This information will be very useful to forecasters in making decisions about the influence MCSs might have on the immediate and future weather. 

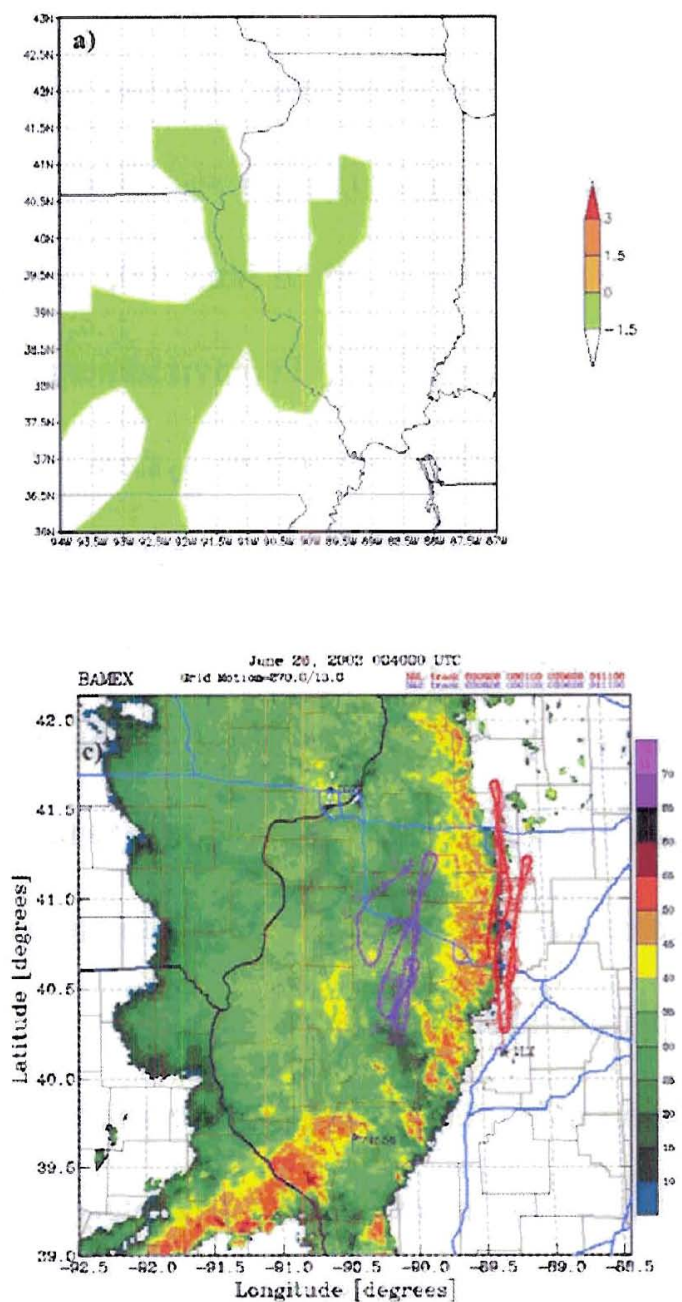
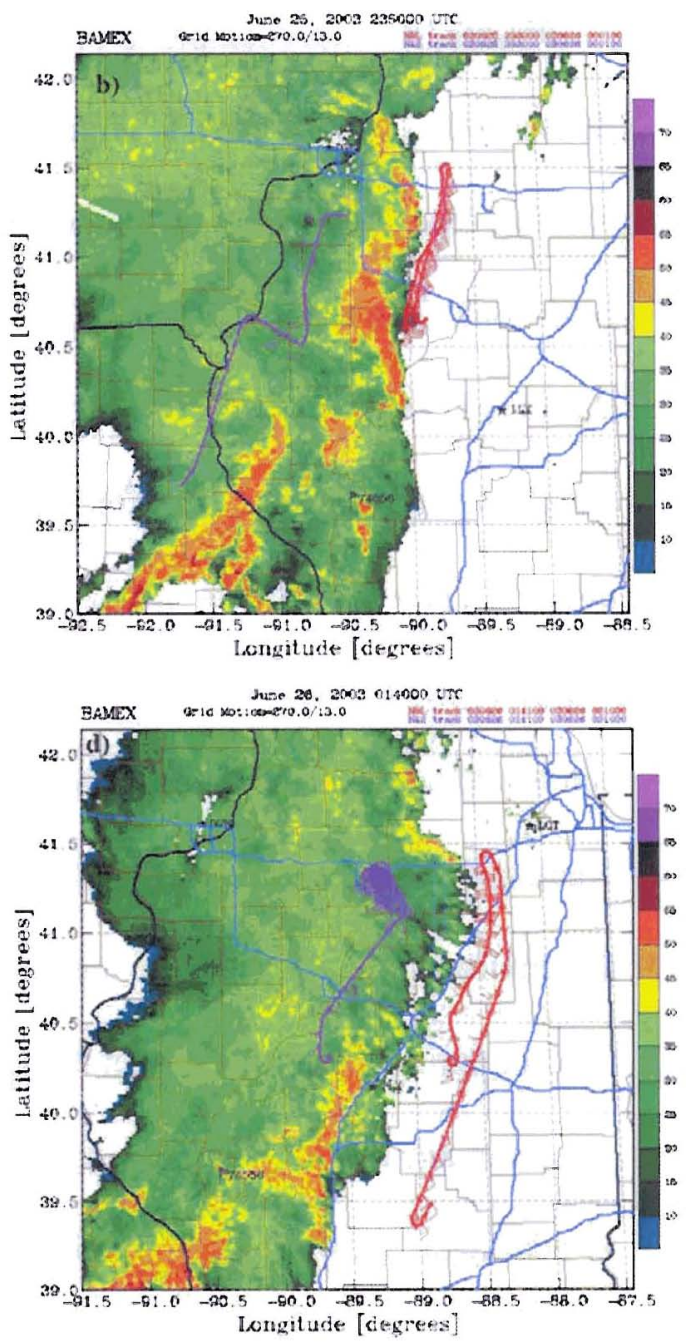

Figure 6.16: MCS index and radar reflectivity for a system studied during BAMEX. MCS index in (a) is the analysis from 0000 UTC on 26 June 2003. Radar reflectivity is from a) 2350 UTC on 25 June 2003, 0040, and 0140 UTC on 26 June 2003. Flight tracks of the NRL P-3 are in red while fight tracks of the NOAA P-3 are in purple. 


\section{Chapter 7}

\section{Summary and conclusions}

\subsection{Summary}

The precursor environments of several hundred MCSs were thoroughly studied in an attempt to gain insight into the predictability of these systems. The triggering mechanism for each system was identified using NCEP surface charts to determine if certain types of MCSs have a tendency to be initiated by specific features. Data from the NARR were

used to examine dozens of parameters that are important to MCS development. A statistical analysis and composite analysis were performed with these parameters to extract valuable information about the environments in which MCSs form. For comparison purposes, environments that do not support MCSs and environments that support unorganized widespread convection were also carefully investigated.

Using the results from the analysis of these different environmental conditions, a MCS index was developed for use in forecasting MCSs. The index is comprised of conditional terms to ensure that the index is defined only in regions that are likely to support convection. The terms of the MCS index equation, which provide a numerical value to the index, indicate the likelihood of highly concentrated convection undergoing upscale growth into MCSs. An evaluation of the MCS index was performed to determine 
if it has significant skill in predicting MCSs and whether it possesses similar diurnal, seasonal, and episodic cycles to MCSs.

\subsection{Discussion and conclusions}

The analysis of environmental conditions led to significant findings about MCS precursor environments and environments that are unable to support organized convective systems. An investigation of the triggering mechanisms of these systems revealed that drylines were generally unfavorable locations of MCS development likely due to a combination of the sparse nature of the convection that develops and unfavorable environmental conditions for supporting convective organization. Stationary and cold fronts were the most common features to generate convection that develops into a MCS. In several instances, however, concentrated convection developed along a frontal boundary that did not evolve into a MCS. Similarly, widespread convection was found to typically form in a region of higher mid-level PV than MCSs. These results suggest that even if some feature is present to enhance the initiation of convection, the environment still often needs to lend additional support for the development and organization of longlived convective systems.

To identify environmental features that aid convective development and organization, the environments of MCSs and widespread convection were analyzed and considerable differences were found between these conditions. Low-level warm air advection was much larger on average prior to MCS development than for unorganized convection aiding convective development. Wind speeds were also much stronger for the MCS precursor environments leading to stronger vertical wind shear through the lower troposphere. In addition, the environments that supported MCS development were 
typically more unstable than the environments of unorganized widespread convection. The maximum of each of these parameters in the MCS-relative composites also showed good correspondence with the location of MCS initiation.

Based on these results, $700 \mathrm{mb}$ temperature advection, 0-3 $\mathrm{km}$ shear, and LI were selected to be part of an index used to forecast MCS development. Low-level warm air advection and ambient shear act to enhance lifting that allows the rising air to tap into convective instability, promoting the development of an organized convective system. These parameters form the numerical basis of the MCS index by providing a likelihood of concentrated convection developing into a MCS. The MCS index is also comprised of conditional terms to ensure that the index is only defined in regions where convective initiation and development are possible. The conditional terms include MSLPDIF, surface specific humidity, TT, $850 \mathrm{mb}$ v-wind, and $5-10 \mathrm{~km}$ shear. Thus, the MCS index is generally only defined in moist, unstable areas with southerly low-level flow and weak-to-moderate upper-level shear. MSLPDIF is especially good at indicating whether a MCS will form over the central U.S. on a given day simply by measuring the east-west surface pressure gradient across the Gulf Coast, which signifies strong, southerly winds advecting warm, moist air into the plains.

The resulting MCS index demonstrated significant skill in forecasting MCSs during the original study period and during BAMEX, an independent convective season. The index possesses skill in forecasting MCSs without knowledge of whether convective initiation will occur. However, the greatest utility of the MCS index is identifying whether existing convection will merge and undergo upscale growth into a MCS. The diurnal and seasonal cycles of the MCS index exhibit similar characteristics to MCSs, 
including a nighttime maximum and a northward shift during the convective season. In addition, the MCS index typically shows good agreement with precipitation episodes even during weakly-forced midsummer conditions. Unfortunately, even though the MCS index is statistically larger on average for line systems than areal systems, it still does not provide much skill in forecasting which type of MCS will form. MCSs, in general, require very specific conditions for their development and survival; thus, the similarity of these conditions makes it difficult to forecast the MCS category. Overall, the MCS index should be very helpful to forecasters in predicting the influence MCSs might have on the weather in a given area, especially considering the lack of formal forecast methods currently available. As long as the MCS index is used in conjunction with other information, such as the expected location and timing of convective initiation, it should lead to improved warm season precipitation forecasts.

\subsection{Suggestions for future research}

The goal of this research was to expand the overall understanding of the predictability of MCSs since there is a general paucity of knowledge on the subject (Ziegler 2000). The results presented in this thesis suggest that a significant step forward has been made in that direction; however, it is really only a beginning step in improving MCS forecasts. Real-time verification of the performance of the MCS index for the U.S. would be useful since the index is intended for use by operational forecasters. In addition, the results of this study are expected to be applicable across the entire globe; thus, studies on the performance of the MCS index in other regions of the world where MCSs commonly form would certainly validate the physical mechanisms found to be important for MCS development. 
The results from this research could also be applied toward parameterizing MCSs in numerical forecast models. For models that are unable to explicitly resolve MCSs, the MCS index could be used to parameterize the likelihood of MCS development. This would ultimately result in improved model forecasts of warm season precipitation, which typically show low skill (Olson et al. 1995; Fritsch et al. 1998). Finally, given the influence that the semi-permanent Bermuda high has on the occurrence of MCSs over the central U.S. through the strength of the east-west pressure gradient across the Gulf Coast, it would be worthwhile exploring if this information could be exploited to create useful seasonal forecasts of MCSs. Undoubtedly, progress in the area of MCS predictability will continue as insight gained from this study will stimulate more studies to improve our understanding of MCSs. 


\section{References}

Anderson, C. J. and R. W. Arritt, 1998: Mesoscale convective complexes and persistent elongated convective systems over the United States during 1992 and 1993. Mon. Wea. Rev., 126, 578-599.

Ashley, W. S. and coauthors, 2003: Distribution of mesoscale convective complex rainfall in the United States. Mon. Wea. Rev., 131, 3003-3017.

Augustine, J. A. and F. Caracena, 1994: Lower-tropospheric precursors to nocturnal MCS development over the central United States. Wea. Forecasting, 9, 116-135.

Augustine, J. A. and K. W. Howard, 1988: Mesoscale convective complexes over the United States during 1985. Mon. Wea. Rev., 116, 685-700.

Augustine, J. A. and K. W. Howard, 1991: Mesoscale convective complexes over the United States during 1986 and 1987. Mon. Wea. Rev., 119, 1575-1589.

Barnes, S. L., 1964: A technique for maximizing details in numerical weather map analysis. J. Appl. Meteor., 3, 396-409.

Bluestein, H. B., and M. H. Jain, 1985: Formation of mesoscale lines of precipitation: Severe squall lines in Oklahoma during the spring. J. Atmos. Sci., 42, 1711-1732.

Carbone, R. E., J. D. Tuttle, D. A. Ahijevich, and S. B. Trier, 2002: Inferences of predictability associated with warm season precipitation episodes. J. Atmos. Sci., 59, 2033-2056.

Coniglio, M. C., D. J. Stensrud, and L. J. Wicker, 2004: How upper-level shear can promote organized convective systems. Preprints, $22^{\text {nd }}$ Conf. on Severe Local Storms, Amer. Meteor. Soc., 4 pp.

Cotton, W. R. and R. A. Anthes, 1989: Storm and Cloud Dynamics, San Diego: Academic Press. 
Cotton, W. R., R. L. George, P. J. Wetzel, and R. L. McAnelly, 1983: A long-lived mesoscale convective complex. Part I: The mountain-generated component. Mon. Wea. Rev., 110, 1893-1918.

Cotton, W. R., M. S. Lin, R. L. McAnelly, and C. J. Tremback, 1989: A composite model of mesoscale convective complexes. Mon. Wea. Rev., 117, 765-783.

Davies-Jones, R., 1984: Streamwise vorticity: The origin of updraft rotation in supercells. J. Atmos. Sci., 41, 2991-3006.

Doswell, C. A. III, 1977: Obtaining meteorologically significant surface divergence fields through the filtering property of objective analysis. Mon. Wea. Rev., 105, 885-892.

Doswell, C. A. III, R. Davies-Jones, and D. L. Keller, 1990: On summary measures of skill in rare event forecasting based on contingency tables. Wea. Forecasting, $\mathbf{5}$, 576-585.

Doswell, C. A. III and J. S. Evans, 2003: Proximity sounding analysis for derechos and supercells: an assessment of similarities and differences. Atmos. Res., 67-68, $117-$ 133.

Doswell, C. A. III and Flueck, J. A., 1989: Forecasting and verifying in a field research project: DOPLIGHT '87. Wea. Forecasting, 4, 97-109.

Douglas, M. W., R. A. Maddox, K. Howard, and S. Reyes, 1993: The Mexican monsoon. J. Climate, 6, 1665-1677.

Fritsch, J. M., and R. J. Kane, and C. R. Chelius, 1986: The contribution of mesoscale convective weather systems to the warm-season precipitation in the United States. J. Climate Appl. Meteor., 25, 1333-1345.

Fritsch, J. M., J. D. Murphy, and J. S. Kain, 1994: Warm core vortex amplification over land. J. Atmos. Sci., 51, 1780-1807.

Fritsch, J. M., and coauthors, 1998: Quantitative precipitation forecasting: Report of the Eighth Prospectus Development Team, U.S. Weather Research Program. Bull. Amer. Meteor. Soc., 79, 285-299.

Hertenstein, R. F. A. and W. H. Schubert, 1991: Potential vorticity anomalies associated with squall lines. Mon. Wea. Rev., 119, 1663-1672.

Houze, R. A., Jr., 1993: Cloud Dynamics. Academic Press, 573 pp.

Houze, R. A., Jr., B. F. Smull, and P. Dodge, 1990: Mesoscale organization of springtime rainstorms in Oklahoma. Mon. Wea. Rev., 118, 613-654. 
Jincai, D., C. A. Doswell III, D. W. Burgess, M. P. Foster, and M. L. Branick, 1992: Verification of mesoscale forecasts made during MAP '88 and MAP '89. Wea. Forecasting, 7, 468-479.

Jirak, I. L., W. R. Cotton, and R. L. McAnelly, 2003: Satellite and radar survey of mesoscale convective system development. Mon. Wea. Rev., 131, 2428-2449.

Johns, R. H., and C. A. Doswell III, 1992: Severe local storms forecasting. Wea. Forecasting, 7, 588-612.

Johnson, R. H., S. Chen, and J. J. Toth, 1989: Circulations associated with a mature-todecaying mesoscale convective system. Part I: Surface features - heat bursts and mesolow development. Mon. Wea. Rev., 117, 942-959.

Laing, A. G. and J. M. Fritsch, 1997: The global population of mesoscale convective complexes. Quart. J. Roy. Meteor. Soc., 123, 389-405.

Laing, A. G. and J. M. Fritsch, 2000: The large-scale environments of the global populations of mesoscale convective complexes. Mon. Wea. Rev., 128, 2756-2776.

Maddox, R. A., 1980: Mesoscale convective complexes. Bull. Amer. Meteor. Soc., 61, 1374-1387.

Maddox, R. A., 1983: Large-scale meteorological conditions associated with midlatitude, mesoscale convective complexes. Mon. Wea. Rev., 111, 126-140.

Maddox, R. A. and C. A. Doswell III, 1982: An examination of jetstream configurations, $500 \mathrm{mb}$ vorticity advection and low-level thermal advection patterns during extended periods of intense convection. Mon. Wea. Rev., 110, 184-197.

McAnelly, R. L. and W. R. Cotton, 1986: Meso- $\beta$ scale characteristics of an episode of meso- $\alpha$ scale convective complexes. Mon. Wea. Rev., 114, 1740-1770.

McCollum, D. M., R. A. Maddox, and K. W. Howard, 1995: Case study of a severe mesoscale convective system in central Arizona. Wea. Forecasting, 10, 643-665.

McNulty, R. P., 1995: Severe and convective weather: A Central Region forecasting challenge. Wea. Forecasting, 10, 187-202.

Mesinger, F. and coauthors, 2004: North American regional reanalysis. Submitted to Bull. Amer. Meteor. Soc.

Olson, D. A., N. W. Junker, and B. Korty, 1995: An evaluation of three decades of quantitative precipitation forecasting at the Meteorological Operations Division of the National Meteorological Center. Wea. Forecasting, 10, 498-511. 
Olsson, P. Q. and W. R. Cotton, 1997: Balanced and unbalanced circulations in a primitive equation simulation of a midlatitude MCC. Part I: The numerical simulation. J. Atmos. Sci., 54, 457-478.

Parker, M. D. and R. H. Johnson, 2000: Organizational modes of midlatitude mesoscale convective systems. Mon. Wea. Rev., 128, 3413-3436.

Rasmussen, E. N., 2003: Refined supercell and tornado forecast parameters. Wea. Forecasting, 18, 530-535.

Rasmussen, E. N. and D. O. Blanchard, 1998: A baseline climatology of soundingderived supercell and tornado forecast parameters. Wea. Forecasting, 13, 11481164 .

Raymond, D. J. and H. Jiang, 1990: A theory for long-lived mesoscale convective systems. J. Atmos. Sci., 47, 3067-3077.

Rhea, J. O., 1966: A study of thunderstorm formation along drylines. J. Appl. Meteor., 5, 58-63.

Rotunno, R., J. B. Klemp, and M. L. Weisman, 1988: A theory for strong, long-lived squall lines. J. Atmos. Sci., 45, 463-485.

Saleeby, S. M. and W. R. Cotton, 2004: Simulations of the North American monsoon system. Part I: Model analysis of the 1993 monsoon season. J. Climate, 17, 19972018 .

Smull, B. F. and J. A. Augustine, 1993: Multiscale analysis of a mature mesoscale convective complex. Mon. Wea. Rev., 121, 103-132.

Stensrud D. J. and J. M. Fritsch, 1994: Mesoscale convective systems on weakly forced large-scale environments. Part II: Generation of a mesoscale initial condition. Mon. Wea. Rev., 122, 2068-2083.

Trier, S. B. and D. B. Parsons, 1993: Evolution of environmental conditions preceding the development of a nocturnal mesoscale convective complex. Mon. Wea. Rev., 121, 1078-1098.

Uccellini, L. W. and D. R. Johnson, 1979: The coupling of upper and lower tropospheric jet streaks and implications for the development of severe convective storms. Mon. Wea. Rev., 107, 682-703.

Weisman, M. L., 1992: The role of convectively generated rear-inflow jets in the evolution of mesoconvective systems. J. Atmos. Sci., 49, 1826-1847. 
Weisman, M. L., 1993: The genesis of severe long-lived bow echoes. J. Atmos. Sci., 50, 645-670.

Weisman, M. L. and J. B. Klemp, 1982: The dependence of numerically simulated convective storms on vertical wind shear and buoyancy. Mon. Wea. Rev., 110, 504520.

Weisman, M. L. and J. B. Klemp, 1984: The structure and classification of numerically simulated convective storms in directionally varying wind shears. Mon. Wea. Rev., 112, 2479-2498.

Weisman, M. L. and R. Rotunno, 2000: The use of vertical wind shear versus helicity in interpreting supercell dynamics. J. Atmos. Sci., 57, 1452-1472.

Weisman, M. L. and R. Rotunno, 2004: "A theory for strong long-lived squall lines" revisited. J. Atmos. Sci., 61, 361-382.

Wilks, D. S., 1995: Statistical Methods in the Atmospheric Sciences. Academic Press, $464 \mathrm{pp}$.

Ziegler, C. L., 2000: "Issues in forecasting mesoscale convective systems: An observational and modeling perspective." Storms Chapter 34, R. Pielke, Jr. and R. Pielke, Sr., eds., Routledge Press, London. 